\title{
Utility of Quasi-Static Gust Loads Certification Methods for Novel Configurations
}

\author{
Anthony P. Ricciardi \\ Thesis submitted to the Faculty of the \\ Virginia Polytechnic Institute and State University \\ in partial fulfillment of the requirements for the degree of \\ Master of Science \\ in \\ Aerospace Engineering
}

Robert A. Canfield, Chair

Mayuresh J. Patil, Co-Chair

Ned Lindsley

September 27, 2011

Blacksburg, Virginia

Keywords: Gust Loads, SensorCraft, Aeroelasticity

(C)2011, Anthony P. Ricciardi 


\title{
Utility of Quasi-Static Gust Loads Certification Methods for Novel Configurations
}

\author{
Anthony P. Ricciardi
}

(ABSTRACT)

Aeroelastic gust and maneuver loads have driven the sizing of primary aircraft structures since the beginning of aviation. Methodologies for determining the gust loads on aircraft have evolved over the last 100 years. There are three general approaches to gust loads analysis: quasi-static, transient, and continuous methods. Quasi-static analysis offers the greatest computational efficiency. A quasi-static formulation referred to as Pratt's Method is the current practice for FAR Part 23 certification requirements. Assumptions made in the derivation of Pratt's Method are acceptable for many conventional aircraft, but additional fidelity from transient and continuous analysis are required to certify FAR Part 25 aircraft.

This work provides an assessment of the usability of Pratt's Method for unconventional high altitude long endurance (HALE) aircraft. Derivation Pratt's Method is reviewed and all assumptions are identified. Error of a key curve fit equation is quantified directly. Application dependent errors are quantified by comparing loads calculated using Pratt's Method to loads calculated from transient analysis. To facilitate this effort, a state of the art nonlinear aeroelastic code has been modified to more accurately capture the transient gust response.

Application dependent errors are presented in the context of a SensorCraft inspired joinedwing HALE model, and a Helios inspired flying wing HALE model. Recommendations are made on the usability of Pratt's Method for aircraft similar to the two HALE models. It is concluded that Pratt's Method is useful for preliminary design of the joined-wing HALE model, but inadequate for the analysis of the flying wing model. Additional recommendations are made corresponding to subtleties in the implementation of Pratt's Method for unconventional configurations. 


\section{Acknowledgments}

I would like to thank my advisors, Dr. Bob Canfield and Dr. Mayur Patil for their outstanding guidance. I value them as excellent examples of professionalism, good character, and positive energy. I also am grateful to Dr. Ned Lindsley for his support and for mentoring me while working together at AFRL. I thank Dr. Craig Woolsey for encouraging me to return to Virginia Tech for graduate school. I am grateful to AFRL and the CCMS for all of the technical and financial support over the last two years.

I would like to give a special thanks to my parents, stepparents, my sister, and future brother-in-law for all of their support and love. I am lucky to have them, and so many other relatives that have enriched my life. I also give a sincere thanks to Erin for her patience and support. I am fortunate to have so many friends, roommates, officemates, classmates, teachers, and students that make every day meaningful. Thank you all.

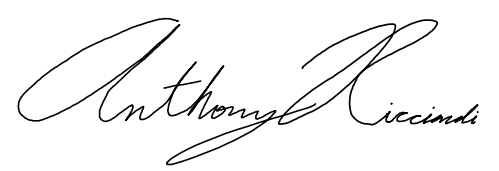

Anthony Ricciardi

September, 2011 


\section{Contents}

1 Introduction $\quad 1$

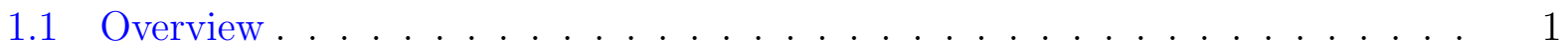

1.2 Motivation . . . . . . . . . . . . . . . . . . . 4

1.2.1 Helios Prototype Crash . . . . . . . . . . . . . 5

1.2.2 Joined-Wing SensorCraft . . . . . . . . . . . . . . . 6

1.3 Background - Gust Response Analysis . . . . . . . . . . . . . . . . 7

1.3.1 Quasi-Static Methods.................. 7

1.3.2 Transient Methods ... . . . . . . . . . . . . . . 10

1.3.3 Continuous Turbulence Methods . . . . . . . . . . . . . . . 11

1.4 Background - Geometric Nonlinearity . . . . . . . . . . . . . . . 12

1.4 .1 Large Deformations . . . . . . . . . . . . . . . . 12

1.4 .2 Follower Forces . . . . . . . . . . . . . . . . . . 14

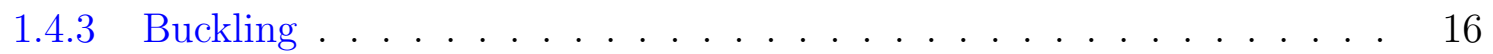

2 Literature Review $\quad 20$

2.1 NATASHA Foundations . . . . . . . . . . . . . . . . . . 20

2.2 Coupled Flight Dynamics and Aeroelasticity . . . . . . . . . . . . . 22

2.3 Joined-Wing Geometric Nonlinearities . . . . . . . . . . . . . . . 25

3 Methodology 29

3.1 Pratt's Quasi-Static Method .................. 29

3.1.1 Derivation of Pratt's Method . . . . . . . . . . . . . 30 
3.1 .2 Pratt's Method Error Sources . . . . . . . . . . . . . . . . . 33

3.2 Evaluation of Error in Pratt's Curve Fit Equation . . . . . . . . . . . . . 34

3.3 Quasi-Static and Transient Gust Analysis . . . . . . . . . . . . . . . . . 35

3.3 .1 Structural Model . . . . . . . . . . . . . . . . . . . . . 36

3.3 .2 Aerodynamic Model . . . . . . . . . . . . . . . . . . . . . 40

3.3 .3 Aeroelastic System . . . . . . . . . . . . . . . . . . . . 47

3.3.4 Transient Gust Response . . . . . . . . . . . . . . . . . . . . 48

3.4 Gust Response Analysis Verification . . . . . . . . . . . . . . . . . . . . 48

3.5 HALE Applications . . . . . . . . . . . . . . . . . . 52

3.5.1 Patil/Hodges Flying Wing HALE Model . . . . . . . . . . . . 52

3.5 .2 Joined-Wing Model . . . . . . . . . . . . . . . . . . . . . . . . 54

3.5.3 Presentation of Results . . . . . . . . . . . . . . . . . . 56

3.6 Computational Framework . . . . . . . . . . . . . . . . 56

4 Results and Discussion $\quad 58$

4.1 Pratt's Curve Fit Error . . . . . . . . . . . . . . . . . . . 58

4.2 Joined-Wing Parameter Interpretation $\ldots \ldots \ldots$

4.3 Application Dependent Quasi-Static Error's . . . . . . . . . . . . . . 61

$4.3 .1 \quad$ Joined-Wing . . . . . . . . . . . . . . . . . . . . . . . 61

4.3 .2 Flying Wing . . . . . . . . . . . . . . . . . . 66

5 Conclusions and Future Work $\quad 76$

5.1 Conclusions . . . . . . . . . . . . . . . . . . 76

5.2 Future Work . . . . . . . . . . . . . . . . . . . . . . 77

$\begin{array}{lr}\text { Bibliography } & 79\end{array}$ 


\section{List of Figures}

1.1 Trends in unmanned intelligence-surveillance-reconnaissance (ISR) aircraft. Aircraft images from Refs. $[25,33,12,17] . \ldots$. . . . . . . . . . . 2

1.2 The Helios prototype vehicle $[30] \ldots \ldots \ldots$. . . . . . . . . 5

1.3 Buckling mode for gust load using nonlinear analysis [3]. . . . . . . . . . . 7

1.4 Hinged rigid rod with torsional spring. A vertical force is applied. . . . . . . 13

1.5 Linear and geometrically exact response of hinged rod. . . . . . . . . . . . . 14

1.6 Hinged rigid rods with torsional springs. A follower force is applied. . . . . . 15

1.7 Linear and geometrically exact response the two hinged rods with a follower force. . . . . . . . . . . . . . . . . . . 17

1.8 Two rigid hinged rods with a torsional spring in the center. A horizontal force is applied at the right hand side. . . . . . . . . . . . . . 18

1.9 Linear and geometrically exact response and stability of the two hinged rod system. . . . . . . . . . . . . . . . . . 18

2.1 Early joined-wing configuration [53]. . . . . . . . . . . . . . . 26

2.2 Boeing joined-wing SensorCraft configuration [25] . . . . . . . . . . 28

3.1 The 1-cosine gust profile. Pratt's Method assumes $T=\frac{25 \bar{c}}{V} \ldots$. . . . . . . . . 32

3.2 Chordwise gust integration method. Superscript $i$ and $B$ indicate the quantities are calculated in the inertial or deformed beam reference frames, respectively. 44

3.3 Aerodynamic velocities at node $n$ in the beam frame. . . . . . . . . . 46

3.4 Rigid wing with large pitch inertia used for verification. . . . . . . . . . . . 49

3.5 Solutions from NATASHA and from Pratt's EOM for a high frequency gust input. . . . . . . . . . . . . . . . . 50 
3.6 Solutions from NATASHA and from Pratt's EOM for a lower intensity gust input at Pratt's specified 25 chord gust length. . . . . . . . . . . . . . . . . 50

3.7 Solutions from NATASHA and from Pratt's EOM for a higher intensity gust input at Pratt's specified 25 chord gust length. . . . . . . . . . . . . . . 51

3.8 Solutions from NATASHA and from Pratt's EOM for a low frequency gust input. . . . . . . . . . . . . . . . . 51

3.9 Geometry of the Patil/Hodges flying wing HALE model [33]. . . . . . . . . . 52

3.10 Joined-wing planform and skeleton. . . . . . . . . . . . . . . 54

3.11 Joined-wing side view. The critical plane is through the elastic axis of the forward and aft wing roots. Bending moment results for the joined-wing are the summed absolute value of the bending about $x_{2_{\text {crit }}}$ at the fore and aft wing roots. . . . . . . . . . . . . . . . . 56

3.12 Primitive network of workstations for parallel transient gust analysis. . . . . . . . 57

4.1 $K_{g}$ knockdown factor calculated using Pratt's curve fit and calculated by directly solving Pratt's equation of motion. . . . . . . . . . . . . . .

4.2 Error in Pratt's curve fit equation for the $K_{g}$ knockdown factor. Example aircraft are plotted for perspective. . . . . . . . . . . . . 60

4.3 Parametric response of the joined-wing model with full fuel. . . . . . . . . . 63

4.4 Response of the full fuel joined-wing model at specific gust lengths. . . . . . 64

4.5 Parametric response of the joined-wing model with $10 \%$ fuel. . . . . . . . . 65

4.6 Response of the $10 \%$ fuel joined-wing model at specific gust frequencies. . . . 66

4.7 Flight dynamic response of joined-wing model to worst case input. Top subfigure shows the flight path and gust input. Bottom subfigure shows the corresponding airspeed. . . . . . . . . . . . . . . 67

4.8 Structural and flight dynamic response of the joined-wing aircraft. . . . . . . 71

4.9 Parametric response of the flying wing model. . . . . . . . . . . . . . . 72

4.10 Response of the flying wing model at specific gust lengths. . . . . . . . . . . 72

4.11 Response of the flying wing model at the critical gust length. Fully nonlinear, extrapolated linear, and rigid cases are presented. . . . . . . . . . . . 73

4.12 Normalized root bending moment response of the flying wing model at critical gust length. . . . . . . . . . . . . . . . . . . 
4.13 Aeroelastic and flight dynamic response of the flying wing model at critical gust length. Flight path of the elastic semispan is plotted every second. . . . 74

4.14 Structural and flight dynamic response of the flying wing aircraft. . . . . . 75 


\section{List of Tables}

3.1 Tuning with high frequency damping parameter . . . . . . . . . . . 48

3.2 Cross-sectional properties for verification wing . . . . . . . . . . . . . 49

3.3 Wing cross-sectional properties . . . . . . . . . . . . . 53

3.4 Model properties. Here $f$ is fuel fraction. Exception: [1] Mass located at $\mathrm{m}_{1} . \quad 55$

3.5 Aerodynamic coefficients. Values are in the beam reference frame. Exceptions: [2] $C_{l_{0}}=0$ on Section A-B and tailboom. [3] $C_{m_{\alpha}}=0$ on Section A-B and Section E-F. [4] $y_{\mathrm{ac}}=c / 2$ on Section A-B. [5] $y_{\text {Elast.Ax }}=c / 4$ on Section E-F. $\quad 55$

3.6 Joined-wing discretization. Rigid sections may have more than one element because the mesh is shared with aerodynamics. . . . . . . . . . 55

4.1 Pratt's Method wing area interpretations. . . . . . . . . . . . . . 61 


\section{Chapter 1}

\section{Introduction}

\section{$1.1 \quad$ Overview}

Maximizing the performance and safety of future intelligence-surveillance-reconnaissance (ISR) aircraft will require aeroelastic analysis capabilities beyond the current state of the art. The need for persistent ISR coverage inspires extreme mission profiles that cannot be achieved with today's aircraft and yesterday's design methodologies. In the future, highaltitude long-endurance (HALE) aircraft will loiter at stratospheric altitudes for days, weeks, months, or even years at a time. Flapping wing micro air vehicles (MAVs) will hide in plain sight by mimicking common birds and insects. These forthcoming aircraft will thrive on flexibility.

The endurance requirements of HALE aircraft will drive wing aspect ratios to new extremes. Light and slender wings will lead to large deformations even at trim. Advanced load alleviation systems will be essential for safe operation. Like conventional aircraft design, gust response and maneuver loads will drive the design of the structure, but conventional gust 
analysis will not be suitable. Geometric nonlinearities will make linear analysis inaccurate. The unique joined-wing configuration will require examination of buckling effects that will also elude the capabilities of linear analysis.

Natural flexibility effects will enhance the flapping motion to propel efficient MAVs. Gust load alleviation systems will be required to control these small vehicles if they are to operate turbulent outdoor air. Design the wing structure and synthesis of the control system will require high fidelity nonlinear transient gust analysis that has yet to be demonstrated.

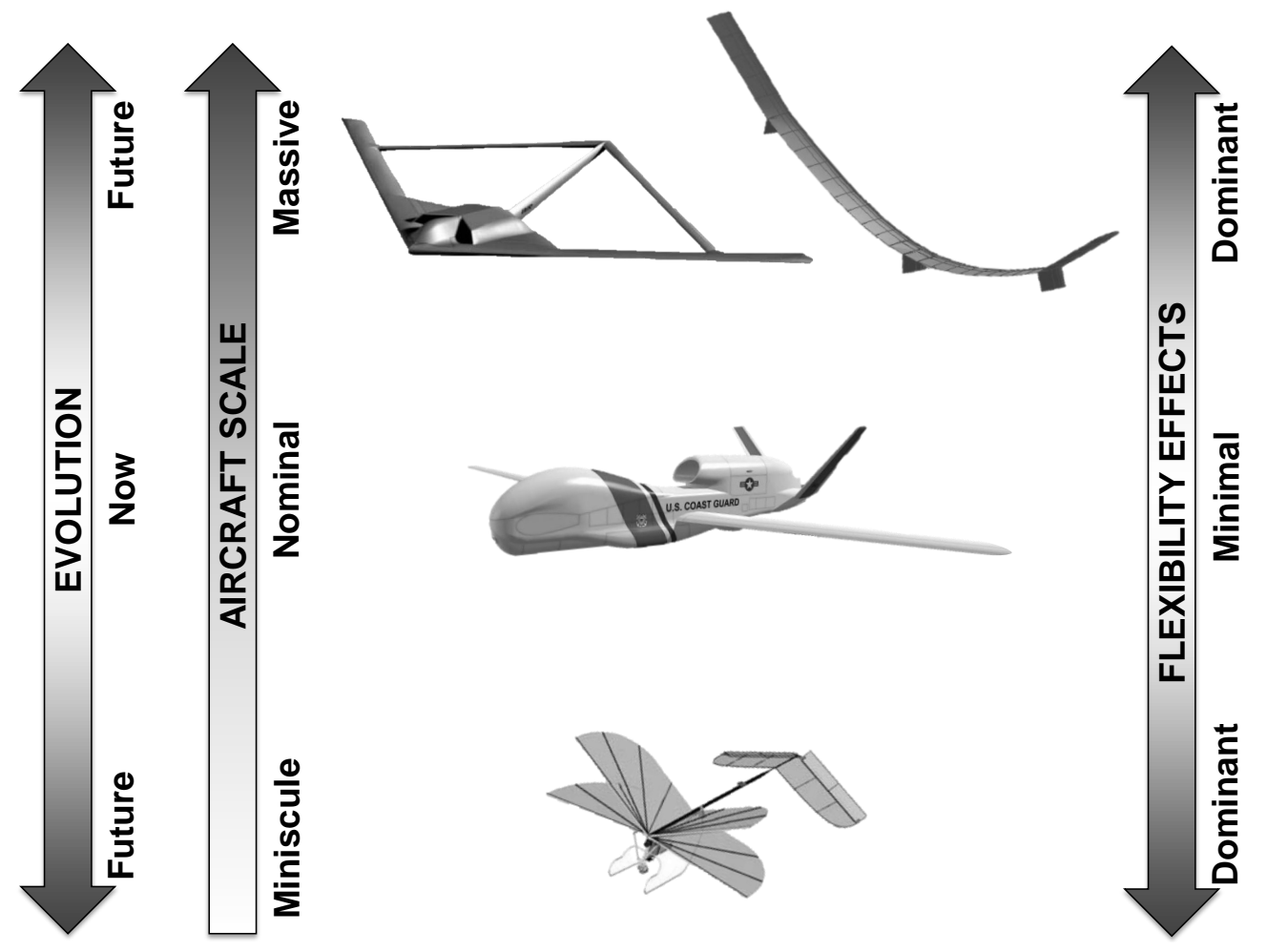

Figure 1.1: Trends in unmanned intelligence-surveillance-reconnaissance (ISR) aircraft. Aircraft images from Refs. [25, 33, 12, 17].

Trends in the evolution of unmanned ISR aircraft are highlighted in Figure 1.1. The airframe is being scaled in both directions and flexibility is increasing profoundly. This work concentrates on the large scale HALE configurations. In particular, the focus is on evaluating the suitability of low cost quasi-static gust response analysis techniques. Quasi- 
static methods allow for gust loads to be calculated at a fraction of the computational cost of higher order transient analysis. The most rational quasi-static method, developed by Pratt and Walker [38], is the basis for gust loads calculations in Federal Aviation Regulations (FAR) Part 23 certification requirements.

The role of quasi-static methods for gust loads analysis in the design and certification process is well established for conventional aircraft. However, highly flexible novel configurations have unique characteristics that may not be sufficiently captured with quasi-static analysis. Quasi-static methods must be re-evaluated before they are used to analyze novel applications. Two such applications are considered in this work: a flying wing high altitude long endurance (HALE) aircraft, and a joined-wing aircraft. A state of the art nonlinear transient analysis has been developed to provide a baseline for the evaluation. It will be shown that quasi-static methods may be useful for preliminary design of the joined-wing aircraft, but will not be robust enough for detailed design or certification of the either application. For clarity, the contributions from this work are highlighted explicitly:

\section{Primary Contributions}

- Evaluation of quasi-static gust response methods for HALE configurations

- Direct quantification of error of Pratt's curve fit equation

- Quantification of application dependent errors for a flying wing and a joined-wing HALE application. Application dependent errors come from assumptions made in the derivation of Pratt's Method.

- Modifications and additions to the NATASHA aeroelastic-flight dynamic analysis code

- Modified the gust field definition from temporal to spatial 
- Modified the gust forcing calculation from pre-calculated (without crucial information from the structural and flight dynamic response) to real time

- Addition of a computational framework for parametric gust analysis

- Creation of post-processors for complete aeroelastic-flight dynamic response visualization

- Derivation of a low order joined-wing aeroelastic model from realistic data

A more detailed case for enhancing HALE focused nonlinear transient analysis for the gust response problem is provided in the motivation section of this chapter. Following the motivation section, the need for special analysis to capture geometrically nonlinear phenomenon is explained using simple examples. The second chapter provides a review of relevant literature. Methodologies for the quasi-static and transient gust analysis are provided in Chapter 3. Two relevant HALE aircraft models are introduced and described. Results are discussed in Chapter 4, and conclusions are reported in the final chapter.

\subsection{Motivation}

This research is motivated by a need to develop high performance HALE aircraft. These aircraft are designed to sustain flight at a very high altitude for long missions. HALE designs tend to be highly flexible as a result of minimizing the structural weight of what end up being long and slender wings. This flexible layout leads to nonlinear effects from large deformations and follower forces; effects that are not captured in traditional analysis. Recommendations following the crash of a high aspect ratio flying wing aircraft are used as a motivation for the efforts to improve NATASHA's transient gust analysis capabilities. 


\subsubsection{Helios Prototype Crash}

The crash of the Helios prototype (see Figure 1.2) strongly indicated the inadequacy of available methods for HALE aircraft gust response analysis. The NTSB's investigation

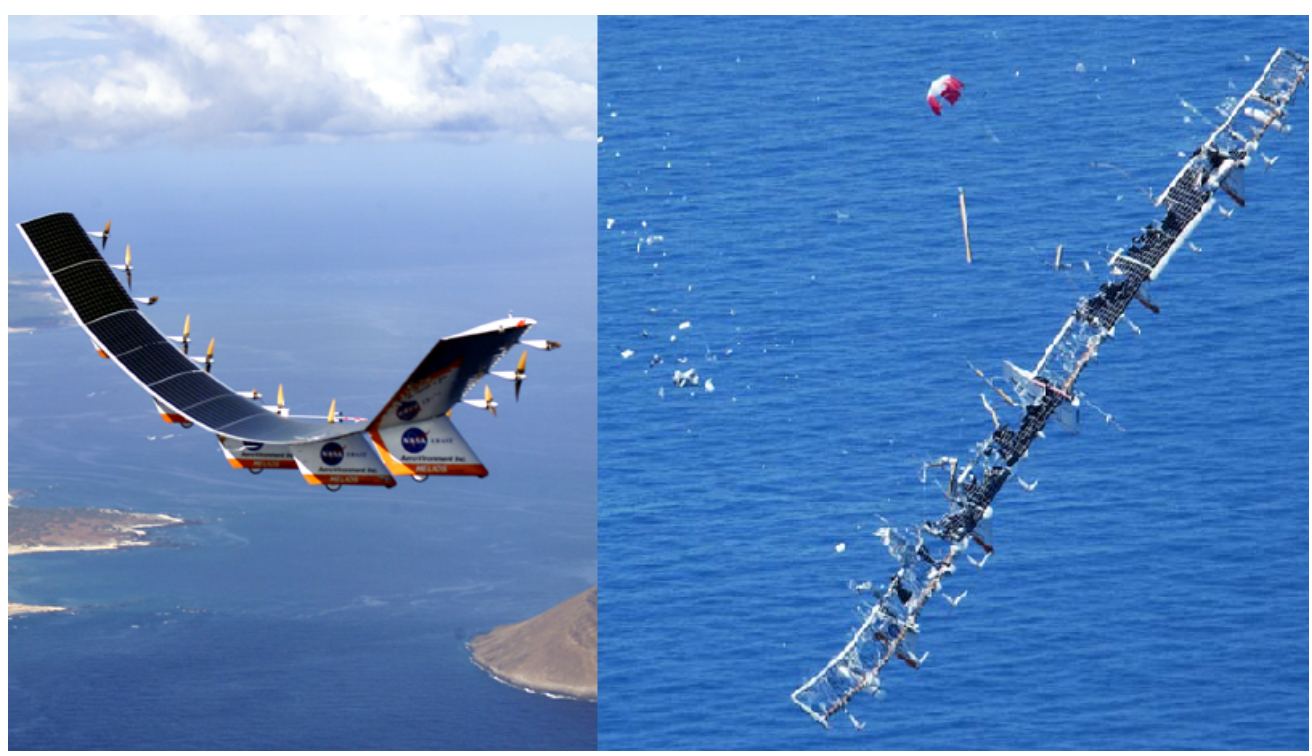

Figure 1.2: The Helios prototype vehicle [30].

identified two root causes of the accident.

- Root Cause 1) Lack of adequate analysis methods led to an inaccurate risk assessment of the effects of configuration changes leading to an inappropriate decision to fly an aircraft configuration highly sensitive to disturbances.

- Root Cause 2) Configuration changes to the aircraft, driven by programmatic and technological constraints, altered the aircraft from a spanloader to a highly pointloaded mass distribution on the same structure significantly reducing design robustness and margins of safety.

Recommendations (2 of 5 recommendations are listed) 
- Root Cause 1, 1st Recommendation) Develop more advanced, multidisciplinary (structures, aeroelastic, aerodynamics, atmospheric, materials, propulsion, controls, etc) "time-domain" analysis methods appropriate to highly flexible, "morphing" vehicles.

- Root Cause 2,1st Recommendation) Develop multidisciplinary (structures, aerodynamic, controls, etc) models, which can describe the nonlinear dynamic behavior of aircraft modifications or perform incremental flight-testing.

This work directly addresses the recommendations made by the NTSB in the mishap report. The need for nonlinear transient gust response capability extends to other HALE configurations. The Air Force Research Laboratory sponsors this work, and provides additional motivation with the SensorCraft platform.

\subsubsection{Joined-Wing SensorCraft}

The joined-wing configuration facilitates housing sensors that provide $360^{\circ}$ of foliage penetrating radar coverage. Its HALE mission also drives its design toward slender flexible wings. In addition to the nonlinear effects from high flexibility, analysis of the joined-wing SensorCraft must also consider nonlinearities due to bucking of the aft wing (see Figure 1.3).

Previous computational studies have shown that nonlinear analysis is required to capture the physics driving the design of the joined-wing SensorCraft [15]. There has been only limited work on transient aeroelastic analysis of a joined-wing configuration. Details of the previous work are discussed in the Literature Review Chapter. 


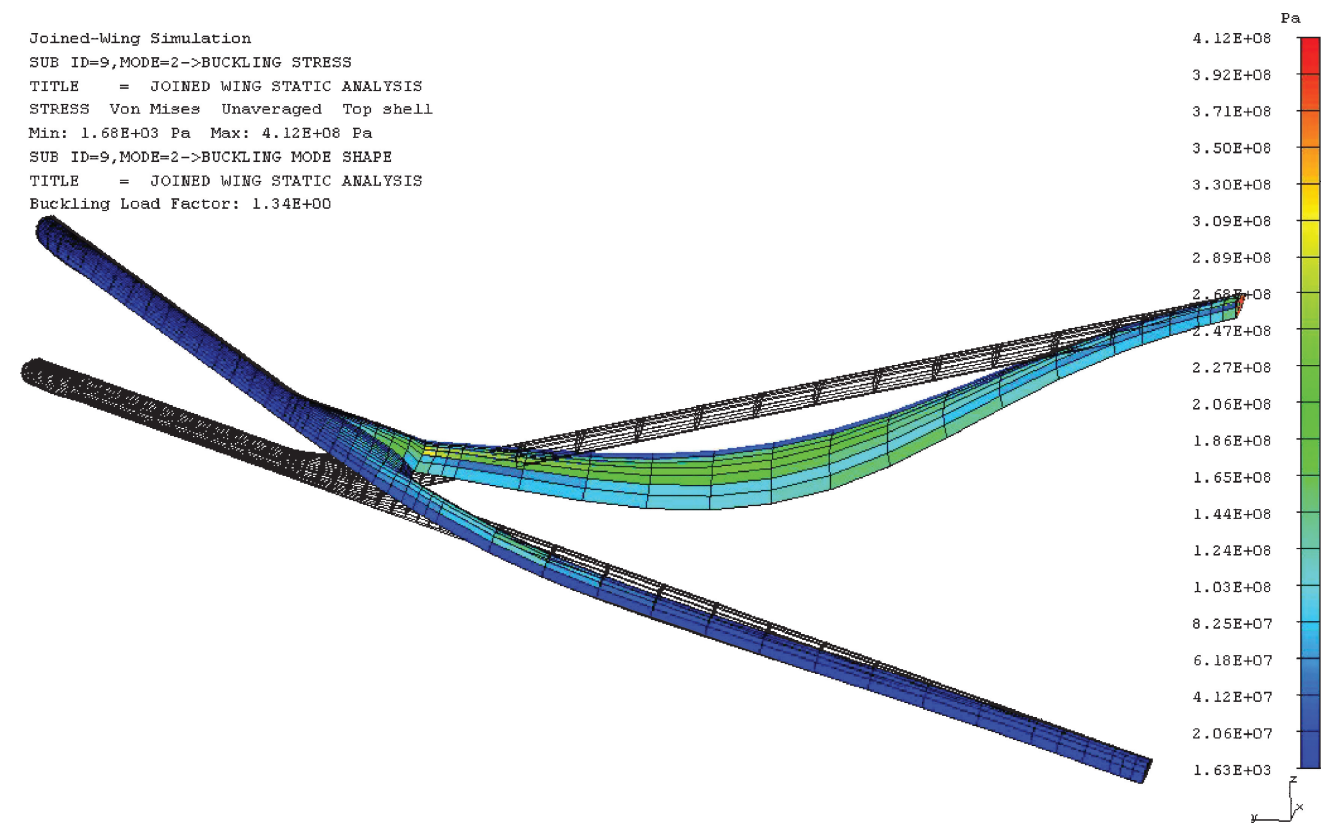

Figure 1.3: Buckling mode for gust load using nonlinear analysis [3].

\subsection{Background - Gust Response Analysis}

Methods for determining gust loads have been the subject of technical interest since the very first NACA publication in 1915 [21]. Over the years many methods have been developed and used for design and certification [18]. These have been placed in the following categories: quasi-static, transient, and continuous turbulence methods. Each of these categories is described in further detail in the following subsections.

\subsubsection{Quasi-Static Methods}

In reality turbulence is a transient phenomenon. However, quasi-static methods enable a static representation of gust encounters. This vastly reduces the computational expense of the analysis. Exploration of a large design space requires analyses to be run repeatedly for hundreds or even thousands of cases. Variable levels of fidelity should be available and 
used in large studies. Quasi-static methods provide a lower fidelity and lower cost option. Computers and higher order methods were not available in the early days of aviation so quasi-static methods were used almost exclusively. Quasi-static methods are broken into the following two categories:

\section{Sharp-Edge Gust Profile}

The sharp-edge gust concept was first published in 1931 [42]. It is derived based on the assumption that the airplane encounters an instantaneous change in the vertical component of velocity $(U)$. This causes a change in the angle of attack resulting in a change in lift. No unsteady aerodynamics, flight dynamics, or structural dynamics are considered. The change in lift is determined using the most basic lift equation

$$
\Delta L=\frac{1}{2} \rho V^{2} S C_{L_{\alpha}} \Delta \alpha
$$

where $\mathrm{L}$ is lift, $\rho$ is atmospheric density, $V$ is airspeed, $S$ is the wing reference area, and $C_{L_{\alpha}}$ is the lift curve slope. The change in angle of attack can be determined as $\Delta \alpha=\arctan \left(\frac{U}{V}\right)$. Change in load factor is then simply $\Delta n=\frac{\Delta L}{W}$. Equation (1.1) was the basis of the first gust loads certification requirements in 1934 [28].

\section{Shaped Gust Profile}

For applications at the time of its introduction, the weakest assumption of the sharp edge formula was that it neglected unsteady aerodynamics and the vertical motion of the aircraft. Thus, in the following years new quasi-static methods were developed that could account for these effects [9]. They are listed here in order of their introduction. 
1. Ramp Gradient Gust Formula

\section{Triangular Gradient Gust Formula}

\section{Revised Gust Formula (Pratt's Method)}

As new methods were introduced they largely superseded previous methods for design and certification. Each of these methods provide a solution to a dimensionless system that encounters a specific gust profile. The solution can then be dimensionalized for any specific case. A weakness of this approach is that many of the assumptions that are made in order to generalize the system are not valid for all applications.

This work focuses Pratt and Walker's [38] Revised Gust Formula (herein referred to as Pratt's Method), because it has been the dominant quasi-static method since its introduction in the mid 1950s. Pratt's Method decouples the flight dynamic response from the aeroelastic response. A simplified rigid flight dynamic equation of motion (EOM) is used to determine the peak load factor experienced in the gust encounter. The aeroelastic or rigid loads are then determined as a static maneuver load at that load factor.

The simple flight dynamic EOM considers only rigid longitudinal dynamics and neglects changes in the forward velocity, pitch and pitch rates. The EOM is only a function of dimensionless time $(s)$ and a dimensionless mass ratio $\left(\mu_{g}\right)$. Pratt and Walker assumed a 1-cosine gust profile and solved the EOM numerically to find the peak load factor. The peak load factor was then related to the load factor determined using a sharp-edge gust analysis by the $K_{g}$ knockdown factor.

$$
\Delta n_{\text {Pratt's Method }}=K_{g} \Delta n_{\text {sharp-edge }}
$$


Pratt and Walker found this $K_{g}$ factor for a range of mass ratios and used regression to derive a curve fit that directly relates the mass ratio to the $K_{g}$ knockdown factor. This curve fit

allows users to determine the loads based on Pratt's Method without the complication of solving the flight dynamic EOM. Details of the derivation of Pratt's Method will be reviewed in the Methodology chapter. It will be shown that Pratt's curve fit matches the solution of Pratt's EOM in the range of mass ratios that correspond to conventional designs, but is erroneous at very low mass ratios that are consistent with HALE aircraft such as Helios [30]. Sources of error from assumptions made to derive and solve the flight dynamic EOM are investigated by comparison to results from transient analysis for two models.

\subsubsection{Transient Methods}

Transience implies that the equations representing the system are solved with time as an independent variable. Pratt's flight dynamic EOM is simple enough to solve though a basic time integration. Structural effects are not considered, so spatial discretization is unnecessary. More realistic transient representations couple flight dynamics with aeroelastic effects and thus require both spatial and temporal discretization to solve transiently.

A challenge when using transient analysis is that selection of discrete gust profiles is nontrivial. It is important that the worst case gusts are represented and accounted for in the design, but the worst case gust profile is not a given. FAR Part 25 certification requires many 1-cosine profile gusts over a range of frequencies be analyzed using transient analysis. But accounting for every possible profile shape and spanwise distribution is impossible. The worst case gust profile could be overlooked.

The few codes available for solving nonlinear transient gust response cases are reviewed in Chapter 2. Patil and Hodges developed a program called Nonlinear Aeroelastic Trim and 
Stability for HALE Aircraft (NATASHA) [33]. The code was modified to better represent the nonlinear transient gust encounter. The improved transient analysis feature of NATASHA was used as a higher fidelity baseline for the evaluation of Pratt's Method.

\subsubsection{Continuous Turbulence Methods}

Turbulence in the atmosphere is continuous and random. Continuous turbulence methods allow for a statistical representation of turbulence in the atmosphere so that all gust frequencies are accounted for. The continuous approach offers a robust representation of the atmosphere, but it has not superseded transient analysis for design and certification. Flight data recorders have shown that larger gusts often stand out as discrete events [13]. Transient analyses are better suited for predicting effects of discrete gust encounters. For these reasons, both continuous turbulence and transient methods are currently required for FAR Part 25 certification.

Continuous turbulence methods are very powerful for linear cases where the response is proportional to the input. A frequency domain analysis can be used to quickly calculate the linear response for any given continuous gust frequency spectrum. Nonlinear cases (such as the applications studied here) must be handled differently, because they are not easily treated in the frequency domain. In fact, execution of continuous analysis for a nonlinear problem requires nonlinear transient analysis. Thus, adequate nonlinear transient analysis is a required gateway to fidelity beyond quasi-static for nonlinear problems. 


\subsection{Background - Geometric Nonlinearity}

Geometric nonlinearities are not captured in traditional aeroelastic analysis because of assumptions made in traditional formulations. The small angle assumption is particularly useful when distilling geometrically complex systems into a linear system of equations. Traditional structural applications are relatively stiff; it is reasonable to assume that any deformations and corresponding angles will be small.

Emerging HALE aircraft exhibit highly flexible behavior not suitable for representation with traditional analysis. Large deformations are routine. Aerodynamic lift and drag are dependent on the deformed shape. Buckling needs to be considered when sections undergo compression. Nonlinear analysis is required to capture these relevant effects. In this section, examples are provided to illustrate the necessity of nonlinear analysis to capture certain phenomenon. Simple rod and spring systems are used.

\subsubsection{Large Deformations}

Consider the system in Figure 1.4. A rigid rod is attached to a hinge with a torsional spring. A force $(F)$ is applied to the tip in the vertical direction. We would like to solve for the equilibrium rotation angle $(\theta)$ as a function of the applied force.

Solution: Sum the moments about the hinge.

$$
\Sigma M=F \ell \cos (\theta)-k_{t} \theta=0
$$

where $k_{t}$ is the torsional spring constant. We arrive at the geometrically exact equation (1.4) by moving the $\theta$ terms to the left hand side. 


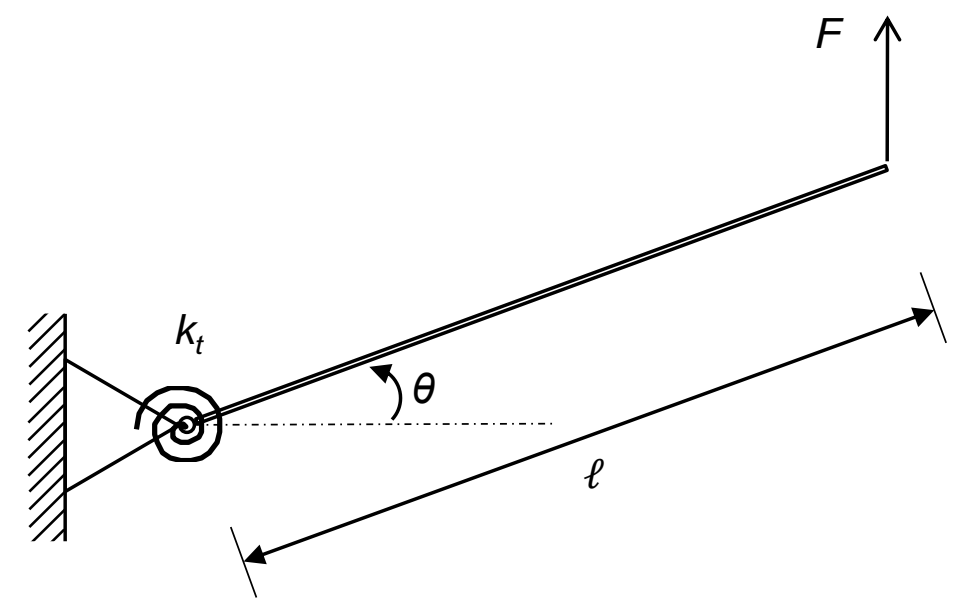

Figure 1.4: Hinged rigid rod with torsional spring. A vertical force is applied.

\section{Geometrically Exact Equation}

$$
\frac{\theta}{\cos (\theta)}=\frac{F \ell}{k_{t}}
$$

It is impossible to analytically solve for $\theta$ explicitly. We are forced to solve the nonlinear equation numerically. If it is reasonable to assume that $\theta$ is small $(\theta<<1)$, then the following small angle approximations can be used:

$$
\begin{aligned}
& \sin (\theta) \approx \theta \\
& \cos (\theta) \approx 1
\end{aligned}
$$

The small angle assumption is typical in traditional analysis. With the small angle assumption we can solve for $\theta$ explicitly and arrive at the linear equation.

\section{Linear Equation}

$$
\theta \cong \frac{F \ell}{k_{t}}
$$

The responses from the linear equation (1.7) and for the nonlinear geometrically exact equa- 
tion (1.4) are plotted in Figure 1.5. The responses depart zero at the same slope as the

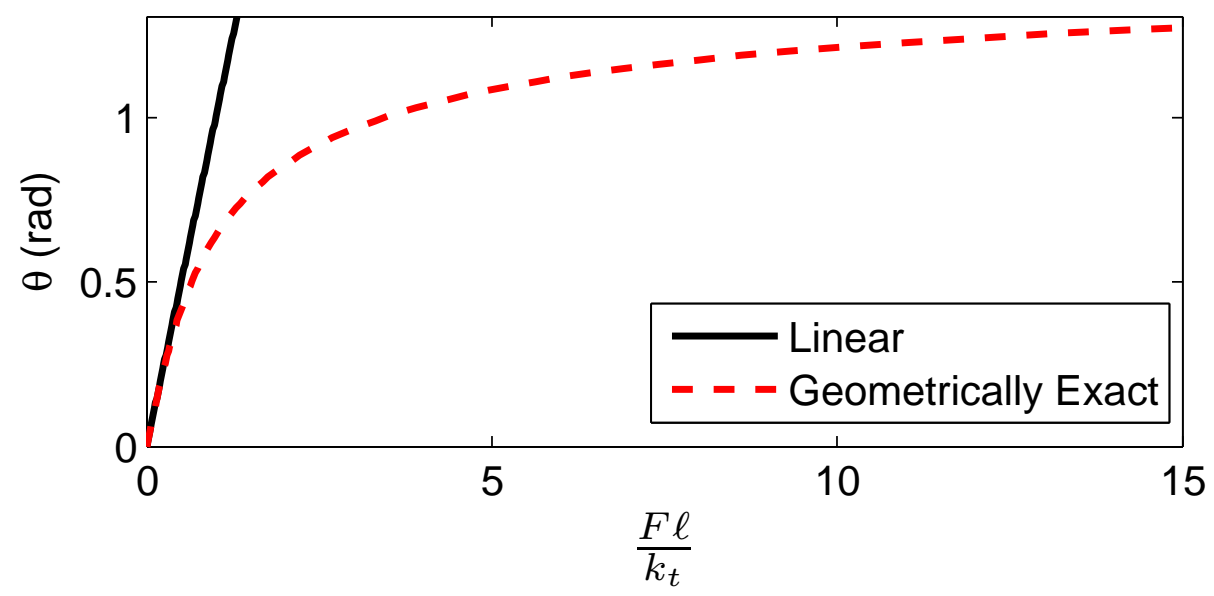

Figure 1.5: Linear and geometrically exact response of hinged rod.

nondimensional force $\left(\frac{F \ell}{K_{t}}\right)$ is applied. The geometrically exact solution is the true response. In reality there is a stiffening effect from the reduction of the moment arm length. The stiffening effect is not captured by the linear equation, and it's accuracy is poor at large angles. The linear equation is accurate at small angles, and it is very efficient to solve because, unlike the nonlinear equation, it does not require an iterative numerical solution.

\subsubsection{Follower Forces}

The system in Figure 1.6 has two hinged rods fitted with torsional springs. A force is applied at the tip that remains perpendicular to the right rod.

Linear Solution: Sum the moments about the hinges (assume small rotation angles).

$$
\begin{aligned}
& \Sigma M_{A}=F \ell-k_{t} \theta_{A}=0 \\
& \Sigma M_{B}=\frac{F \ell}{2}-k_{t} \theta_{B}=0
\end{aligned}
$$




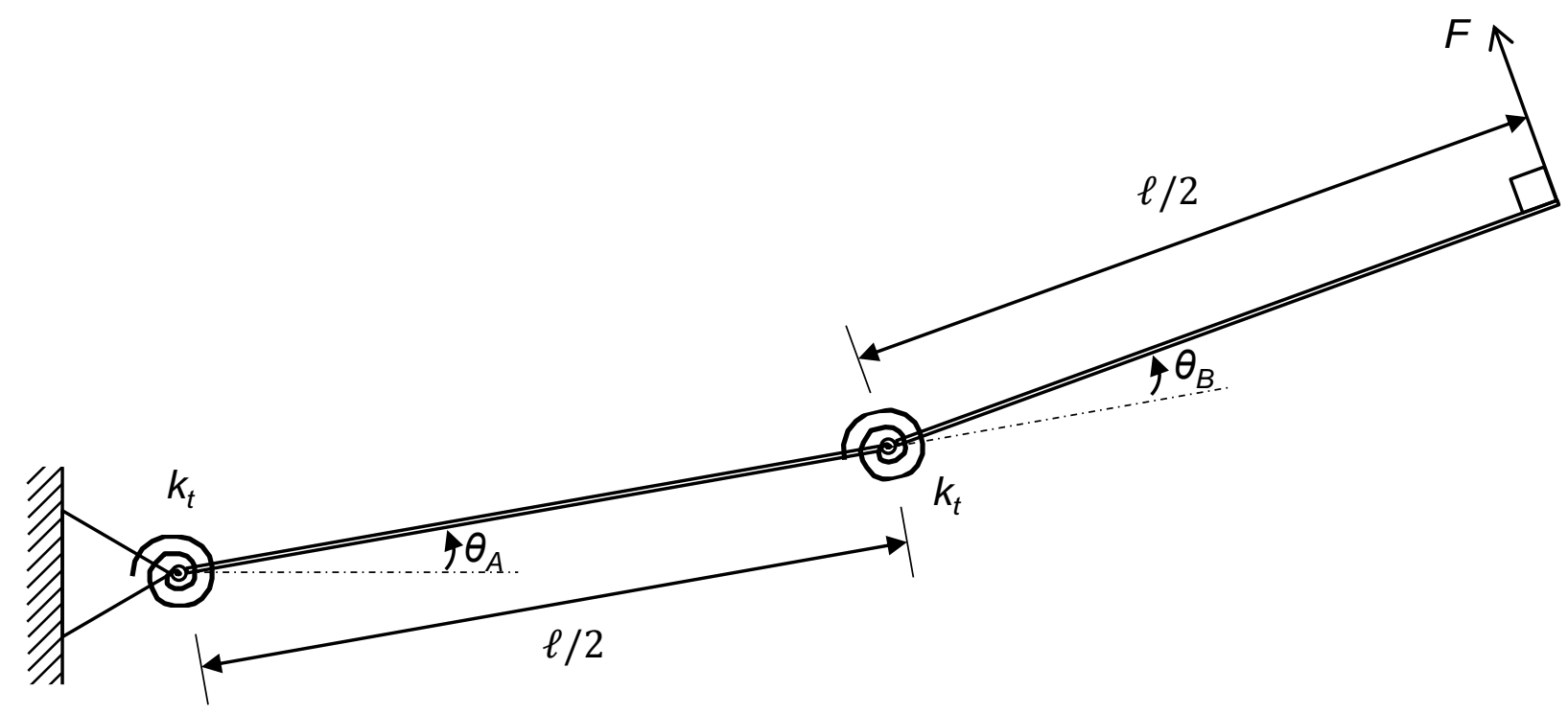

Figure 1.6: Hinged rigid rods with torsional springs. A follower force is applied.

Solve for the rotation angles.

$$
\begin{aligned}
\theta_{A} & =\frac{F \ell}{k_{t}} \\
\theta_{B} & =\frac{F \ell}{2 k_{t}}
\end{aligned}
$$

Geometrically Exact Solution The exact solution for $\theta_{B}$ is simple because the moment arm about the center hinge does not depend on the rotation. $\theta_{B}$ is found explicitly by summing the moments about the center hinge.

$$
\begin{aligned}
\Sigma M_{B} & =\frac{F \ell}{2}-k_{t} \theta_{B}=0 \\
\theta_{B} & =\frac{F \ell}{2 k_{t}}
\end{aligned}
$$

Solving for $\theta_{A}$ is more difficult than it was for the linear case. The moment about the left hinge is dependent on both deformation angles. It impossible to solve for the $\theta_{A}$ rotation 
angle as a function of the force magnitude explicitly. The nonlinear equation is derived by summing the moments about the left hinge.

$$
\Sigma M_{A}=\vec{r} \times \vec{F}-k_{t} \vec{\theta}_{A}=0
$$

where

$$
\begin{gathered}
\vec{r}=\frac{\ell}{2}\left[\left(\cos \left(\theta_{A}\right)+\cos \left(\theta_{A}+\theta_{B}\right)\right) \hat{i}+\left(\sin \left(\theta_{A}\right)+\sin \left(\theta_{A}+\theta_{B}\right)\right) \hat{j}\right] \\
\vec{F}=F\left[\sin \left(\theta_{A}+\theta_{B}\right) \hat{i}+\cos \left(\theta_{A}+\theta_{B}\right) \hat{j}\right]
\end{gathered}
$$

and

$$
\overrightarrow{\theta_{B}}=\theta_{B} \hat{k}
$$

The nonlinear system was solved by following the steps below. Applying a force magnitude F

1. Solve for $\theta_{B}$ using Equation 1.13

2. Iteratively find $\theta_{A}$ using the Newton-Raphson method so that Equation 1.14 is satisfied.

The resulting rotations and vertical tip displacements are plotted in Figure 1.7. Notice that the nonlinear solution departs from zero with the same slope as the linear solution. The linear solution does not capture the stiffening effect that comes from the change in direction of the force at large deformation angles. The linear solution for tip deflection and $\theta_{A}$ rotation angle are not correct at large deformations.

\subsubsection{Buckling}

Consider the system in Figure 1.8. Again we would like to solve for the rotation angle $\theta$ as a 

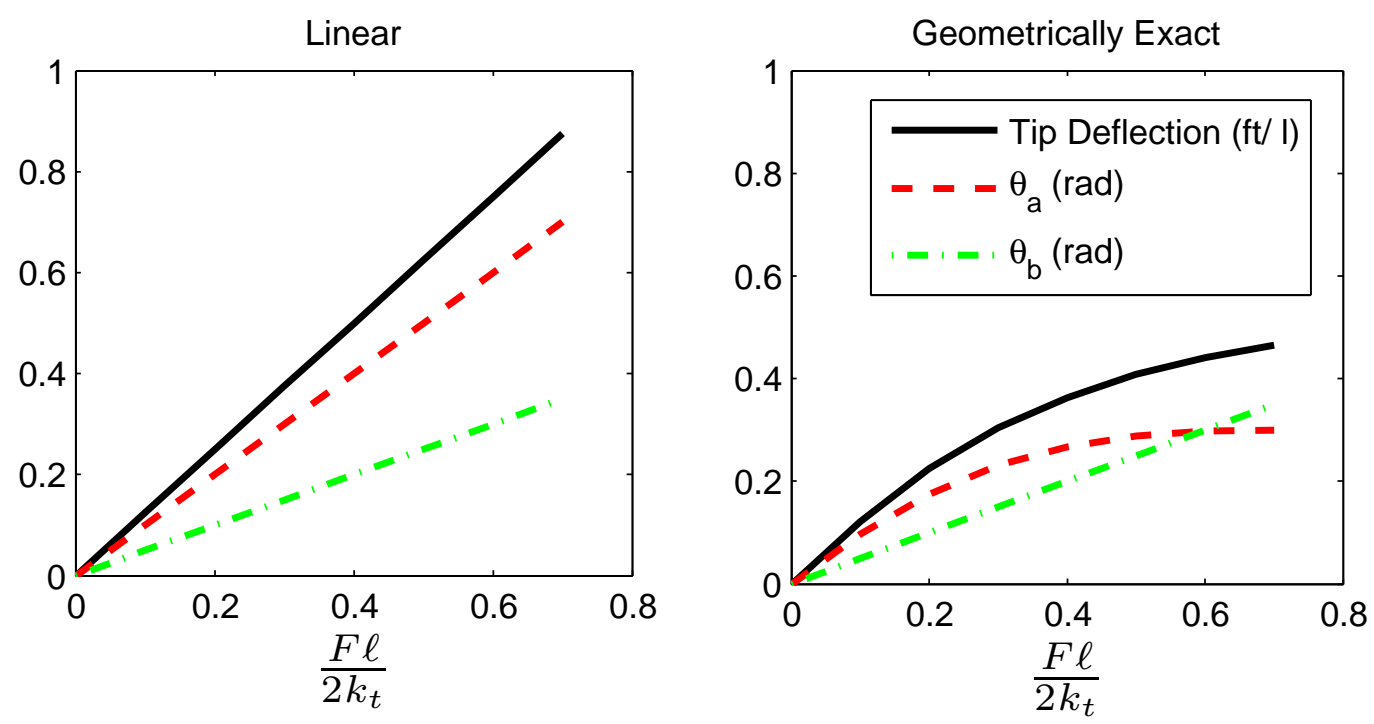

Figure 1.7: Linear and geometrically exact response the two hinged rods with a follower force.

function of the applied force $(F)$. By isolating the left rod and summing the moments about the left hinge we arrive at the following equation of equilibrium.

$$
\Sigma M=F \frac{\ell}{2} \sin (\theta)-k_{t} 2 \theta=0
$$

The geometrically exact equation is derived by moving the $\theta$ terms to the left hand side.

\section{Geometrically Exact Equation}

$$
\frac{\theta}{\sin (\theta)}=\frac{F \ell}{4 k_{t}}
$$

Equation 1.19 is another nonlinear equation requiring an iterative solution. The small angle assumption is made so that $\theta$ can be solved explicitly in the linear equation.

\section{Linear Equation}

$$
1=\frac{F \ell}{4 k_{t}}
$$

The linear equation provides a critical force for which the system becomes unstable. At any 


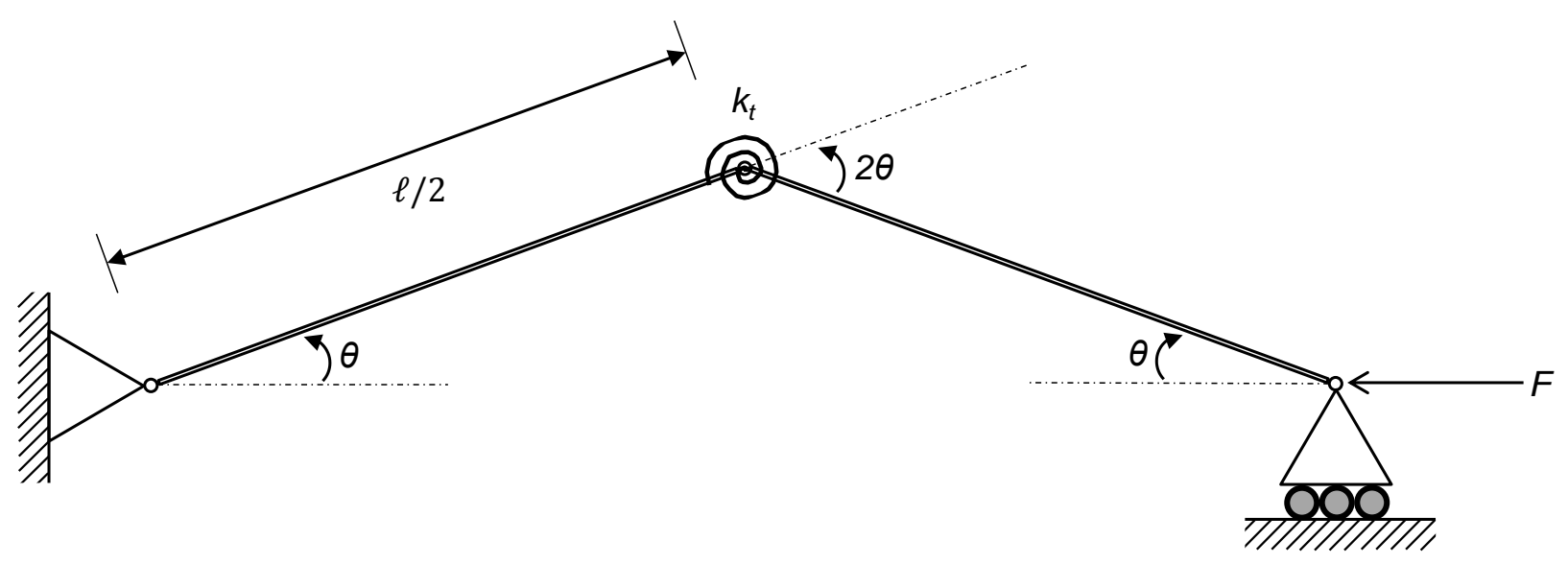

Figure 1.8: Two rigid hinged rods with a torsional spring in the center. A horizontal force is applied at the right hand side.

subcritical applied force $\left(F<\frac{4 k_{t}}{\ell}\right)$ the spring will force $\theta$ to zero. The linear equation does not correctly capture equilibrium points of the post buckled system. The geometrically exact equation provides correct solutions after the force exceeds its critical value. See Figure 1.9 for the comparison.

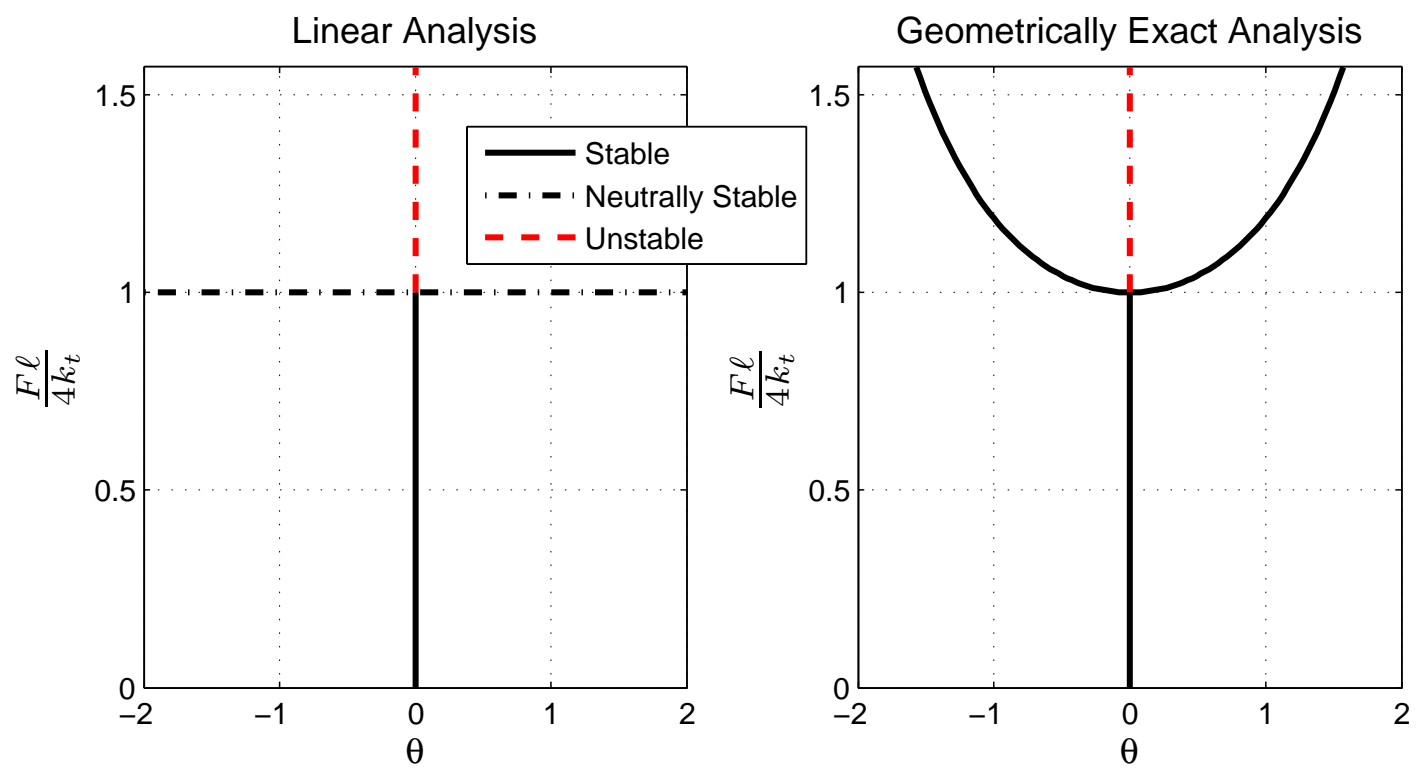

Figure 1.9: Linear and geometrically exact response and stability of the two hinged rod system.

The bifurcation of the geometrically exact stable curve indicates that two post buckled 
solutions exist for this case. The linear response incorrectly indicates neutral stability at any $\theta$ for $\frac{F \ell}{4 k_{t}}=1$. 


\section{Chapter 2}

\section{Literature Review}

The analysis presented in Chapter 4 was executed in a program called Nonlinear Aeroelastic Trim and Stability for HALE Aircraft (NATASHA). NATASHA is a capability built on broad body of scientific research. Research directly related to the development of NATASHA is reviewed in the first section of this chapter. Additional efforts in the area of coupled flight dynamics and aeroelasticity are reviewed in the following section.

Previous joined-wing work has established the need to capture geometric nonlinearities in the aeroelastic analysis. Literature leading to this realization is reviewed in the final section of the chapter.

\subsection{NATASHA Foundations}

The equations governing the structure in NATASHA are Hodges' [19] intrinsic (i.e., without displacement and rotational variables) equations for the dynamics of initially curved and twisted beams in a moving frame. Ref. [19] provided kinematical relations based on dis- 
placement and rotation. Hodges [20] later derived intrinsic kinematical equations. Because they are geometrically exact, it is the intrinsic kinematical equations that are implemented in NATASHA. This robust geometrically-exact intrinsic beam formulation allows NATASHA to handle geometric nonlinearities, including large deformations, follower forces, and buckling.

Peters and Johnson [36] presented a 2-D finite-state airloads model. Later Peters et al. [37] derived an inflow model based on linear potential flow. The resulting closed-form equations for the inflow and states give excellent correlation with Theodorsen and Wagner functions. Peters' airloads and inflow model are implemented in NATASHA.

In 2000, Patil et al. [34] published results from a precursor analysis based on the same principles. Flutter results were validated through comparison to the analytical Goland [16] wing solution. Examples of different nonlinear aeroelastic effects were also presented. Later Patil and Hodges [32] developed another precursor code that helped quantify the importance of capturing geometric nonlinearities in aeroelasitic analysis of HALE aircraft. This code had the option to use either the aformentioned Peters' aerodynamics, or a nonplanar, unsteady, fixed-wake doublet-lattice method to allow for geometrically exact representation of the aerodynamics. There was a negligible difference between the airloads calculated using the exact nonplanar wing geometry as compared to loads calculated assuming a planar wing. It was demonstrated that the dominant nonlinearity for long slender wings is dependence of the structural dynamic properties on the wing deformation.

Patil and Hodges [33] published the baseline NATASHA formulation in 2006. Flight dynamic results where presented for the flying wing HALE model that is used in this work. An extreme sensitivity to loading (alluded to in the Helios mishap report) was confirmed. The classical phugoid mode was shown to be unstable at a sufficiently high payload. Patil and Taylor [35] added gust functionality to NATASHA. Frequency domain continuous gust analysis was performed. Different models for the spanwise gust cross correlation were used. 
The spanwise non-uniform gust model predicted response many times that predicted by the spanwise uniform gust model. Patil [31] later added a transient gust analysis capability to NATASHA. The nonlinear continuous gust response from transient analysis was compared to the continuous response from linearized frequency analysis. The results matched well for a case with relatively small disturbances.

Ricciardi et al. [43] examined the utility of Pratt's quasi-static gust response methodology for the Patil and Hodges developed HALE model and for a newly developed joined-wing model. A parametrized 1-cosine gust profile was used as input for the transient analysis. Results from the transient analysis were used as a baseline for evaluating the quasi-static method. It was concluded that quasi-static analysis was useful for preliminary analysis of the joined-wing model, but not useful for the flying wing HALE model. Although this work has similar conclusions, an improved transient gust analysis was used for more accurate results.

\subsection{Coupled Flight Dynamics and Aeroelasticity}

Milne [26] was among the first to study flight dynamics of elastic aircraft. General equations of motion for a flexible aircraft were developed. The analysis was applied to study the static stability of an example configuration. The paper was the first to introduce the concept of mean axis for an elastic system. This concept was expanded on in [27]. Longitudinal and lateral dynamics of elastic airplanes were modeled and validated experimentally by Swaim et al. [47, 48]. The state space model expressed aerodynamic forces from elastic vibration in terms of stability derivatives based on the rigid body modes. The model showed reasonably good agreement with flight data for the B-1 bomber.

Waszak and Schmidt [50] derived the equations of motion for an elastic aircraft using Lagrange's equation and the principle of virtual work. Equations were derived in the mean 
axis system assuming small deformations and a constant inertia matrix. Quasi-steady strip theory aerodynamics were used. A rigid model and simplified flexible model was derived by including residualized modes. The higher fidelity full aeroelastic model was used to quantify adequacies and deficiencies of simplifying assumptions that were used to derive lower order models. It was shown formulating with assumed elastic modes could account for static effects of elastic coupling and better approximate the dynamics of a moderately flexible vehicle. However, the residualized-mode model had significant errors if flexibility was sufficiently increased. It was also shown that the models obtained under the rigid-body assumption may not be accurate, even when the form of the desired model is that of a rigid vehicle. Crimaldi et al. [8] formulated a continuous, linear elastic, three dimensional gust model for the B-2 aircraft. Responses from both symmetric and asymmetric gust loading conditions were compared. It was shown that symmetric gusts produced the highest loads for that particular flying wing configuration.

The work in [50] was used by Schmidt and Raney [44] to develop a modeling approach that could add flexibility effects to existing rigid body simulations. The required data for modeling a specific vehicle included aerodynamic stability derivatives, aerodynamic influence coefficients, elastic mode shapes, modal frequencies and damping, and generalized masses. The authors presented two case studies that involved the development of motion based simulators. Transient and continuous responses were presented as well as evaluations of elastic effects on handling characteristics. Results showed the strong impact that dynamic aeroelasticity could have on flying qualities. A need was demonstrated for aeroelastically accurate motion-based simulation facilities to facilitate the understanding of flight dynamic and flying quality characteristics of flexible aircraft.

Fully nonlinear rigid body equations of motion coupled with linearized flexibility effects were developed by Reschke [41]. The influence of inertial coupling terms on simulation and 
loads computation was shown using a dynamic simulation of a transport aircraft. Kier [22] applied different aerodynamic theories to Reschke's work and compared the computational cost and resulting loads. The gust response was calculated for a range of symmetric 1-cosine gust inputs. High sensitivity to the gust frequency was indicated.

Nguyen [29] derived aeroelastic flight dynamic equations that account for propulsive and inertial coupling. Structural modes obtained for the wing from a finite element beam model were used as generalized coordinates. Flight dynamic equations were coupled with the structural dynamics through force and moment expressions.

The surveyed work up to this point of the section has been aeroelasticlly linear. There has been limited work in the area of flight dynamics coupled with nonlinear aeroelasticity. The previously discussed NATASHA work is in this exclusive category. Three additional efforts are discussed below.

Drela [10] developed ASWING, a licensed integrated analysis tool with exceptional documentation. The code uses unsteady lifting line aerodynamics and a structural model based on geometrically nonlinear isotropic beam analysis. Gust field inputs can be specified. Love et al. [24] used ASWING to model the behavior of a flying wing SensorCraft configuration. Results indicated that body freedom flutter is an issue for that configuration over lower altitude portions of the flight envelope. A case was made for exploring active flutter suppression systems. Recently ASWING has been modified to analyze flapping wing MAVs. Willis et al. [51] describe a multifidelity framework that includes the new ASWING capability.

Nonlinear Aeroelastic Simulation Toolbox (NAST) has been developed in a parallel effort. Cesnik and Brown $[5,6]$ introduced the strain-based structural modeling approach. NAST incorporates the previously reviewed Peters $[36,37]$ aerodynamic formulation that is also used in NATASHA. Transient gust analysis for a joined-wing configuration was demonstrated 
in [6]. Cesnik and Su [7] extended NAST by adding fuselage flexibility; effects on singlewing and joined-wing SensorCraft responses were studied. It was shown that the joined-wing vehicle is more susceptible to the induced flexibility of the fuselage and tail when considering roll maneuvers. Adding flexibility to both the fuselage and vertical tail reduced the linearized flutter speed of joined-wing configuration, but it did not significantly impact the flutter speed of the single-wing configuration. It was also noted that adding flexibility to the fuselage decreased buckling speed, but adding the flexibility to the vertical tail increased it for the case studied. Shearer and Cesnik [45] used NAST to show that nonlinear flight dynamics coupled with linearized aeroelastic equations could significantly differ from solutions using the fully nonlinear system. Therefore fully nonlinear simulations are required to accurately predict the response for some cases. Su and Cesnik [46] performed gust response analysis on the Patil/Hodges [33] flying wing HALE. A model to capture the change in the wing torsional stiffness due to skin wrinkling arising from large bending curvatures was demonstrated. It was found that skin wrinkling associated with the wing torsional stiffness significantly affected motions of the vehicle only in the lateral direction.

Finally, Wang et al. [49] used the previously discussed Hodges beam modeling [19, 20] coupled with unsteady vortex lattice aerodynamics. The formulation was demonstrated for a Goland [16] wing model and the Patil/Hodges [33] HALE model. Unique transient results of the spanwise deformed wake were presented for an extreme HALE case. Trim results were similar to those reported by Patil and Hodges.

\subsection{Joined-Wing Geometric Nonlinearities}

Wolkovitch [52] first patented the joined-wing configuration in 1976. An example of an early Wolkovitch configuration is shown in Figure 2.1. By 1986, Wolkovitch [54] had evidence to 

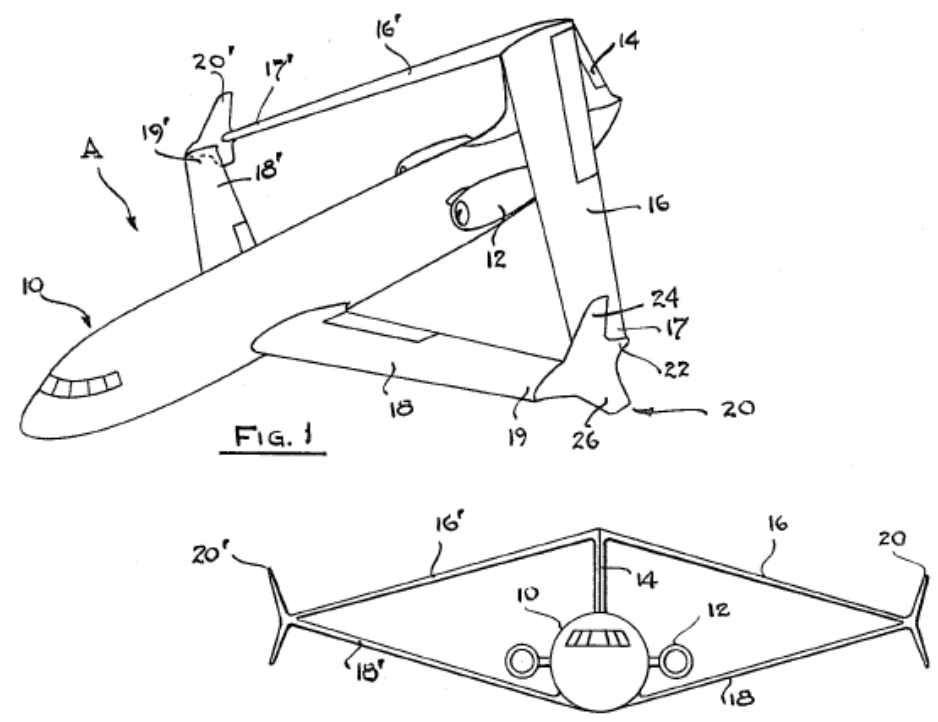

Figure 2.1: Early joined-wing configuration [53].

claim many advantages for the joined-wing configuration. These included:

- Light weight

- High stiffness

- Low induced drag

- Good transonic area distribution

- High trimmed CL max

- Reduced wetted area and parasite drag

- Direct lift control capability

- Direct sideforce control capability

- Good stability and control 
Unfortunately, the supporting studies for these claims had not considered nonlinear aft wing buckling. Ultimately it was determined that buckling is a design driver. With buckling considered, many of the above advantages are seriously deflated.

Gallman el al. $[14,15]$ applied numerical optimization to the joined-wing configuration and presented a quantitative comparison of a joined-wing and a conventional aircraft designed for the same medium range transport mission. This study quantified the importance of including constraints on nonlinear aft wing buckling. A 5.3\% penalty in operating cost was shown as a direct result of including the buckling constraints. The overall direct operating cost of the joined-wing design was $3.2 \%$ greater than a conventional tube and wing design that was optimized using the same framework. Although this study was only performed for one mission profile it did shed light on some of the overlooked weaknesses of the joined-wing configuration. Interest in the configuration was reduced after the findings were released.

In 2001 Livne [23] published a valuable review of aeroelastic design work for the joinedwing configuration. Interest was rejuvenated in the early 2000s when the SensorCraft concept was initiated by the Air Force Research Laboratory [25]. Boeing's Phantom Works developed a detailed joined-wing concept for the mission (see Figure 2.2). Because the SensorCraft concept has wing-embedded sensors, the joined-wing configuration provides an unmatched $360^{\circ}$ of foliage penetrating radar coverage. The importance of aft wing buckling was again realized by SensorCraft motivated work.

Blair and Canfield [2] initiated nonlinear exploration of a SensorCraft concept with approximately twice the span of the model used by Gallman el al. Blair el al. [3] continued the effort with the development of a joined-wing design model integrated with automated aerodynamic and structural analysis in a single environment. Importance of geometric nonlinearities and aft wing buckling for SensorCraft optimization were demonstrated. Rasmussen el al. $[39,40]$ applied static aeroelastic analysis to perform joined-wing vehicle design opti- 


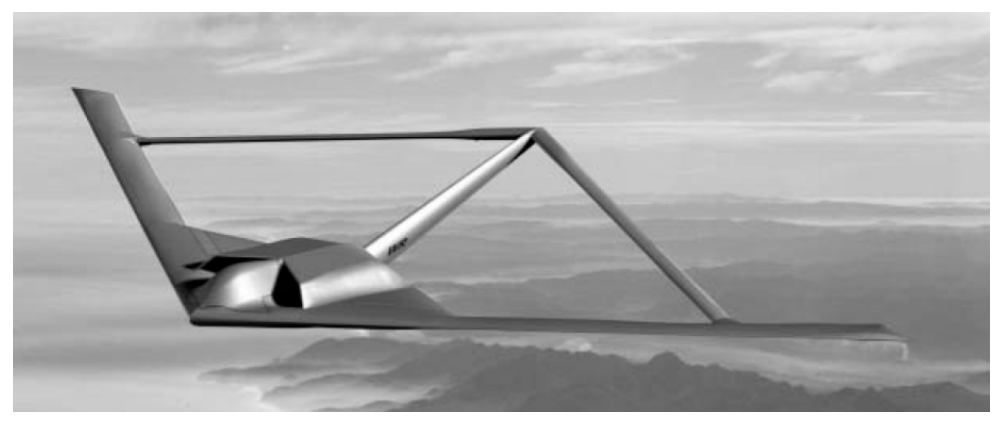

Figure 2.2: Boeing joined-wing SensorCraft configuration [25].

mization. Effective use of response surface methods facilitated a lower cost optimization and a more fundamental understanding of the design space. Adaptive refinement of the response surface around local optima was recommended for accuracy. It was shown that panel buckling in addition global buckling could be critical, especially if the forward and aft wings are coplanar. Related efforts motivated by the joined-wing SensorCraft concept continue. 


\section{Chapter 3}

\section{Methodology}

This chapter describes the details of the theory essential for this work. The derivation of Pratt's method is reviewed, and possible sources of error are identified. The method used to systematically quantify the error of Pratt's curve fit equation is developed. Formulation and modifications to the NATASHA aeroelastic code are reviewed. Validation of NATASHA's modified transient gust analysis is provided. Two HALE aircraft models are presented before investigation of their gust response behavior. Lastly, the computational framework for parallel analysis is explained.

\subsection{Pratt's Quasi-Static Method}

First introduced in the 1930s, quasi-static methods for gust loads analysis culminated with Pratt and Walker's [38] "Revised Gust Formula" (Pratt's Method) in 1954. Pratt's Method remains important to the design and certification of aircraft today. Pratt's Method is still the only method required for gust loads analysis in Federal Aviation Regulations (FAR) Part 23 certification. FAR Part 25 certification mandates the use of more advanced methods, but 
manufacturers adhering to Part 25 continue to use Pratt's Method for exploration of large design spaces to reduce computational cost. In this section, Pratt's derivation is reviewed, and the possible sources of in Pratt's Method are outlined.

\subsubsection{Derivation of Pratt's Method}

Pratt identified the following assumptions when deriving the flight dynamic equation of motion (EOM):

1. The airplane is a rigid body.

2. The airplane forward speed is constant.

3. The airplane is in steady level flight prior to entry into the gust.

4. The airplane can rise but cannot pitch.

5. The lift increments of the fuselage and horizontal tail are negligible in comparison with the wing lift increment.

6. The gust velocity is uniform across the wing span and is parallel to the vertical axis of the airplane at any instant.

Neglecting lag in the buildup of lift, the governing EOM is:

$$
M \ddot{z}+\frac{\rho}{2} V^{2} S C_{L_{\alpha}} \frac{\dot{z}}{V}=\frac{\rho}{2} V^{2} S C_{L_{\alpha}} \frac{U(t)}{V}
$$

where $M$ is the vehicle mass, $z$ is position in the vertical direction, $t$ is time, and $U(t)$ is the gust velocity as a function of time. () implies differentiation with respect to time. The first term in Equation 3.1 is the the product of mass and acceleration, the second term is the 
lift due to the vertical motion of the airplane, and the final term is the lift due to vertical gust. To allow a generalized solution, Pratt nondimensionalized time using chord length and velocity

$$
s=\frac{t V}{\bar{c}}
$$

where $\bar{c}$ is the wing mean aerodynamic chord. The Küssner function $\left(K_{G}\right)$ was used to account for the delay in lift due to the chord not entering the gust instantaneously, and the Wagner function $\left(K_{W}\right)$ was used to account for unsteady circulatory effects. Pratt assumed an infinite aspect ratio to simplify the lift lag functions to the following:

$$
\begin{gathered}
\frac{1}{2 \pi} K_{W}(s)=1.00-0.165 e^{-0.90 s}-0.335 e^{-0.600 s} \\
\frac{1}{2 \pi} K_{G}(s)=1.00-0.236 e^{-0.116 s}-0.513 e^{-0.728 s}-0.171 e^{-4.84 s}
\end{gathered}
$$

The dimensionless mass ratio $\left(\mu_{g}\right)$ is used to generalize the equation of motion.

$$
\mu_{g}=\frac{2 W}{\rho g S \bar{c} C_{L_{\alpha}}}
$$

where $W$ is the weight of the aircraft, and $g$ is gravitational acceleration. Integrating Equation 3.1 after including the unsteady lift functions and substituting with Equation 3.1 and 3.5 Pratt and Walker transformed the flight dynamic equation to nondimensional form

$$
\frac{d^{2} z}{d s^{2}}+\frac{1}{\mu_{g}} \int_{0}^{s} K_{W}\left(s-s^{\prime}\right) \frac{d^{2} z}{d s^{\prime 2}} d s^{\prime}=\frac{1}{\mu_{g}} \frac{\bar{c} U_{0}}{V} \int_{0}^{s} K_{G}\left(s-s^{\prime}\right) \frac{d}{d s^{\prime}}\left(\frac{U}{U_{0}}\right) d s^{\prime}
$$

where $U_{0}$ is the gust intensity. Given a value for $\mu_{g}$, the acceleration term $\frac{d^{2} z}{d s^{2}}$ in Equation (3.6) can be solved over $s$, provided values are assumed for $\frac{\bar{c} U_{0}}{V}$, and $\frac{U}{U_{0}}$ for all $s$. Pratt assumed that $\frac{\bar{c} U_{0}}{V}=1$. This is justified with the assumption that Pratt's EOM is linear with respect to $U_{0}$. A gust intensity normalized 1-cosine gust profile was selected for $\frac{U}{U_{0}}$. The 
1-cosine gust profile shape is shown in Figure 3.1. The normalized gust profile equation is given in as

$$
\frac{U}{U_{0}}=\frac{1}{2}\left(1-\cos \frac{2 \pi s}{25}\right)
$$

The gust length is assumed to be 25 chords. This gust length was selected based on empirical

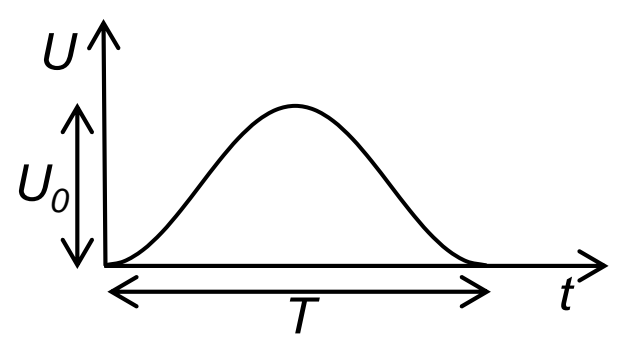

Figure 3.1: The 1-cosine gust profile. Pratt's Method assumes $T=\frac{25 \bar{c}}{V}$.

data which shows that legacy aircraft respond to gust loads at certification intensity at a period corresponding to 25 spatial chord lengths on average.[9]. Provided these assumptions, Equation (3.6) was solved for a range of $\mu_{g}$ 's, and the maximum acceleration encountered in the time history of each case was determined. With the maximum acceleration, the maximum change in load factor can be solved using:

$$
\Delta n=\left.\frac{1}{g} \frac{V^{2}}{\bar{c}^{2}} \frac{\bar{c} U_{0}}{V}\left(\frac{d^{2} z}{d s^{2}}\right)\right|_{\frac{\bar{c} U_{0}}{V}=1}
$$

By multiplying and dividing by $\mu_{g}$ Equation (3.8) reduces to

$$
\Delta n=\left.\mu_{g} \frac{\rho \bar{c} S C_{L_{\alpha}}}{2 M} \frac{1}{g} \frac{V^{2}}{\bar{c}^{2}} \frac{\bar{c} U_{0}}{V}\left(\frac{d^{2} z}{d s^{2}}\right)\right|_{\frac{\bar{c} U_{0}}{V}=1}=\underbrace{\left.\mu_{g}\left(\frac{d^{2} z}{d s^{2}}\right)\right|_{\frac{\bar{d} U_{0}}{V}=1}}_{K_{g}} \underbrace{\frac{\rho U_{0} V C_{L_{\alpha}}}{2 W / S}}_{\Delta n_{\text {sharp-edge gust }}}
$$


So we arrive at Pratt's original goal of a knockdown factor for the classic sharp-edge gust equation. Pratt's curve fit approximation for $K_{g}$ is:

$$
K_{g}=\frac{0.88 \mu_{g}}{5.3+\mu_{g}}
$$

Pratt's method allows the loads analyst to determine the gust response by a simple three step process.

1. Calculate the aircraft mass ratio $\left(\mu_{g}=\frac{2 W}{\rho g S \bar{c} C_{L_{\alpha}}}\right)$

2. Calculate the knockdown factor $\left(K_{g}=\frac{0.88 \mu_{g}}{5.3+\mu_{g}}\right)$

3. Calculate the change in load factor $\left(\Delta n=K_{g} \frac{\rho U_{0} V C_{L_{\alpha}}}{2 W / S}\right)$

Although this method may appear crude on the surface, the curve fit equation fully encapsulates the solution to Pratt's EOM. Evidence of the method's effectiveness is provided by thousands of Part 23 aircraft that operate safely every day.

Pratt's method does have limitations. Assumptions that were made are not valid for every case. Pratt's assumptions are outlined in the following section.

\subsubsection{Pratt's Method Error Sources}

\section{Assumptions made to derive Pratt's EOM}

(a) The airplane is a rigid body.

(b) The airplane forward speed is constant.

(c) The airplane is in steady level flight prior to entry into the gust.

(d) The airplane can rise but cannot pitch. 
(e) The lift increments of the fuselage and horizontal tail are negligible in comparison with the wing lift increment.

(f) The gust velocity is uniform across the wing span and is parallel to the vertical axis of the airplane at any instant.

\section{Assumptions made to solve Pratt's EOM}

(a) The response in linear with respect to gust intensity

(b) The gust encounter is a spanwise uniform 1-cosine gust with a 25 chord gust length.

\section{Error in Pratt's curve fit equation}

The error in Pratt's curve fit equation will be quantified directly using the method described in the next section. The magnitude of the remaining sources of error are application dependent. These errors will be quantified for the two HALE applications that are introduced later in this chapter. Nonlinear transient gust analysis is compared to the response from Pratt's Method for those applications.

\subsection{Evaluation of Error in Pratt's Curve Fit Equation}

Pratt's curve fit equation

$$
K_{g}=\frac{0.88 \mu_{g}}{5.3+\mu_{g}}
$$

encapsulates the solution to the EOM for every mass ratio.

$$
\mu_{g}=\frac{2 W}{\rho g S \bar{c} C_{L_{\alpha}}}
$$


The curve fit error was quantified directly by solving for the precise knockdown factor $\left(K_{g}\right)$ from Pratt's EOM.

$$
\frac{d^{2} z}{d s^{2}}+\frac{1}{\mu_{g}} \int_{0}^{s} K_{W}\left(s-s^{\prime}\right) \frac{d^{2} z}{d s^{\prime 2}} d s^{\prime}=\frac{1}{\mu_{g}} \frac{\bar{c} U_{0}}{V} \int_{0}^{s} K_{G}\left(s-s^{\prime}\right) \frac{d}{d s^{\prime}}\left(\frac{U}{U_{0}}\right) d s^{\prime}
$$

The nondimensionalized acceleration $\left(\frac{d^{2} z}{d s^{2}}\right)$ was solved over a range of nondimensionalized time $(s=0-25)$. A Newton-Raphson solver was used to determine $\frac{d^{2} z}{d s^{2}}$ at every time step. The error tolerance was set to $10^{-12}$. The $s$ domain was discretized into 250 time steps. The maximum $\frac{d^{2} z}{d s^{2}}$ in the response was used to determine the knockdown factor

$$
K_{g}=\left.\mu_{g} \frac{d^{2} z}{d s^{2}}\right|_{\max }
$$

as demonstrated in Equation 3.9. This process was executed for a range of mass parameters $\left(\mu_{g}=10^{-2}-10^{2}\right)$. Results are presented in the following chapter.

\subsection{Quasi-Static and Transient Gust Analysis}

The NATASHA aeroelastic code is capable of solving both steady state and transient cases for nonlinear applications. This capability allows NATASHA to be used for both the quasistatic and transient gust analysis. NATASHA's formulation is reviewed in this chapter. The modifications to the transient gust calculations are explained. 


\subsubsection{Structural Model}

Hodges' [19] geometrically exact equations for the dynamics of a general, non-uniform, twisted, curved, anisotropic beam are

$$
\begin{gathered}
F^{\prime}+(\widetilde{k}+\widetilde{\kappa}) F+f=\dot{P}+\widetilde{\Omega} P \\
M^{\prime}+(\widetilde{k}+\widetilde{\kappa}) M+\left(\widetilde{e_{1}}+\widetilde{\gamma}\right) F+m=\dot{H}+\widetilde{\Omega} H+\widetilde{V} P
\end{gathered}
$$

where () denotes the absolute time derivative and ()$^{\prime}$ denotes the derivative with respect to the undeformed beam reference line. $F(x, t)$ and $M(x, t)$ are the measure numbers of the internal force and moment vector, respectively, $P(x, t)$ and $H(x, t)$ are the measure numbers of the linear and angular momentum vector, respectively, and $V(x, t)$ and $\Omega(x, t)$ are the linear and angular velocity measures, respectively. All measure numbers are calculated in the deformed cross-sectional frame. $k$ is a vector of the initial beam twist and curvature, $e_{1}$ is a unit vector tangent to the beam in the beam frame, and $f(x, t)$ and $m(x, t)$ are the external forces and moments, respectively, including thrust $\left(f_{T}, m_{T}\right)$, aerodynamic loads $\left(f_{\text {aero }}, m_{\text {aero }}\right)$, and gravity $\left(f_{g}, m_{g}\right)$. The dynamic equations are augmented by Hodges [20] intrinsic kinematical equations.

$$
\begin{gathered}
V^{\prime}+(\widetilde{k}+\widetilde{\kappa}) V+\left(\widetilde{e_{1}}+\widetilde{\gamma}\right) \Omega=\dot{\gamma} \\
\Omega^{\prime}+(\widetilde{k}+\widetilde{\kappa}) \Omega=\dot{\kappa}
\end{gathered}
$$

where $\gamma(x, t)$ and $\kappa(x, t)$ are the beam strains and curvatures, respectively. 


\section{Cross-sectional constitutive laws}

The secondary beam variables are linearly related to the primary variables by the crosssectional constitutive laws

$$
\begin{gathered}
\left\{\begin{array}{l}
\gamma \\
\kappa
\end{array}\right\}=\left[\begin{array}{cc}
R & S \\
S^{T} & T
\end{array}\right]\left\{\begin{array}{l}
F \\
M
\end{array}\right\} \\
\left\{\begin{array}{l}
P \\
H
\end{array}\right\}=\left[\begin{array}{cc}
\mu \Delta & -\mu \widetilde{\xi} \\
\mu \widetilde{\xi} & I
\end{array}\right]\left\{\begin{array}{l}
V \\
\Omega
\end{array}\right\}
\end{gathered}
$$

Variables in the inertia matrix, $\mu, \xi, I$ are the mass per unit length, mass center offset, and mass moment of inertia per unit length, respectively. These relations are derived based on the assumptions of slenderness and small strain. The flexibility matrix is composed of $R, S$, and $T$, each $3 \times 3$ matrices of cross-sectional flexibility coefficients. These can be obtained from various means for generalized cases $[4,55]$. The matrices of cross-sectional flexibility coefficients for an isotropic material with the shear center and tension center at the beam reference axis, and the shear and bending principal axes coincident with the beam lateral and vertical axes are

$$
\begin{aligned}
& R=\left[\begin{array}{ccc}
\frac{1}{E A} & 0 & 0 \\
0 & \frac{1}{k_{2} G A} & 0 \\
0 & 0 & \frac{1}{k_{3} G A}
\end{array}\right] \\
& S=[0] \\
& T=\left[\begin{array}{ccc}
\frac{1}{G J} & 0 & 0 \\
0 & \frac{1}{E I_{2}} & 0 \\
0 & 0 & \frac{1}{E I_{3}}
\end{array}\right]
\end{aligned}
$$




\section{Finite element discretization}

Finite element discretization is used to solve the structural equations. An energy conservation approach is used [20]. Consider an example variable $X$. Let the nodal values of the variable after discretization be $\widehat{X}_{l}^{n}$ and $\widehat{X}_{r}^{n}$, where the superscript denotes the node number, the subscript denotes the left or right side of the node, and the hat denotes that it is nodal value. For the element $n$

$$
\begin{gathered}
X^{\prime}=\frac{\widehat{X}_{l}^{n+1}-\widehat{X}_{r}^{n}}{d l} \\
X=\bar{X}^{n}=\frac{\widehat{X}_{l}^{n+1}+\widehat{X}_{r}^{n}}{2}
\end{gathered}
$$

where barred quantities correspond to values of $X$ in the element interior, while the hatted quantities are nodal values of $X$. In a discretized form the equations of motion can be written as

$$
\begin{gathered}
\frac{\widehat{F}_{l}^{n+1}-\widehat{F}_{r}^{n}}{d l}+\left(\widetilde{\bar{\kappa}^{n}}+\widetilde{k^{n}}\right) \bar{F}^{n}+\bar{f}^{n}-\dot{\bar{P}}^{n}-\widetilde{\bar{\Omega}}^{n} \bar{P}^{n}=0 \\
\frac{\widehat{M}_{l}^{n+1}-\widehat{M}_{r}^{n}}{d l}+\left(\widetilde{\bar{\kappa}^{n}}+\widetilde{k^{n}}\right) \bar{M}^{n}+\left(\widetilde{e_{1}}+\widetilde{\bar{\gamma}^{n}}\right) \bar{F}^{n}+\bar{m}^{n}-\dot{\bar{H}}^{n}-\widetilde{\bar{\Omega}}^{n} \bar{H}^{n}-\widetilde{\bar{V}}^{n} \bar{P}^{n}=0 \\
\frac{\widehat{V}_{l}^{n+1}-\widehat{V}_{r}^{n}}{d l}+\left(\widetilde{\bar{\kappa}^{n}}+\widetilde{k^{n}}\right) \bar{V}^{n}+\left(\widetilde{e_{1}}+\widetilde{\bar{\gamma}}^{n}\right) \bar{\Omega}^{n}-\dot{\bar{\gamma}}^{n}=0 \\
\frac{\widehat{\Omega}_{l}^{n+1}-\widehat{\Omega}_{r}^{n}}{d l}+\left(\widetilde{\bar{\kappa}^{n}}+\widetilde{k^{n}}\right) \bar{\Omega}^{n}-\dot{\bar{\kappa}}^{n}=0
\end{gathered}
$$

The barred and hatted quantities of the primary variables are related through Equations 3.21 and 3.22 while the barred secondary variables are related to the barred primary variables through the defined cross-sectional constitutive laws. 


\section{Gravity loads}

Gravitational forces are applied through the force term in the equations of motion. The gravitational force and moment are

$$
\begin{aligned}
f_{g} & =\mu g \\
m_{g} & =\mu \widetilde{\xi} g
\end{aligned}
$$

where $g$ is the gravity vector.

The measure numbers of $g$ are known in the inertial frame, but unknown in the deformed beam frame. They can be calculated using

$$
\begin{aligned}
g^{\prime}+(\widetilde{\kappa}+\widetilde{k}) g & =0 \\
\dot{g}+\widetilde{\Omega} g & =0
\end{aligned}
$$

which is discretized as

$$
\begin{array}{r}
\frac{\widehat{g}_{l}^{n+1}-\widehat{g}_{r}^{n}}{d l}+\left(\widetilde{\bar{\kappa}^{n}}+\widetilde{k^{n}}\right) \bar{g}^{n}=0 \\
\dot{\widehat{g}}+\widetilde{\widehat{\Omega}} \widehat{g}=0
\end{array}
$$

Equation (3.32) is satisfied at one node, while Equation (3.31) is used to obtain the $g$ vector at other nodes. They are matrix equations made up of three scalar equations. In both cases, the three combined scalar equations must satisfy a constraint of constant length for the $g$ vector. Thus, any one of the three dynamic equations can be replaced by the static form of this length constraint. This removes the artificial eigenvalue caused by a constraint differentiation. The constraint is also satisfied when the dynamic terms are neglected for the 
steady-state calculation. So, Equation 3.32 is written as

$$
\left(e_{1} e_{1}^{T}+e_{2} e_{2}^{T}\right) \dot{\hat{g}}^{n_{g}}+\left(e_{1} e_{1}^{T}+e_{2} e_{2}^{T}\right) \widetilde{\widehat{\Omega}^{n_{g}}} \widehat{g}^{n_{g}}+\left(e_{3} e_{3}^{T}\right)\left|\widehat{g}^{n_{g}}\right|=e_{3}
$$

\subsubsection{Aerodynamic Model}

The airloads are calculated based on 2-D aerodynamics using known airfoil parameters. Aerodynamic forces from the flight dynamic velocities are calculated separately from the gust airloads. Modifications to the gust airloads calculations are explained.

\section{Flight dynamic airloads}

Velocities at the mid-chord in the aerodynamic frame are

$$
\begin{gathered}
\bar{V}_{a}^{n}=C_{a}^{n^{T}} \bar{V}^{n}-\widetilde{y}_{\mathrm{mc}}^{n} C_{a}^{n^{T}} \bar{\Omega}^{n} \\
\bar{\Omega}_{a}^{n}=C_{a}^{n^{T}} \bar{\Omega}^{n}
\end{gathered}
$$

where $C_{a}^{n}$ transforms a vector from the aerodynamic frame to the undeformed beam frame and $y_{\mathrm{mc}}^{n}$ is the vector from the beam reference axis to the mid-chord.

The aerodynamic model is unsteady with wake (inflow) effects and apparent mass effects. Here the Peters 2-D theory [37] is used to calculate an inflow $\left(\lambda_{0}\right)$. The force and moment 
expressions are

$$
f_{a}^{n}=\rho b^{n}\left\{\begin{array}{c}
0 \\
-\left(C_{l_{0}}^{n}+C_{l_{\beta}}^{n} \beta^{n}\right) V_{T}^{n} V_{a_{3}}^{n}+C_{l_{\alpha}}^{n}\left(V_{a_{3}}^{n}+\lambda_{0}^{n}\right)^{2}-C_{d_{0}}^{n} V_{T}^{n} V_{a_{2}}^{n} \\
\left(C_{l_{0}}^{n}+C_{l_{\beta}}^{n} \beta^{n}\right) V_{T}^{n} V_{a_{2}}^{n}-C_{l_{\alpha}}^{n} \dot{V}_{a_{3}}^{n} b / 2-C_{l_{\alpha}}^{n} V_{a_{2}}^{n}\left(V_{a_{3}}^{n}+\lambda_{0}^{n}-\Omega_{a_{1}}^{n} b^{n} / 2\right)-C_{d_{0}}^{n} V_{T}^{n} V_{a_{3}}^{n}
\end{array}\right\}
$$

and

$m_{a}^{n}=2 \rho b^{n^{2}}\left\{\begin{array}{c}\left(C_{m_{0}}^{n}+C_{m_{\beta}}^{n} \beta^{n}\right) V_{T}^{n^{2}}-C_{m_{\alpha}}^{n} V_{T}^{n} V_{a_{3}}^{n}-b^{n} C_{l_{\alpha}}^{n} / 8 V_{a_{2}}^{n} \Omega_{a_{1}}^{n}-b^{n^{2}} C_{l_{\alpha}}^{n} \dot{\Omega}_{a_{1}}^{n} / 32+b^{n} C_{l_{\alpha}}^{n} \dot{V}_{a_{3}}^{n} / 8 \\ 0 \\ 0\end{array}\right\}$

where

$$
V_{T}^{n}=\sqrt{V_{a_{2}}^{n^{2}}+V_{a_{3}}^{n^{2}}}
$$

subscripts of $V_{a_{2}}^{n}$ and $V_{a_{3}}^{n}$ are the measure numbers of $\bar{V}_{a}^{n} . \beta^{n}$ is the flap deflection of the $\mathrm{n}^{\text {th }}$ element.

The inflow model is written as

$$
\left[A_{\text {inflow }}\right]\left\{\dot{\lambda^{n}}\right\}+\left(\frac{V_{T}^{n}}{b^{n}}\right)\left\{\lambda^{n}\right\}=\left(-\dot{V}_{a_{3}}^{n}+\frac{b^{n}}{2} \dot{\Omega}_{a_{1}}^{n}\right)\left\{c_{\text {inflow }}\right\}
$$

and

$$
\lambda_{0}^{n}=\frac{1}{2}\left\{b_{\text {inflow }}\right\}^{T}\left\{\lambda^{n}\right\}
$$


where $\left[A_{\text {inflow }}\right],\left\{c_{\text {inflow }}\right\},\left\{b_{\text {inflow }}\right\}$ are constant matrices derived in Ref. [37], and $\lambda^{n}$ is a vector of inflow states for the $n^{\text {th }}$ element,

Finally, the derived aerodynamic forces from the flight dynamics are transformed to the deformed beam frame and transferred to the beam reference axis.

$$
\begin{gathered}
\bar{f}_{\text {aero }}^{n}=C_{a}^{n} f_{a}^{n} \\
\bar{m}_{\text {aero }}^{n}=C_{a}^{n} m_{a}^{n}+C_{a}^{n} \widetilde{y}_{\text {ac }}^{n} f_{a}^{n}
\end{gathered}
$$

\section{Real-time position integration}

NATASHA does not require explicit nodal positions to solve the aeroelastic equations. The gust profile in the original NATASHA required the gust profile to be input as function of time. Because positions were not needed for the analysis, they were not integrated in real time.

Real-time nodal position was required so that NATASHA could be modified to use a more natural spatial gust definition. The steady state analysis provides the initial nodal positions at trim. The positions are integrated using a center finite difference scheme.

$$
\widehat{\chi}^{t+\delta t}=\widehat{\chi}^{t}+\frac{\delta t}{2}\left(C^{i B^{t+\delta t}} \widehat{V}^{t+\delta t}+C^{i B^{t}} \widehat{V}^{t}\right)
$$

where $\hat{\chi}^{t}$ is the nodal position vector at time $t, C^{i B^{t}}$ transforms a vector from the deformed beam frame to the inertial frame at time $t$, and $\delta t$ is the time step. 


\section{Spatial gust field definition}

The gust field is defined as

$$
w_{g}^{n}=\left\{\begin{array}{l|c}
0 & \widehat{\chi}_{2}^{n} \leq s_{\text {initial }} \\
\frac{1}{2} U_{0}\left(1-\cos \left(\frac{2 \pi\left(\widehat{\chi}_{2}^{n}-s_{\text {initial }}\right)}{T}\right)\right) & s_{\text {initial }} \geq \widehat{\chi}_{2}^{n} \leq s_{\text {initial }}+T \\
0 & \widehat{\chi}_{2}^{n}>s_{\text {initial }}+T
\end{array}\right.
$$

where $T$ is the gust period or length and $U_{0}$ is the gust intensity. A delay space $\left(s_{\text {initial }}\right)$ provides a section of calm air so that steady state conditions are verified prior to gust entry. The gust velocity is determined as function of the nodal position vector $\hat{\chi}$. A spanwise varying (i.e., a function of $\chi_{1}$ as well as $\chi_{2}$ ) gust could be implemented just as easily with the already completed modifications.

\section{Gust airloads}

This analysis needs an unsteady gust airloads model that captures chordwise variation of the gust field while considering the deformed state of the vehicle. An interpretation of the Peters [36] airloads model is presented that accounts for these effects. Consider the airfoil section in Figure 3.2. The total induced flow $\left(w^{B}\right)$ is simply the vertical gust velocity in the deformed beam frame (indicated by the superscript $B$ ). A velocity normalized lift coefficient, $\bar{L}$, is provided by Peters

$$
\bar{L}=w_{0}+\frac{1}{2} w_{1}+\frac{1}{2}\left(\dot{w}_{0}+\frac{1}{2} \dot{w}_{1}\right) \frac{b}{V_{T}}
$$

where $w_{n}$ is the coefficient of the $n^{\text {th }}$ Chebychev polynomial mode shape when $w^{B}$ is approximated as

$$
w^{B}=\sum_{0}^{N} w_{n} T_{n}
$$




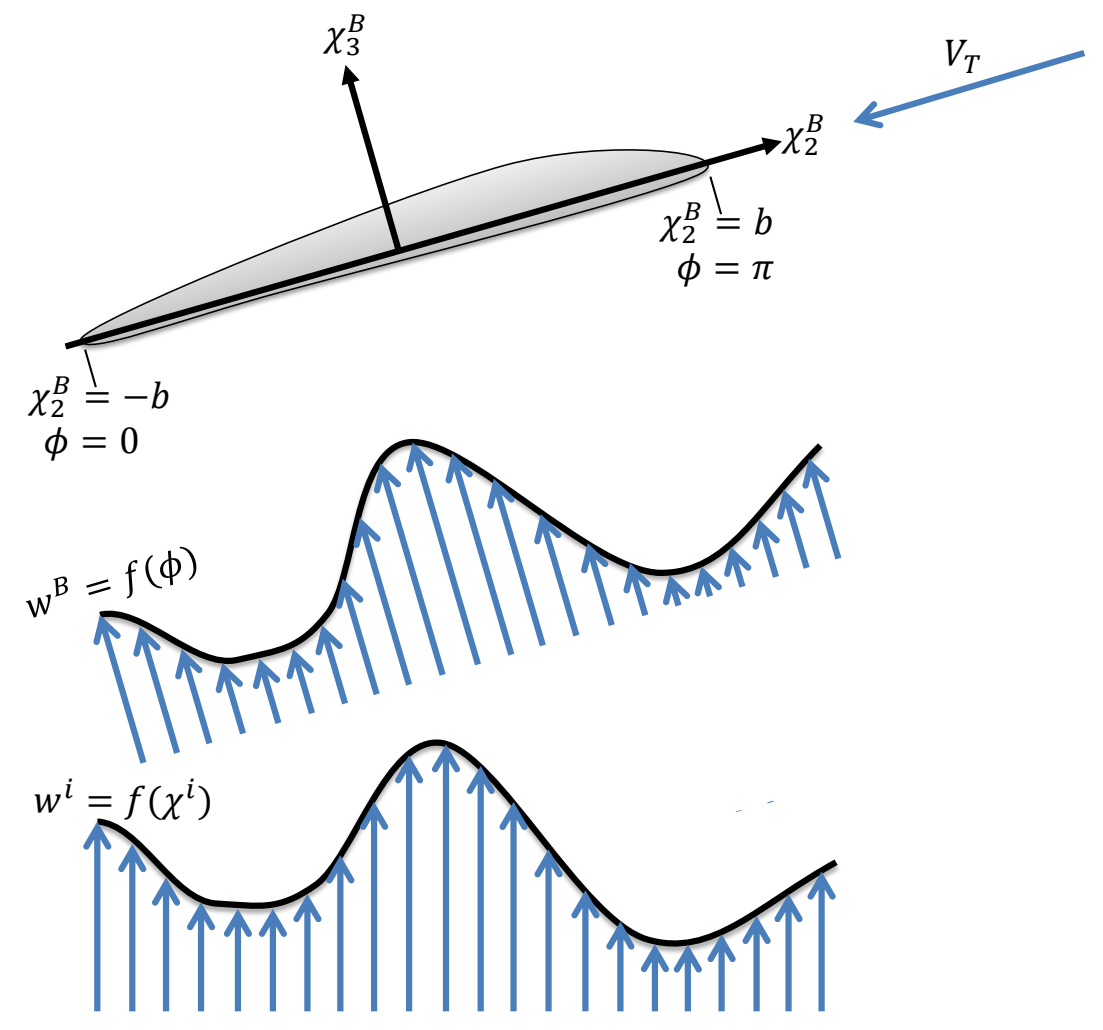

Figure 3.2: Chordwise gust integration method. Superscript $i$ and $B$ indicate the quantities are calculated in the inertial or deformed beam reference frames, respectively.

The Chebychev polynomials are

$$
T_{n}=\cos (n \phi)
$$

where $\phi$ is from the Glauert transformation of $\chi_{2}^{B}$

$$
\phi=\arccos \left(\frac{\chi_{2}^{B}}{b}\right)
$$

The Chebychev polynomial coefficients are determined using

$$
w_{n}=\frac{\int_{0}^{\pi} w^{B} T_{n} d \phi}{\int_{0}^{\pi} T_{n}^{2} d \phi}
$$


Finally, the gust force is calculated using

$$
f_{\text {aerog }}=\left[\begin{array}{c}
0 \\
-\rho b C_{\ell_{\alpha}}\left(V_{3}+w_{0}\right) \bar{L} \\
\rho b C_{\ell_{\alpha}} V_{2} \bar{L}
\end{array}\right]
$$

and the gust contribution to the inflow is

$$
\lambda_{0_{w}}=\dot{w}_{0}+\frac{1}{2} \dot{w}_{1}
$$

The gust inflow $\left(\lambda_{0_{w}}\right)$ is added to the inflow from Equation 3.40 for the total inflow. The gust force $\left(f_{\text {aerog }}\right)$ is added to the gust force from Equation 3.36. There will be errors for large gust inputs and responses because the force and inflow above are combined linearly with the force and inflow from the flight dynamic airloads.

Prior to the modifications, the gust airloads were calculated assuming small structural and flight dynamic deviation from steady state conditions. These assumptions are eliminated with the modified formulation.

\section{Rotation of flight dynamic force vector}

Addition of the gust velocity $\left(V_{g}^{n}\right)$ changes the direction of the total aerodynamic velocity $\left(V_{t o t}^{n}\right)$. The aerodynamic lift and drag forces should act perpendicular and parallel respectively to $V_{t o t}^{n}$, but the lift and drag calculated from the flight dynamic velocity $\left(V_{a}^{n}\right)$ are not. Figure 3.3 illustrates the velocity orientations. The previously calculated flight dynamic airload vector $\left(\bar{f}_{\text {aero }}^{n}\right)$ should be rotated about beam axis by the gust angle $\alpha_{g}^{n}$. First $V_{\text {tot }}^{n}$ is calculated

$$
V_{t o t}^{n}=V_{a}^{n}+V_{g}^{n}
$$




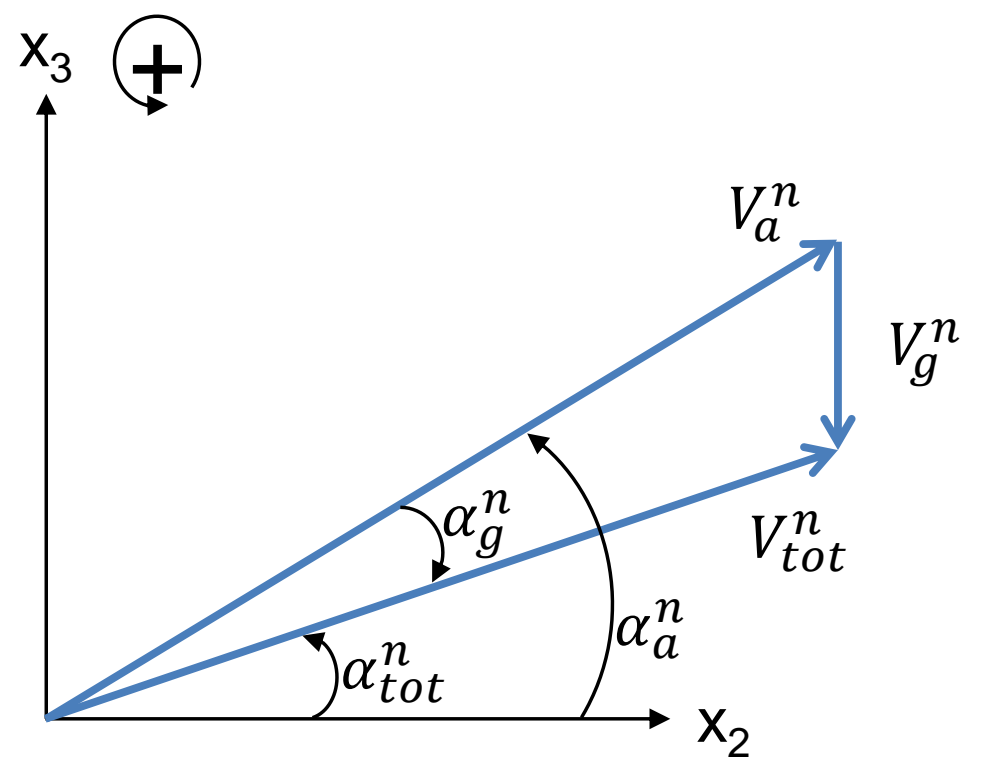

Figure 3.3: Aerodynamic velocities at node $n$ in the beam frame.

The corresponding angles are calculated using basic trigonometry.

$$
\begin{gathered}
\alpha_{a}^{n}=\arctan \left(\frac{V_{a_{3}}^{n}}{V_{a_{2}}^{n}}\right) \\
\alpha_{t o t}^{n}=\arctan \left(\frac{V_{t o t_{3}}^{n}}{V_{t o t_{2}}^{n}}\right) \\
\alpha_{g}^{n}=\alpha_{t o t}^{n}-\alpha_{a}^{n}
\end{gathered}
$$

With $\alpha_{g}^{n}, \bar{f}_{\text {aero }}^{n}$ is rotated about the beam axis with the $C_{g}^{n}$ rotation matrix.

$$
C_{g}^{n}=\left[\begin{array}{ccc}
1 & 0 & 0 \\
0 & \cos \alpha_{g}^{n} & -\sin \alpha_{g}^{n} \\
0 & \sin \alpha_{g}^{n} & \cos \alpha_{g}^{n}
\end{array}\right]
$$


The correctly oriented aerodynamic force from the flight dynamic velocity is

$$
\bar{f}_{\text {aerofd }}^{n}=C_{g}^{n} \bar{f}_{\text {aero }}^{n}
$$

\subsubsection{Aeroelastic System}

NATASHA's aeroelastic system is formed by coupling the aerodynamic equations from the previous section with the structural equations presented earlier. The aeroelastic equations are nonlinear in terms of the primary structural variables $\left(F_{l}^{n}, F_{r}^{n}, M_{l}^{n}, M_{r}^{n}, V_{r}^{n}, \Omega_{r}^{n}\right.$ and $\left.g_{r}^{n}\right)$ and aerodynamic variables $\left(\lambda^{n}\right)$.

The system is in the form

$$
[A]\{\dot{x}\}+\{\mathcal{B}(x)\}=\left\{f_{\text {cont }}\right\}+\left\{f_{\text {gust }}\right\}
$$

where $\{x\}$ is a vector of all the aeroelastic variables, $\left\{f_{\text {cont }}\right\}$ is the vector of the flight controls and $\left\{f_{\text {gust }}\right\}$ is a vector of gust loads.

The steady-state trim solution is solved using Newton-Raphson method with a trim algorithm to calculate the control settings for a given flight condition. The linearized system can be represented as

$$
[A]\{\dot{\hat{x}}\}+[B]\{\hat{x}\}=\left\{\hat{f}_{\text {cont }}\right\}+\left\{f_{\text {gust }}\right\}
$$

where, () refers to the perturbation about the steady-state values. The eigenvalues of the linearized system could be calculated to estimate the stability of the aircraft at the trim to small perturbation. 


\subsubsection{Transient Gust Response}

The transient gust response is calculated by solving the dynamic aeroelastic equations in time. The time marching algorithm uses a central difference scheme with high frequency damping. For the linearized system

$$
\frac{1}{\delta t}[A]\left(\left\{\hat{x}^{t+\delta t}\right\}-\left\{\hat{x}^{t}\right\}\right)+\frac{1}{2}[B]\left((1+c)\left\{\hat{x}^{t+\delta t}\right\}+(1-c)\left\{\hat{x}^{t}\right\}\right)=\left\{\hat{f}_{\text {cont } t}\right\}+\left\{f_{\text {gust }}\right\}
$$

where $\delta t$ is the time step and $c$ is the high frequency damping parameter. Table 3.1 highlights the range of tuning options .

Table 3.1: Tuning with high frequency damping parameter

\begin{tabular}{rllc}
\hline \hline $\mathrm{c}$ & Scheme & Accuracy & Damping \\
\hline 0 & Central Diff. & $2^{\text {nd }}$ Order & 0 \\
+1 & Backward Diff. & $1^{\text {st }}$ Order & + \\
-1 & Forward Diff. & $1^{\text {st }}$ Order & - \\
\hline \hline
\end{tabular}

Because the equations are very stiff (due to a number of infinite frequency or constraint equations), some high frequency damping is required. Using $c \approx 0.01$ gives a good time marching algorithm with close to second-order accuracy and sufficient high-frequency damping.

\subsection{Gust Response Analysis Verification}

The wing shown in Figure 3.4 is designed to match the assumptions used to derive Pratt's EOM (outlined is Section 3.1.1).

$$
\frac{d^{2} z}{d s^{2}}+\frac{1}{\mu_{g}} \int_{0}^{s} K_{W}\left(s-s^{\prime}\right) \frac{d^{2} z}{d s^{\prime 2}} d s^{\prime}=\frac{1}{\mu_{g}} \frac{\bar{c} U_{0}}{V} \int_{0}^{s} K_{G}\left(s-s^{\prime}\right) \frac{d}{d s^{\prime}}\left(\frac{U}{U_{0}}\right) d s^{\prime}
$$


Thus, for this model, the transient response from the modified version of NATASHA should match the transient response from solving Equation 3.6. The wing will not pitch because a

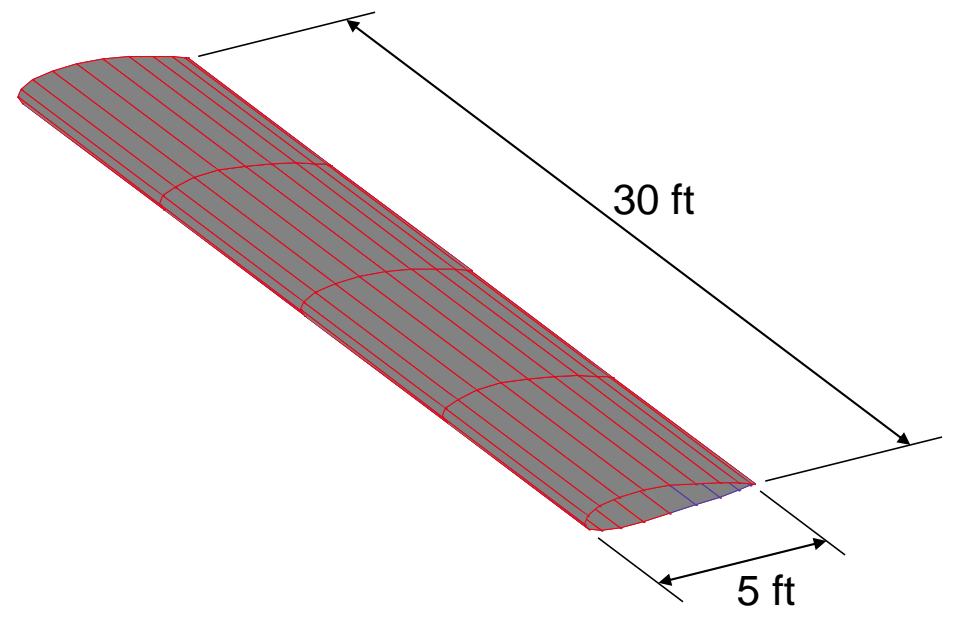

Figure 3.4: Rigid wing with large pitch inertia used for verification.

large inertia is specified. The cross-sectional properties for the verification model are given in Table 3.2. Four validation cases are presented here. The first example uses a high frequency

Table 3.2: Cross-sectional properties for verification wing

\begin{tabular}{|r|l|}
\hline \hline Elastic (reference) axis & $25 \%$ chord \\
Mass per unit length & $133.33 \mathrm{lbs} / \mathrm{ft}$ \\
Center of gravity & $25 \%$ chord \\
Centroidal Mass Moment of Inertia & $1 \mathrm{E} 7 \mathrm{lb} \mathrm{ft}$ (Huge) \\
Aerodynamics Coefficients (25\% chord): & \\
$C_{l_{\alpha}}$ & $2 \pi$ \\
$C_{l_{\delta}}$ & 1 \\
$C_{d_{0}}$ & 0.01 \\
$C_{m_{0}}$ & 0.025 \\
$C_{m_{\delta}}$ & -0.25 \\
\hline \hline
\end{tabular}

gust input. The second two examples use gust inputs at Pratt's specified 25 chord gust length; a small and a large gust intensity are shown. The final case uses a long gust length input. Figures 3.5-3.8 show that the responses from the modified version of NATASHA match the corresponding solutions of Pratt's EOM. 


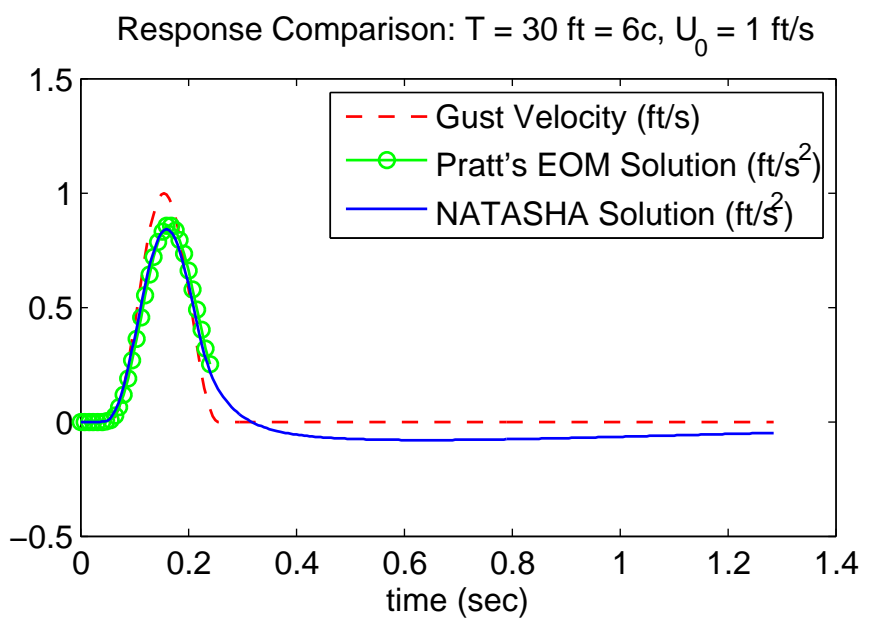

Figure 3.5: Solutions from NATASHA and from Pratt's EOM for a high frequency gust input.

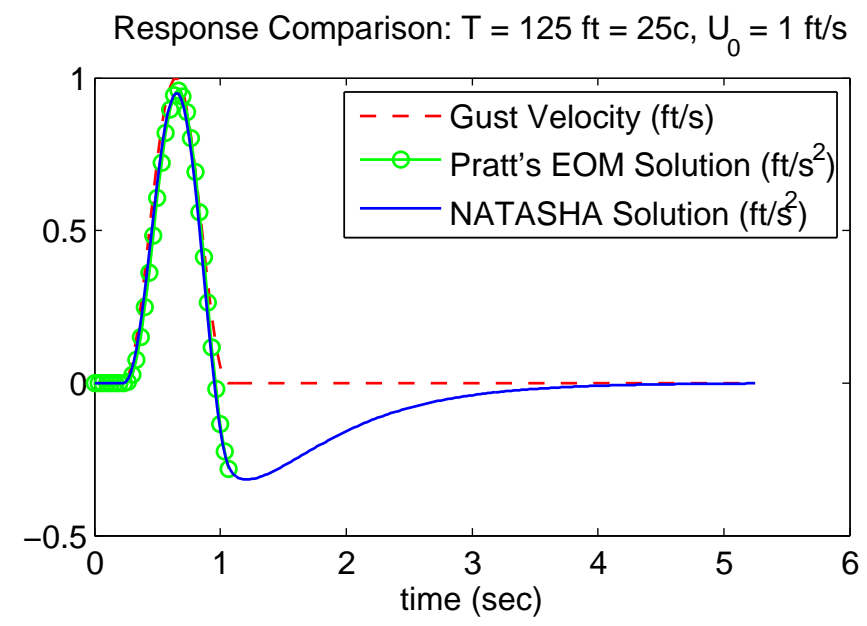

Figure 3.6: Solutions from NATASHA and from Pratt's EOM for a lower intensity gust input at Pratt's specified 25 chord gust length. 


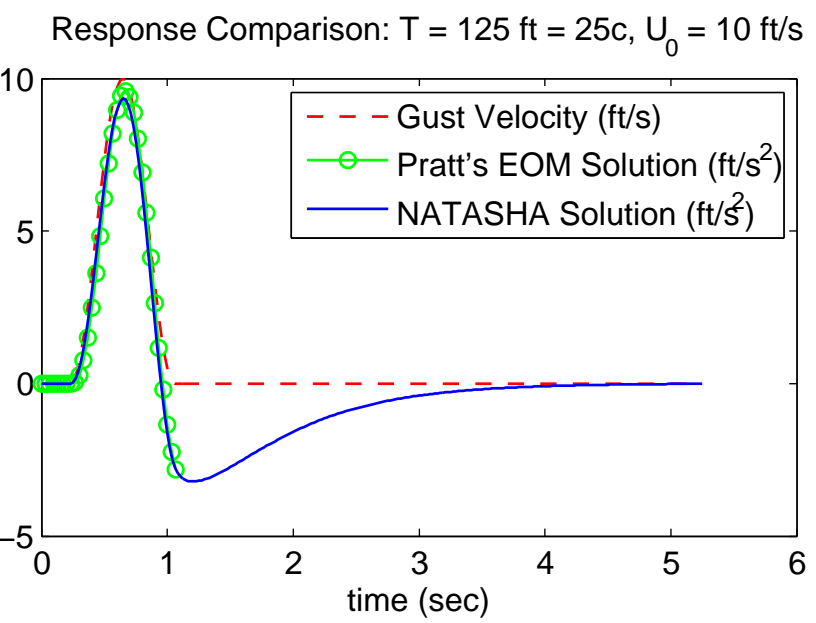

Figure 3.7: Solutions from NATASHA and from Pratt's EOM for a higher intensity gust input at Pratt's specified 25 chord gust length.

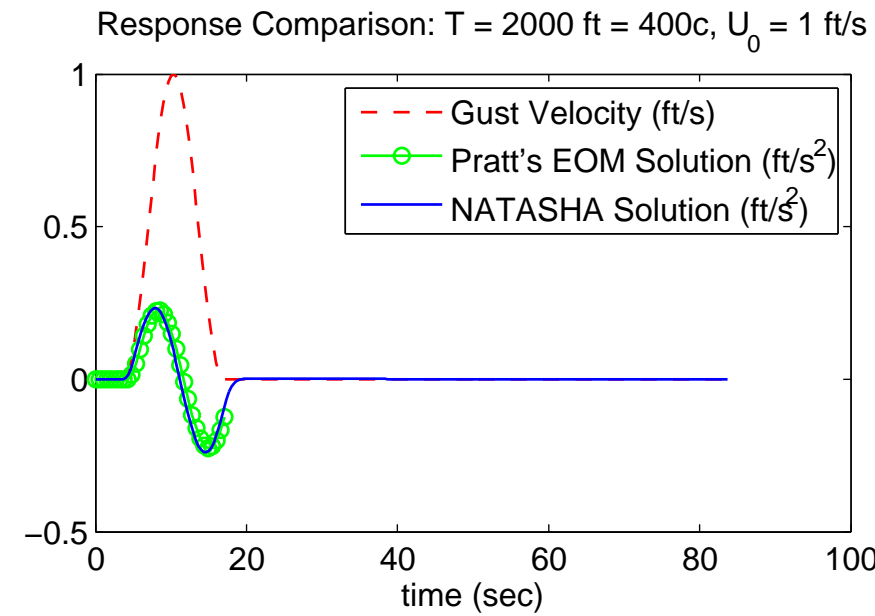

Figure 3.8: Solutions from NATASHA and from Pratt's EOM for a low frequency gust input. 


\subsection{HALE Applications}

Specific applications are required for evaluation of Pratt's method beyond curve fit error. Models representing two categories of HALE aircraft were studied. A flying wing HALE model developed by Patil and Hodges [33], and a newly developed joined-wing HALE model. Properties and specifications are provided in this section.

\subsubsection{Patil/Hodges Flying Wing HALE Model}

This flying wing HALE model was developed by Patil and Hodges [33]. Their work was similarly motivated by the Helios prototype mishap and recommendations. The model has aeroelastic characteristics similar to the Helios HP03 [30].

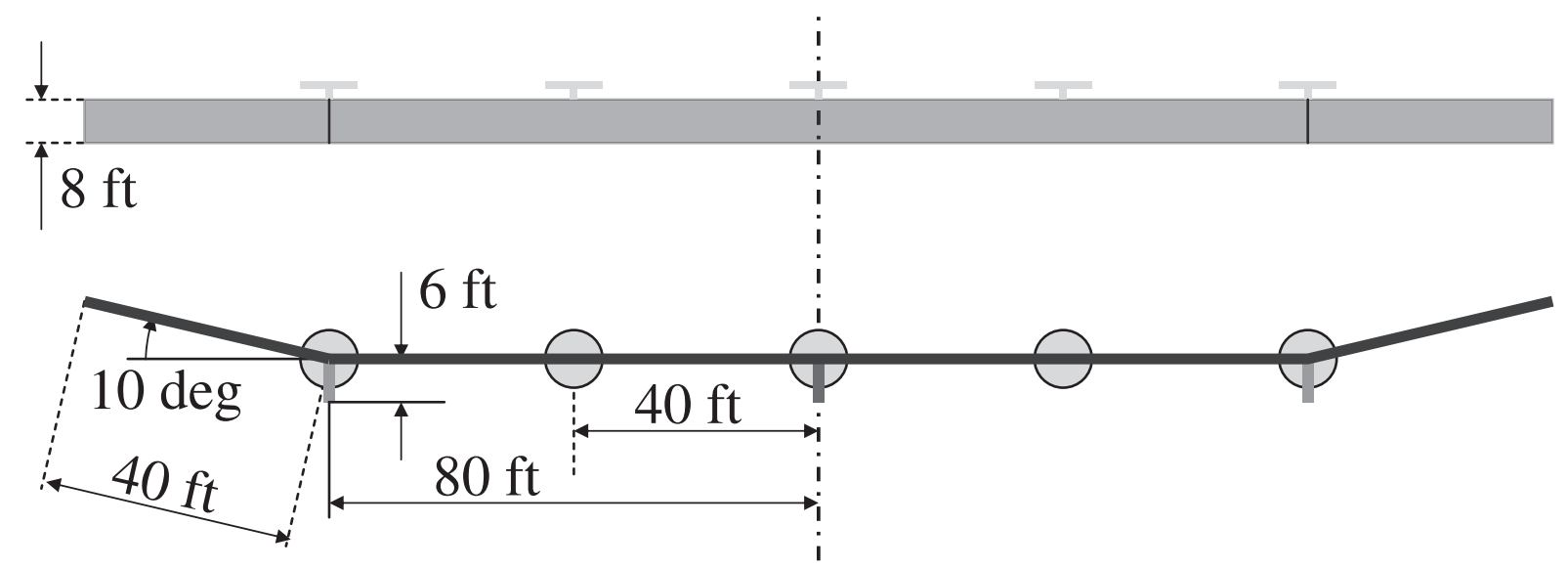

Figure 3.9: Geometry of the Patil/Hodges flying wing HALE model [33]. 
Table 3.3: Wing cross-sectional properties

\begin{tabular}{|r|l|}
\hline \hline Elastic (reference) axis & $25 \%$ chord \\
Torsional rigidity & $0.4 \times 10^{6} \mathrm{lb} \mathrm{ft}^{2}$ \\
Bending rigidity & $2.5 \times 10^{6} \mathrm{lb} \mathrm{ft}^{2}$ \\
Bending rigidity (chordwise) & $30 \times 10^{6} \mathrm{lb} \mathrm{ft}^{2}$ \\
Mass per unit length & $6 \mathrm{lbs} / \mathrm{ft}^{2}$ \\
Center of gravity & $25 \% \mathrm{chord}$ \\
Centroidal Mass Moment of Inertia & $30 \mathrm{lb} \mathrm{ft}$ \\
Aerodynamics Coefficients (25\% chord): & \\
$C_{l_{\alpha}}$ & $2 \pi$ \\
$C_{l_{\delta}}$ & 1 \\
$C_{d_{0}}$ & 0.01 \\
$C_{m_{0}}$ & 0.025 \\
$C_{m_{\delta}}$ & -0.25 \\
\hline \hline
\end{tabular}

The geometry is illustrated in Figure 3.9. The aircraft has a span of $238.78 \mathrm{ft}$, a constant chord of $8 \mathrm{ft}$, and $1 / 6^{\text {th }}$ of the span at each end has a dihedral of $10^{\circ}$. The inertial, elastic, and aerodynamic properties of the wing cross section are given in Table 3.3.

There are five propulsive units: one at the mid-span and two each at $1 / 3^{r d}$ and $2 / 3^{r d}$ semi-span distance from the mid-span. There are three vertical surfaces (pods) which act as the landing gear. Two of the pods weigh $50 \mathrm{lb}$ each and are located at $2 / 3^{\text {rd }}$ semi-span distance from the mid-span. The central pod also acts as a bay for payload and weighs $250 \mathrm{lb}$. The pod/payload weight is assumed to a be a point mass hanging $3 \mathrm{ft}$ under the wing. The aerodynamic coefficients for the pods are $C_{l_{\alpha}}=5$ and $C_{d_{0}}=0.02$. The wing is discretized using 30 finite elements of equal lengths. It is assumed that the gust loads act only on the wing. The aircraft is trimmed at $40 \mathrm{ft} / \mathrm{s}$ at sea level for the cases considered. 


\subsubsection{Joined-Wing Model}

The joined-wing model is illustrated in Figure 3.10. The overall span is $150 \mathrm{ft}$. The aircraft is configured with a tailboom and aft wing rather than a conventional empennage. The chord and twist vary linearly between wing stations. The forward wing has a dihedral of $7^{\circ}$, and the leading edge is swept $36^{\circ}$. The aft wing has a $11.76^{\circ}$ anhedral and is is swept forward $38.68^{\circ}$. Pitch trim control is provided by control surfaces that span the aft wing (Section E-F). The aircraft would have embedded turbofan engines; thrust acts through the reference node in the body fixed $y$ direction. The inertial, elastic, and aerodynamic properties of the model

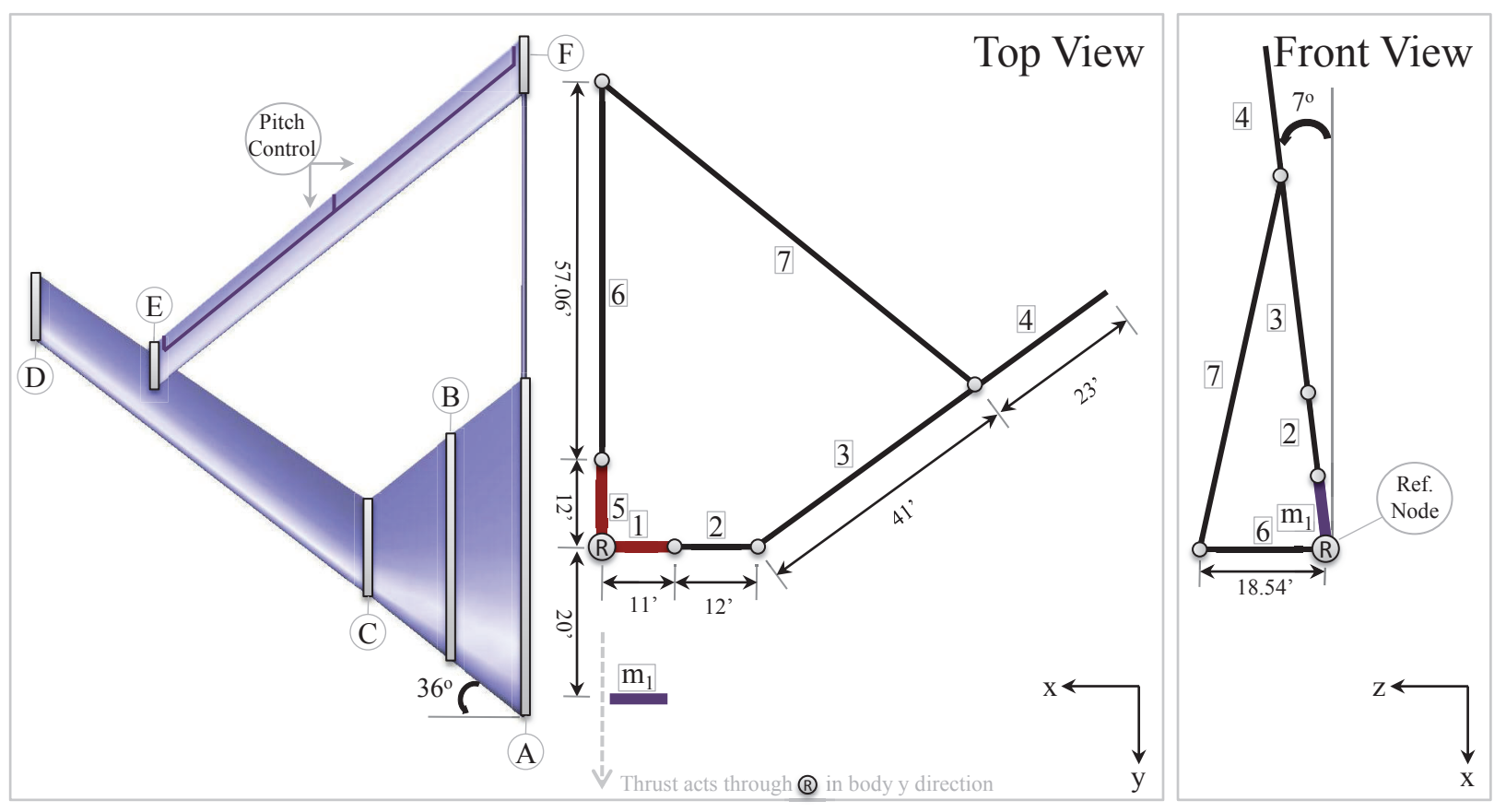

Figure 3.10: Joined-wing planform and skeleton.

are given in Tables 3.4 and 3.5. The mass and inertias are parameterized by fuel fraction $(f)$. They are distributed directly on the beam sections in Figure 3.10 (except for beam 1, it's mass is distributed on $\mathrm{m}_{1}$ ). The beam cross-sections (and cross-sectional properties) are twisted with the aerodynamic sections. The $y$-axis of the cross-section is aligned with the 
Table 3.4: Model properties. Here $f$ is fuel fraction. Exception: [1] Mass located at $\mathrm{m}_{1}$.

\begin{tabular}{|cccccc|ccc|}
\hline \hline $\begin{array}{c}\text { Beam } \\
\text { Section }\end{array}$ & $E I_{1}$ & $E I_{2}$ & $G J$ & Mass & $I_{x}$ & $\begin{array}{c}\text { Wing } \\
\text { Station }\end{array}$ & $\begin{array}{c}\text { Incidence } \\
\text { Angle }\end{array}$ & $\begin{array}{c}\text { Chord } \\
\text { Length }\end{array}$ \\
\hline- & $\mathrm{lb} \mathrm{ft}^{2}$ & $\mathrm{lb} \mathrm{ft}^{2}$ & $\mathrm{lb} \mathrm{ft}^{2}$ & slugs/ft & $\mathrm{lb} \mathrm{ft}$ & - & $\mathrm{deg}$ & $\mathrm{ft}$ \\
\hline 1 & $\infty$ & $\infty$ & $\infty$ & $(25+25 f)^{[1]}$ & $900(1+f)$ & $\mathrm{A}$ & 0 & 50 \\
2 & $8.5 \mathrm{E} 8$ & $1.5 \mathrm{E} 10$ & $1.8 \mathrm{E} 8$ & $6.0+23 f$ & $13+50 f$ & $\mathrm{~B}$ & 2 & 33 \\
3 & $1.1 \mathrm{E} 8$ & $3.7 \mathrm{E} 9$ & $3.2 \mathrm{E} 7$ & $1.8+6.0 f$ & $3+9 f$ & $\mathrm{C}$ & 4 & 14 \\
4 & $2.2 \mathrm{E} 7$ & $3.7 \mathrm{E} 8$ & $1.7 \mathrm{E} 7$ & $1.0+3.5 f$ & $1.1+4 f$ & $\mathrm{D}$ & -3 & 9.6 \\
5 & $\infty$ & $\infty$ & $\infty$ & $23+25 f$ & $41+43 f$ & $\mathrm{E}$ & 1 & 6.9 \\
6 & $2.2 \mathrm{E} 8$ & $6.7 \mathrm{E} 8$ & $7.8 \mathrm{E} 7$ & $0.25+2.0 f$ & $1.2+15 f$ & $\mathrm{~F}$ & 5 & 8.6 \\
7 & $1.5 \mathrm{E} 8$ & $1.4 \mathrm{E} 9$ & $8.0 \mathrm{E} 6$ & $1.2+1.6 f$ & $2+2.5 f$ & & & \\
\hline \hline
\end{tabular}

Table 3.5: Aerodynamic coefficients. Values are in the beam reference frame. Exceptions: [2] $C_{l_{0}}=0$ on Section A-B and tailboom. [3] $C_{m_{\alpha}}=0$ on Section A-B and Section E-F. [4] $y_{\mathrm{ac}}=c / 2$ on Section A-B. [5] $y_{\text {Elast.Ax. }}=c / 4$ on Section E-F.

\begin{tabular}{|cccccccc|cc|}
\hline \hline$C_{l_{0}}^{[2]}$ & $C_{l_{\alpha}}$ & $C_{l_{\delta}}$ & $C_{d_{0}}$ & $C_{d_{\alpha^{2}}}$ & $C_{m_{0}}$ & $C_{m_{\alpha}}^{[3]}$ & $C_{m_{\delta}}$ & $y_{\mathrm{ac}}^{[4]}$ & $y_{\text {Elast.Ax. }}^{[5]}$ \\
\hline 0.4 & $2 \pi$ & 1 & 0.03 & 3 & 0.025 & $\pi / 2$ & -0.25 & $\mathrm{c} / 4$ & $\mathrm{c} / 2$ \\
\hline \hline
\end{tabular}

chord. The position of the beams relative to the chord is given by $y_{\text {Elast.Ax }}$ in Table 3.5. The aerodynamic center is at the quarter chord for all the sections except for section A-B where it is at $50 \%$ chord.

Only symmetric conditions were considered, so a symmetric finite element model was used. The number of evenly spaced elements on each beam section is shown in Table 3.6.

Table 3.6: Joined-wing discretization. Rigid sections may have more than one element because the mesh is shared with aerodynamics.

\begin{tabular}{c|ccccccc|}
\hline \hline Beam Section & 1 & 2 & 3 & 4 & 5 & 6 & 7 \\
\hline Number of Elements & 2 & 2 & 8 & 4 & 1 & 10 & 10 \\
\hline \hline
\end{tabular}

The aircraft was trimmed at 170 KTAS at sea level. 


\subsubsection{Presentation of Results}

Bending moments from the quasi-static and transient response are compared in the results section. Simple bending about the root is presented for the flying wing HALE cases. The joined-wing model has an indeterminate load path; the absolute value of the critical (see critical plane in Figure 3.11) bending moment at the root of fore and aft wings are summed to find the total reactive moment.

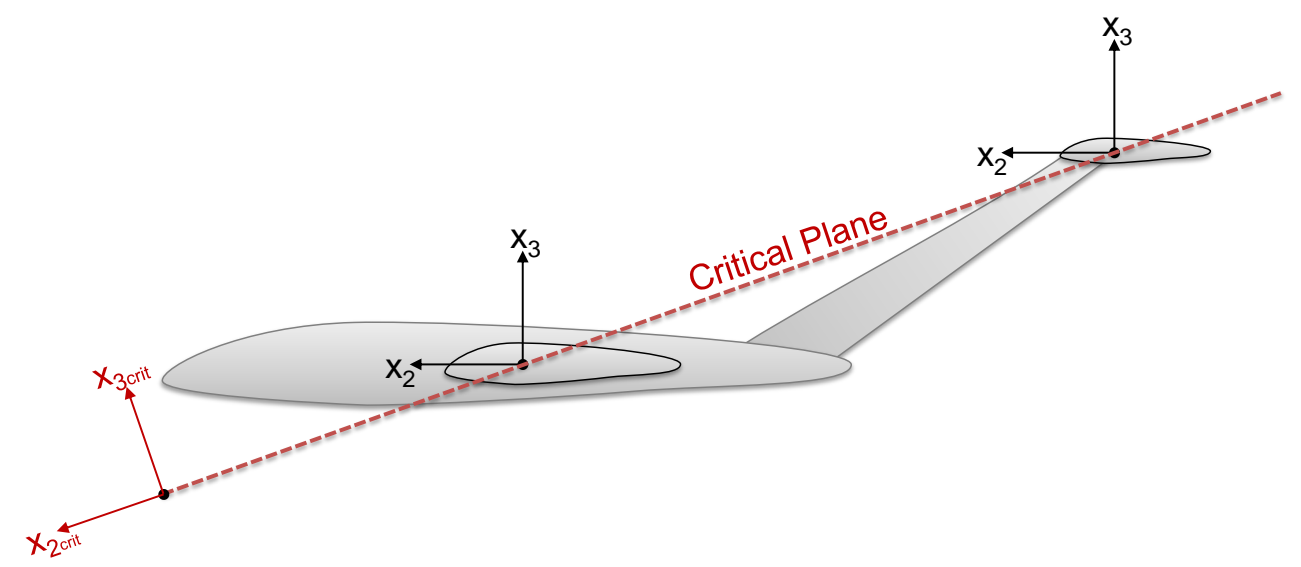

Figure 3.11: Joined-wing side view. The critical plane is through the elastic axis of the forward and aft wing roots. Bending moment results for the joined-wing are the summed absolute value of the bending about $x_{2_{\text {crit }}}$ at the fore and aft wing roots.

\subsection{Computational Framework}

A framework for parallel analysis and data management was developed to facilitate parametric gust studies. The system was designed to maximize the output of immediately available computing resources: student workstations maintained by Virginia Tech's Aerospace and Ocean Engineering Department.

Hundreds of transient gust cases were run. Each case was a completely separate task from all other cases. In parallel computing, this type of workload is known as coarsely parallel or 
embarrassingly parallel. A primitive network of workstations was developed to distribute the work. The network of workstations concept was first proposed by Anderson et al[1]. Figure 3.12 illustrates the developed system layout.
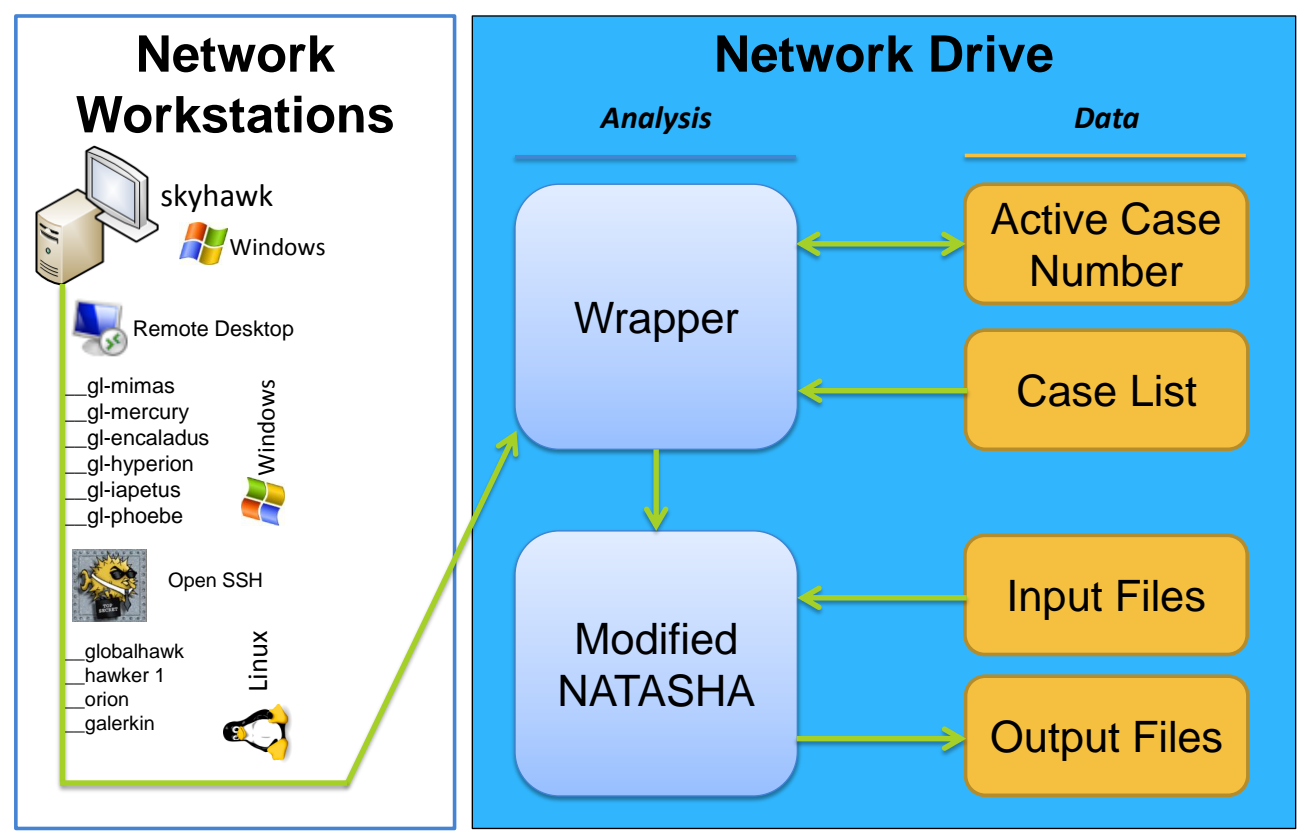

Figure 3.12: Primitive network of workstations for parallel transient gust analysis.

All the analysis and data files are stored on an accessible network drive. The wrapper references a user provided case list and launches the case corresponding to the active case number. Folder locations for input and output files are passed to NATASHA. All of the active computers continue to run until all of the cases are complete. The human workload is limited to logging into each computer and launching the wrapper. Error handling and logging is built in. 


\section{Chapter 4}

\section{Results and Discussion}

Results are presented and discussed in this chapter. The directly quantified error in Pratt's curve fit is presented first. Responses from transient analysis are compared to responses from quasi-static analysis for the two HALE applications. Two fuel levels are considered for the joined-wing case.

\subsection{Pratt's Curve Fit Error}

Figure 4.1 shows the results from directly calculating the quasi-static knockdown factor $\left(K_{g}\right)$ from Pratt's EOM compared to the $K_{g}$ values from Pratt's curve fit. Percent error is plotted in Figure 4.2 for a more precise comparison. Results for several example aircraft are shown for reference. It is important to point out the significance of wing loading $(W / S)$ to the $\mu_{g}$ calculation.

$$
\mu_{g}=\left(\frac{W}{S}\right) \frac{2}{\rho g \bar{c} C_{L_{\alpha}}}
$$




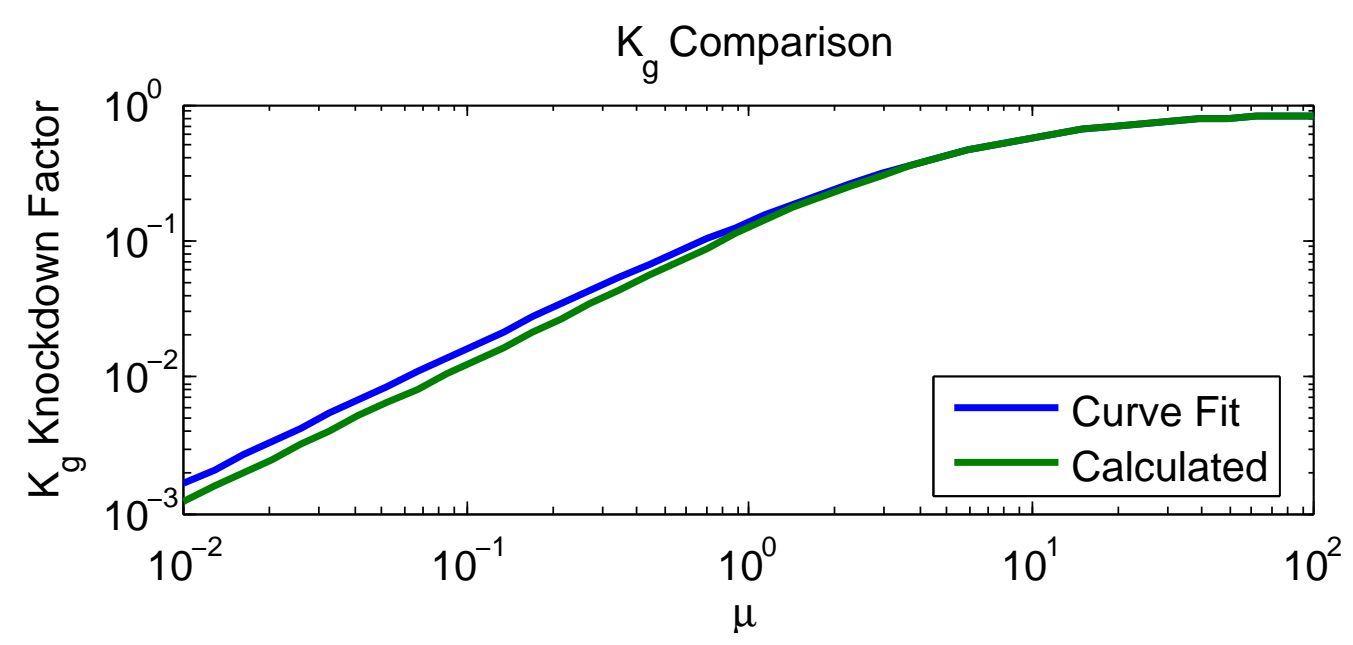

Figure 4.1: $K_{g}$ knockdown factor calculated using Pratt's curve fit and calculated by directly solving Pratt's equation of motion.

HALE aircraft tend to have extremely low wing loadings. For example, the Patil/Hodges HALE model has a wing loading less than $1 \mathrm{lb} / \mathrm{ft}^{2}$. Wing loading of this magnitude leads to $\mu_{g}$ values that were inconceivably low at the time that Pratt and Walker derived the curve fit equation. It is unlikely that Pratt and Walker were concerned with accuracy of the curve fit outside of the indicated conventional region. Figure 4.2 shows that the curve fit equation is very accurate at mass ratios corresponding to conventional aircraft, but accuracy suffers when $\mu_{g}$ falls beneath conventional values. The error in the curve fit for high aspect-ratio flying-wing HALE aircraft like NASA Pathfinder, Helios HP03, and the Patil/Hodges Model are on the order of $20 \%$. Ultimately it will be shown that other sources of error in Pratt's Method are even more significant than the curve fit error for the Patil/Hodges HALE model.

\subsection{Joined-Wing Parameter Interpretation}

Take note of the SensorCraft model(s) in Figure 4.2. The aircraft is over $40 \%$ fuel by weight when fully loaded. It's mass ratio more than doubles from $\mu_{g}=3.2$ at $10 \%$ fuel to 


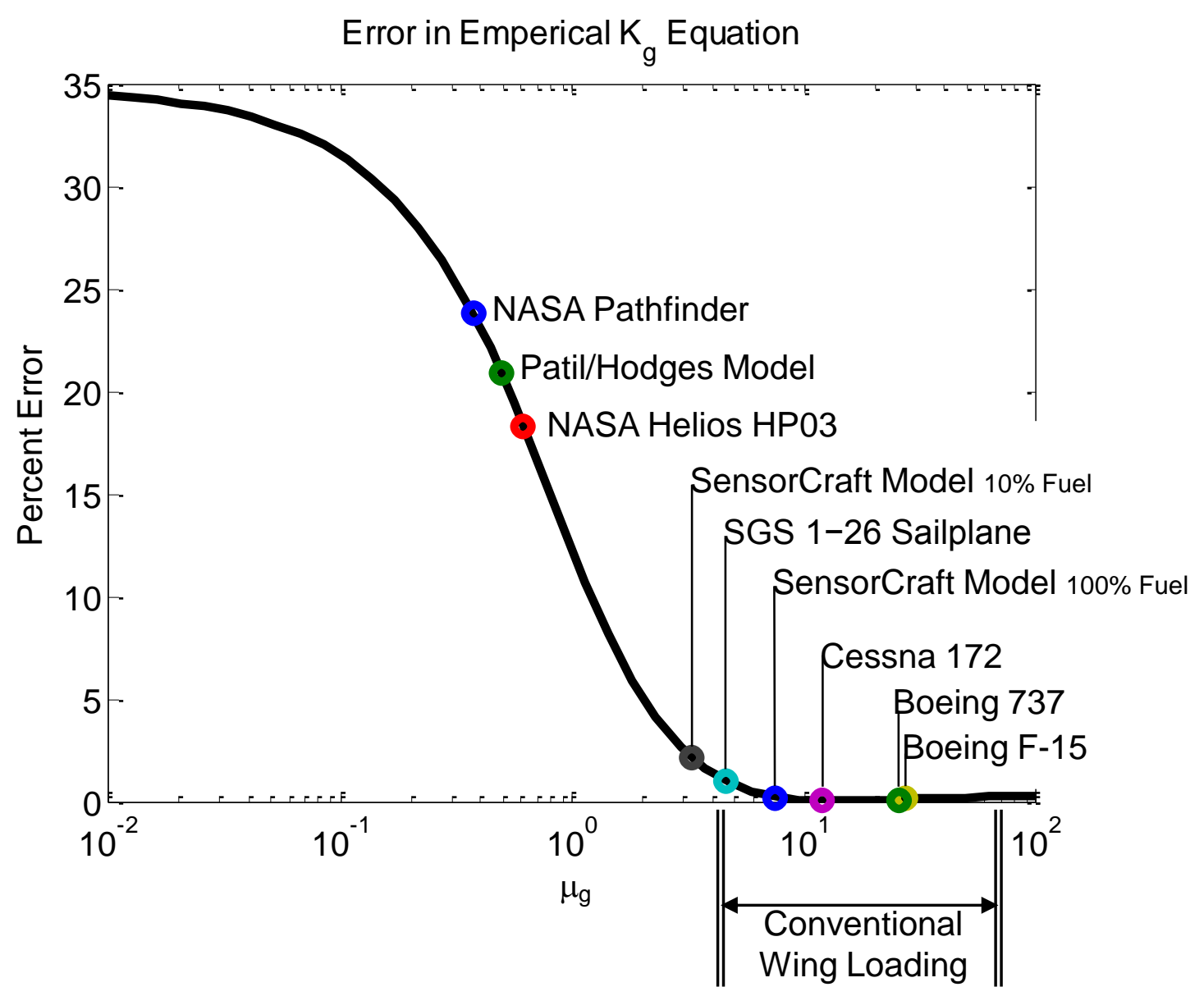

Figure 4.2: Error in Pratt's curve fit equation for the $K_{g}$ knockdown factor. Example aircraft are plotted for perspective.

$\mu_{g}=7.5$ at full fuel. It is also important to note the ambiguity in calculating Equation 3.5 input parameters like wing area $(S)$ and mean aerodynamic chord $(\bar{c})$ for unconventional configurations. For conventional aircraft, the wing area is simply the area of the main wing. But for the joined-wing configuration, the forward wing, body, and aft wing act as primary lifting surfaces. Whether or not too included all of these areas in the wing area calculation is up to interpretation. The calculated wing area then feeds into the $\bar{c}$ calculation.

$$
\bar{c}=\frac{S}{b_{s}}
$$


where $b_{s}$ is the wingspan. Table 4.1 includes some different interpretations and results for the joined-wing model.

Table 4.1: Pratt's Method wing area interpretations.

\begin{tabular}{c|ccc|c|cccc}
\hline \hline Case & \multicolumn{3}{|c}{ Included in S } & $\mathrm{S}\left(f t^{2}\right)$ & \multicolumn{2}{c|}{ Full Fuel } & \multicolumn{2}{c}{$10 \%$ Fuel } \\
& Main Wing & Aft Wing & Body & & $\mu_{g}$ & $K_{g}$ & $\mu_{g}$ & $K_{g}$ \\
\hline 1 & $\mathrm{X}$ & & & 1255.0 & 69.7 & 0.82 & 30.0 & 0.75 \\
2 & $\mathrm{X}$ & $\mathrm{X}$ & & 2148.5 & 23.8 & 0.72 & 10.2 & 0.58 \\
3 & $\mathrm{X}$ & $\mathrm{X}$ & $\mathrm{X}$ & 3833.4 & 7.5 & 0.51 & 3.2 & 0.3324 \\
\hline \hline
\end{tabular}

There is a lot of disparity in the $K_{g}$ knockdown factor for the different interpretations of wing area. The $K_{g}$ knockdown factor is directly proportional to the resulting loads from Pratt's Method. The practice of including all of the primary lifting surfaces in the wing area calculation is interpreted as most rational by the author. The values for Case 3 are used for the remaining joined-wing results.

\subsection{Application Dependent Quasi-Static Error's}

This section offers a quantification of application dependent errors in quasi-static results in the context of the two HALE applications. Worst case loads are determined using parametric transient analysis and compared to results using Pratt's Method. The worst case time domain response is used to check assumptions made to derive Pratt and Walker's equation of motion.

\subsubsection{Joined-Wing}

The joined-wing transient analysis was evaluated for the range of discrete 1-cosine gust profiles specified in Part 25 certification requirements. The gust intensities $\left(U_{0}\right)$ range from 0 to $60 \mathrm{ft} / \mathrm{s}$, and the gust lengths $(T)$ range from 0 to $700 \mathrm{ft}$. Results are presented for full 
and $10 \%$ fuel levels. Sea level density is used.

\section{Full fuel}

Figure 4.3 shows the parametric response for the full fuel joined-wing case. Each point on the surface represents the maximum critical bending moment (as described in Figure 3.11) experienced in each particular transient gust encounter. A total of 100 transient cases are included.

The most severe response is excited when the gust input has a length close to $180 \mathrm{ft}$. Pratt's specified 25 chord gust has a length of $358 \mathrm{ft}$, nearly double the critical length indicated by the transient analysis. In Figure 4.3, a solid red curve is drawn on the transient response at the most severe gust length, and a dashed black curve is drawn at Pratt's 25 chord gust. These two curves are transfered to Figure 4.4.

Figure 4.4 gives a more precise view of key output. The response using Pratt's Method is shown by the blue dashed line. Agreement is much better than expected. Further discussion is postponed until results are presented for the $10 \%$ fuel case.

\section{$10 \%$ fuel}

Figure 4.5 shows the parametric response for the $10 \%$ fuel joined-wing case. As expected, the critical response is shifted to a shorter length input as the mass is reduced. The most severe response is excited when the gust input has a length around $137 \mathrm{ft}$. Pratt's 25 chord gust has the same $358 \mathrm{ft}$ length as the previous case; now more than double the critical length indicated by the transient analysis. Again, a solid red curve is drawn on the transient response at the most severe gust length, and a dashed black curve is drawn at Pratt's 25 chord gust length. The two curves are transfered to Figure 4.6. 


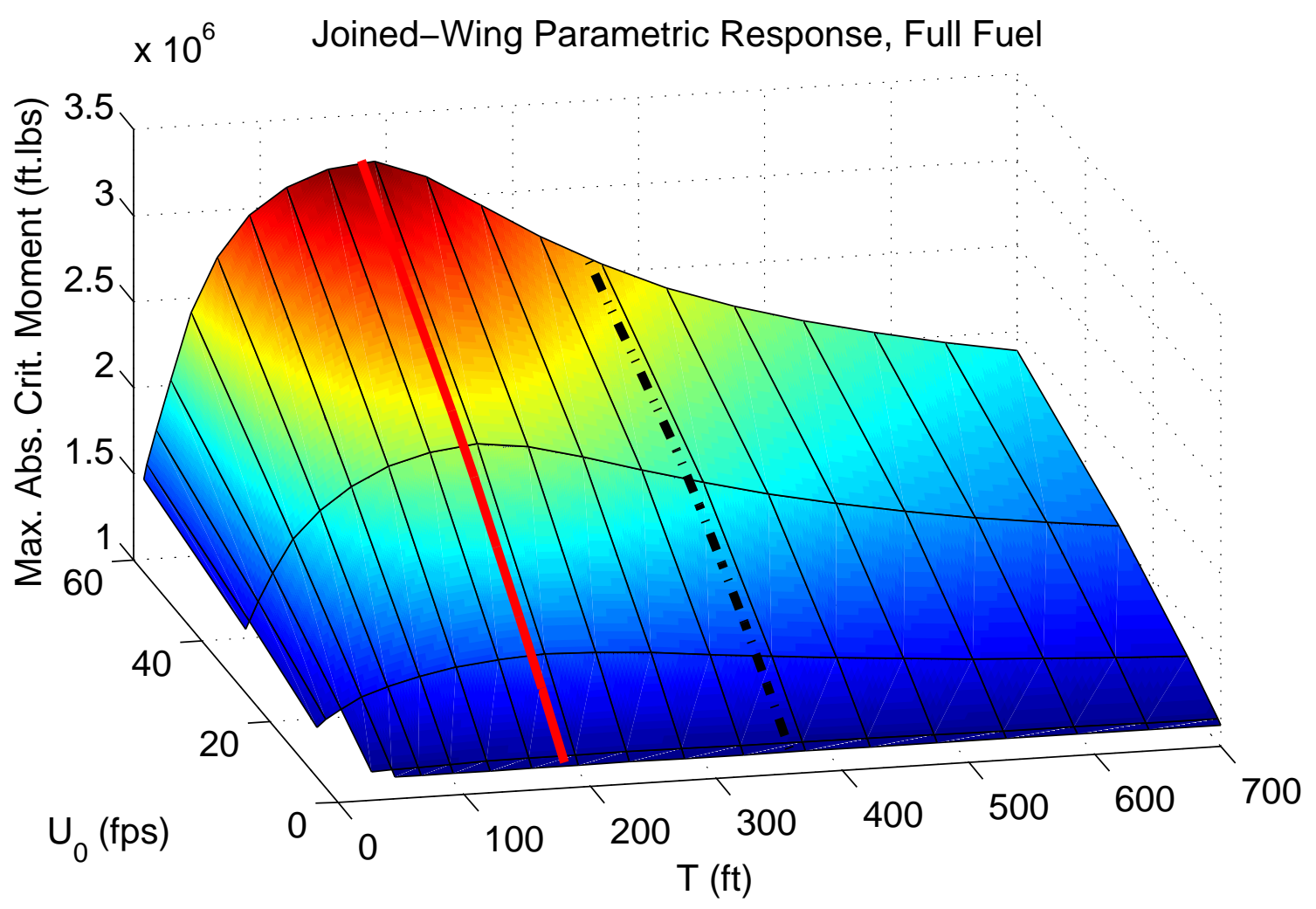

Figure 4.3: Parametric response of the joined-wing model with full fuel.

Like Figure 4.4, Figure 4.6 gives a precise view of key output. At the lower fuel level bending moment at trim (corresponding to $U_{0}=0$ ) is about $35 \%$ lower than for the full fuel case. The critical response is further from Pratt's 25 chord gust length than the previous case; accordingly, the magnitude of the response at Pratt's 25 chord gust length is further from the critical response. The highest bending moment experienced at 10\% fuel is slightly lower than the highest for full fuel.

Note that the acceleration of the model is inversely proportional to the mass. The lighter model will experience a higher load factor, but with higher acceleration comes more inertia relief. The change from trim to maximum bending moment is roughly the same for both models. The heavier model starts with more bending moment at trim and has higher maximum bending moment. 


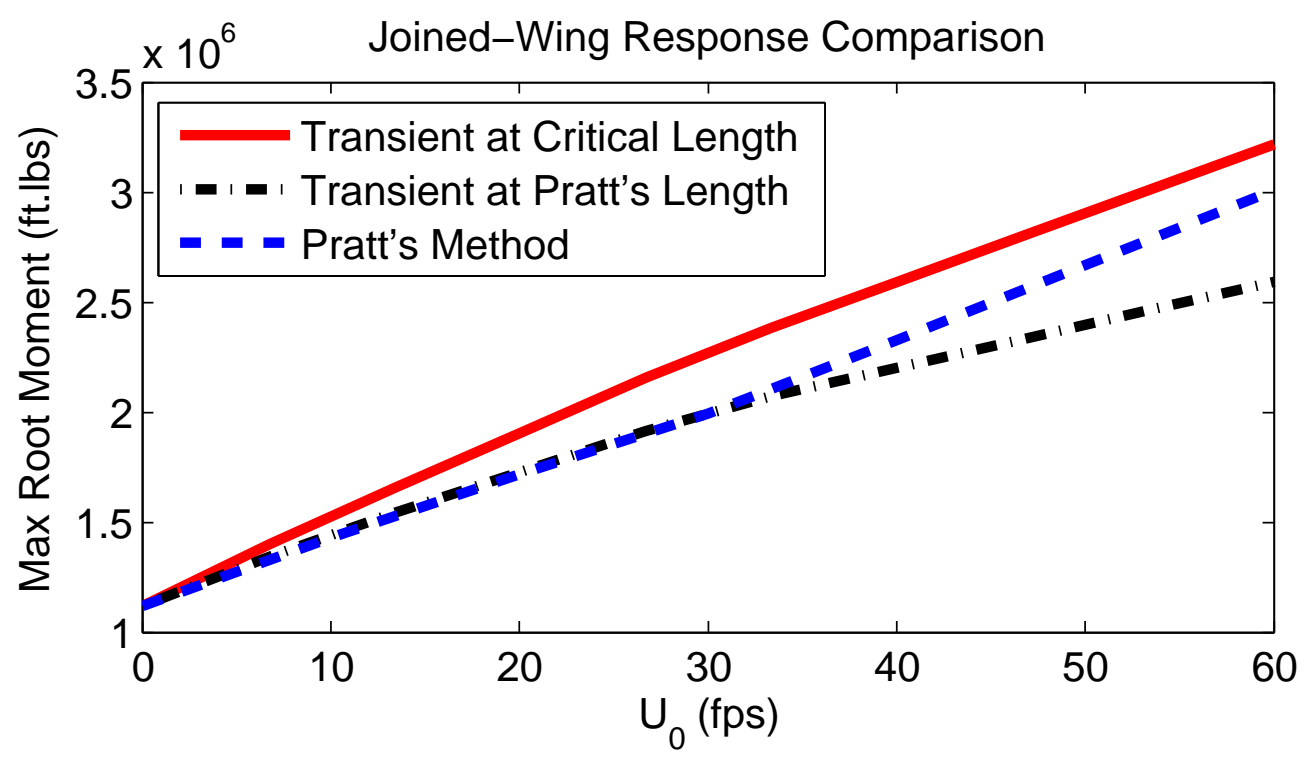

Figure 4.4: Response of the full fuel joined-wing model at specific gust lengths.

\section{Transient response of worst case}

The highest critical bending moment indicated in the parametric analysis was experienced at full fuel with a gust intensity of $60 \mathrm{ft} / \mathrm{s}$ and a gust length near $180 \mathrm{ft}$. The transient response for the worst case gust input is used to check the validity of Pratt and Walker's assumptions. The flight dynamic response is shown in Figure 4.7. The aircraft gains altitude as it enters the gust and then establishes itself in a slightly descending equilibrium. Variation of the airspeed is small in the response. Pratt and Walker assumed that horizontal speed was constant when deriving the EOM. To check this assumption, pure horizontal velocity is plotted in Figure 4.8(c). Assuming a constant horizontal velocity seems reasonable for this model based on the small deviation in horizontal velocity indicated in Figure 4.8(c). Similarly, the assumption that the aircraft would not pitch is checked by plotting the pitch response of the worst case in Figure 4.8(b). The changes in pitch attitude are not negligible, but not extreme. 




Figure 4.5: Parametric response of the joined-wing model with $10 \%$ fuel.

\section{Joined-Wing Discussion}

At both fuel levels, the response from Pratt's Method remains linear, but the transient responses slowly curve downward at higher gust intensities. At full fuel (Figure 4.4), the response using Pratt's Method aligns with the transient response at Pratt's gust length for low velocities. At 10\% fuel (Figure 4.5), the response using Pratt's Method does not align with the transient response at Pratt's gust length, but rather has fortuitously good agreement with the critical transient response. Transient response to the worst case input showed that the assumptions made by Pratt and Walker to derive the EOM were violated, but not outlandish.

The stresses from the $60 \mathrm{ft} / \mathrm{s}$ gust intensity and critical gust length case would be used 


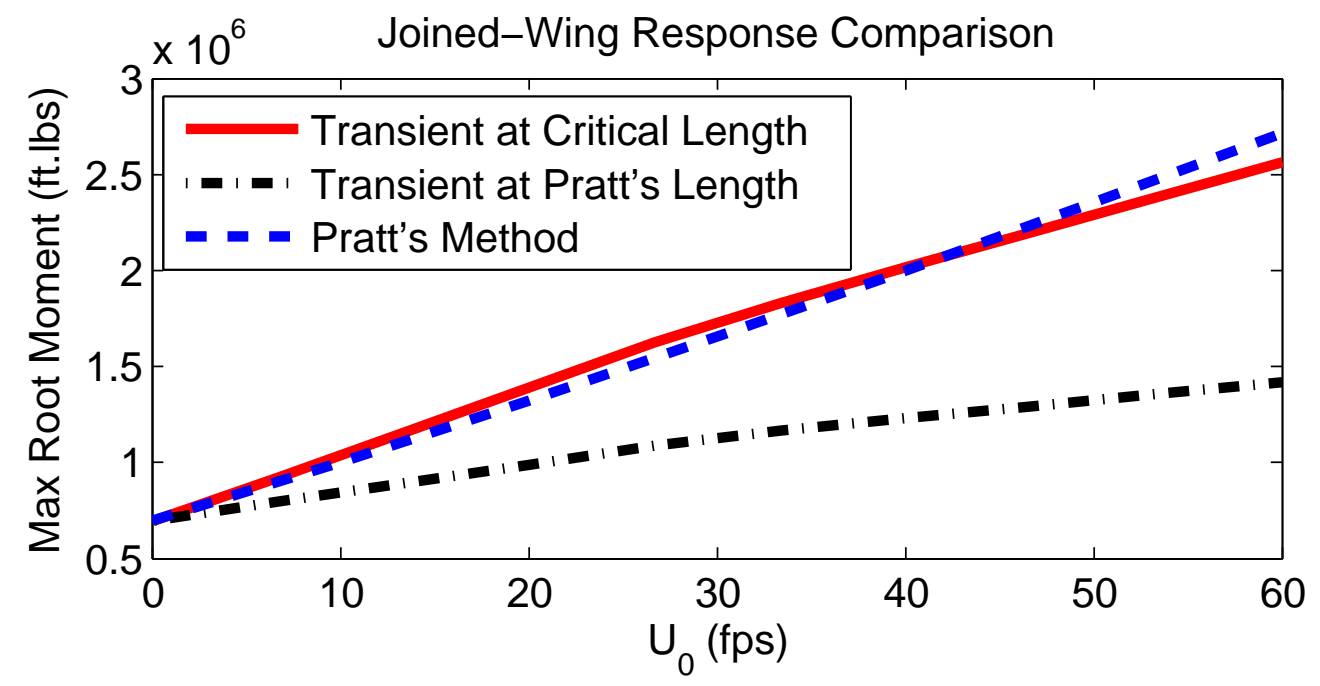

Figure 4.6: Response of the $10 \%$ fuel joined-wing model at specific gust frequencies.

to design and/or optimize the model. At both fuel levels, the joined-wing model response using Pratt's Method is reasonably close to the critical transient response at $U_{0}=60 \mathrm{ft} / \mathrm{s}$. Based on these results, it is concluded that Pratt's Method is a reasonable means to calculate loads for preliminary design of joined-wing models with aeroelastic character similar to the model presented in this study. Care should be taken when interpreting conventional input parameters. It is recommended that all of the primary lifting surfaces be included in the wing area calculation. Although useful for preliminary design, the accuracy and confidence required for loads used in detailed design and certification warrants higher fidelity transient analysis.

\subsubsection{Flying Wing}

Normally the gust input parameters for analysis are specified by civil or military certification requirements. However, gust intensities specified in conventional certification requirements are far too intense for a model with such an extremely low wing loading $\left(0.94 \mathrm{lb} / \mathrm{ft}^{2}\right)$. As 


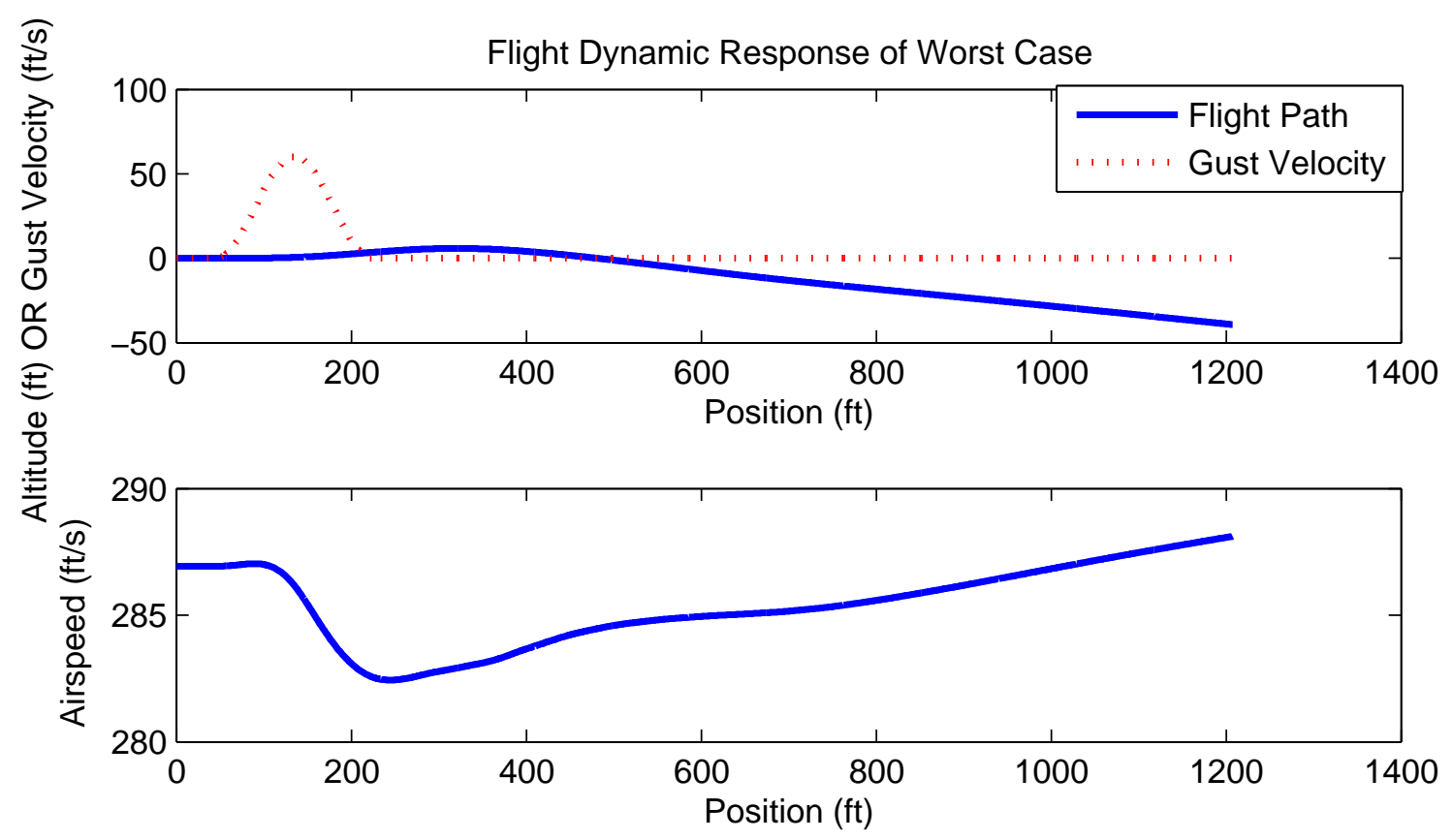

Figure 4.7: Flight dynamic response of joined-wing model to worst case input. Top subfigure shows the flight path and gust input. Bottom subfigure shows the corresponding airspeed.

a result, Helios type aircraft must be operated in relatively calm conditions. Unfortunately no specific gust differential used for design or operating limitations of a Helios type aircraft has been found in public literature. A steady wind speed of $17 \mathrm{ft} / \mathrm{s}$ has been published as a limitation for takeoff and landing of the Helios prototype [11].

It was decided that a range of gust intensities from 0 to $10 \mathrm{ft} / \mathrm{s}$ would be evaluated. The transient analysis used a range of gust lengths from 0 to $700 \mathrm{ft}$. Figure 4.9 illustrates the results from the transient parametric analysis. Each point on the surface represents the maximum root bending moment experienced in a particular transient response. A total of 390 cases are included.

The most severe response is excited when the gust input has a length around $135 \mathrm{ft}$. Pratt's specified 25 chord gust length has a length of $200 \mathrm{ft}$; this is not spot on, but it's 
closer than the worst case length for the joined-wing cases. In Figure 4.9, a solid red curve is drawn on the transient response at the most severe gust length, and a dashed black curve is drawn at Pratt's 25 chord gust length. These two curves are transfered to Figure 4.10. The results using Pratt's Method (taking $K_{g}$ from the curve fit) are also shown in Figure 4.10.

The maximum bending moment for all three responses remains linear with respect to gust intensity while $U_{0}<5 \mathrm{ft} / \mathrm{s}$. The transient responses show nonlinear behavior as the gust intensity exceeds that threshold. The response from Pratt's Method closely matches the transient response at Pratt's 25 chord gust length before the transient response becomes nonlinear. Quasi-static results are poor in the nonlinear region.

The worst case response in Figure 4.9 was experienced when the input gust had an intensity of $10 \mathrm{ft} / \mathrm{s}$ and a length of $135 \mathrm{ft}$. The time domain flight dynamic response to that input is shown in Figures 4.11 and 4.12. In in Figure 4.11, fully nonlinear, linear (from extrapolating $U_{0}=0.1 \mathrm{ft} / \mathrm{s}, \mathrm{T}=135 \mathrm{ft}$ case), and rigid cases are presented. The top subfigure shows the flight path of the vehicle along with the gust input. Corresponding airspeed is shown in the bottom subfigure. The fully nonlinear and rigid responses show that as the vehicle enters the gust there is a large pitch up rotation. The aircraft dynamically enters an unsustainable climb and rapidly slows down. An apex is reached and the aircraft begins a dive because of the loss of lift from insufficient airspeed. The aircraft appears to be stabilizing as the analysis ends. Because the linear case was extrapolated from a very small input $\left(U_{0}=0.1 \mathrm{ft} / \mathrm{s}\right)$, pitch rotations did not lead to an unsustainable climb and a more traditional response and dynamic stabilization is observed.

Figure 4.12 is used to isolate the onset of nonlinearities with respect to the gust intensity of the input. Normalized root bending moment is plotted for a range of gust intensities at the critical gust length. For a linear system all responses would lie on top of one another. The two smallest inputs $\left(U_{0}=0.01\right.$ and $\left.0.1 \mathrm{fps}\right)$ show linear behavior. Nonlinearity of the 
response is apparent as gust intensities exceed $U_{0}=0.1 \mathrm{fps}$. The dimensionalized values plotted in Figure 4.10 corresponded to the absolute value of the most negative bending moment plotted in Figure 4.12. The position of this critical bending moment occurs just before the peak gust for the linear cases. As the response becomes nonlinear, the critical bending moment position switches from just before the gust peaks to slightly ahead of where the gust ends. This nonlinearity is dominated by the rapid pitch and dive effect that becomes apparent between $U_{0}=4$ and $U_{0}=5$ fps. It is this flight dynamic effect that contributes most to the divergence of the root moment response in Figure 4.10.

Another visualization of the fully nonlinear response is provided in Figure 4.13. The flight path of the elastic semispan is plotted every second. The pitch and airspeed changes are apparent. Deformation of the wing is not obvious, but its effect on the flight dynamic response is clear from Figure 4.11.

Figure 4.14(a) is included to explicitly show elastic effects. The tip deflection (change in position of the tip relative to the root in the body frame) of the fully nonlinear case is shown. Elastic effects are most apparent as the aircraft enters the dive. The aircraft reduces in natural dihedral shape and then stabilizes to its trim deformation state. Pure horizontal velocity of the fully nonlinear case is plotted in Figure 4.14(c). Large variation in the horizontal velocity is indicated. Pratt and Walker's assumption of constant horizontal velocity is not good for this case. Pratt and Walker also assumed that the aircraft would not pitch. The no pitch assumption is also poor as indicated in Figure 4.14(b). The pitch attitude exceeds $30^{\circ}$. Though angle of attack is likely smaller than the attitude, stall angle of attack is probably exceeded in this maneuver. The aerodynamic formulation does not include a stall model. Aerodynamic forces applied in that portion of the response may not be accurate. The quasi-static analysis had poor accuracy in the nonlinear region of the response. The transient analysis showed that many of the assumptions made to derive the 
EOM used to calculate the quasi-static load factor were not valid. Because of these findings it is concluded that current quasi-static analysis is not useful for aircraft like Helios or the Patil/Hodges model. 


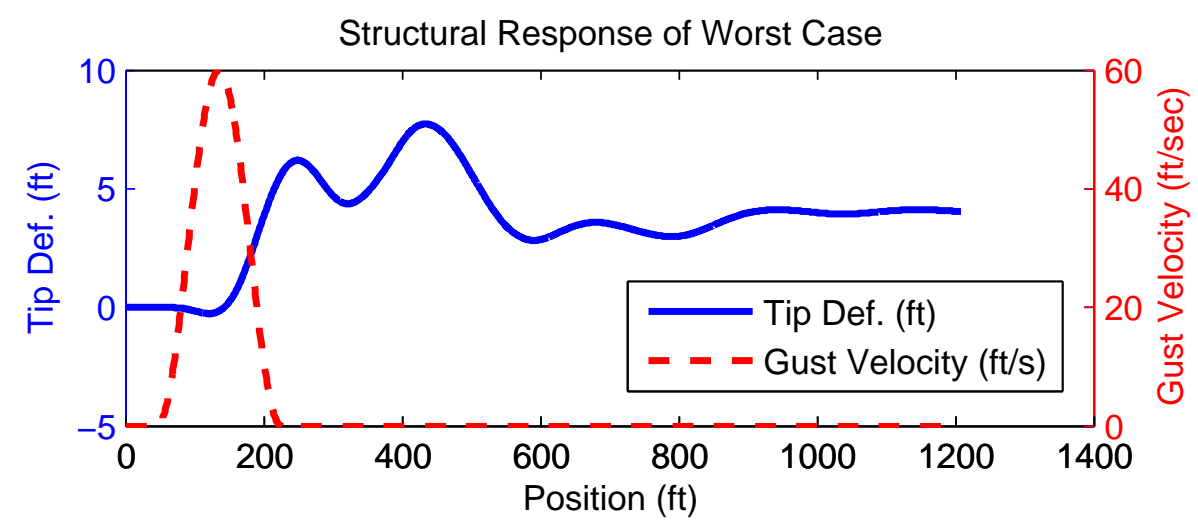

(a) Wing tip deflection in the body frame.

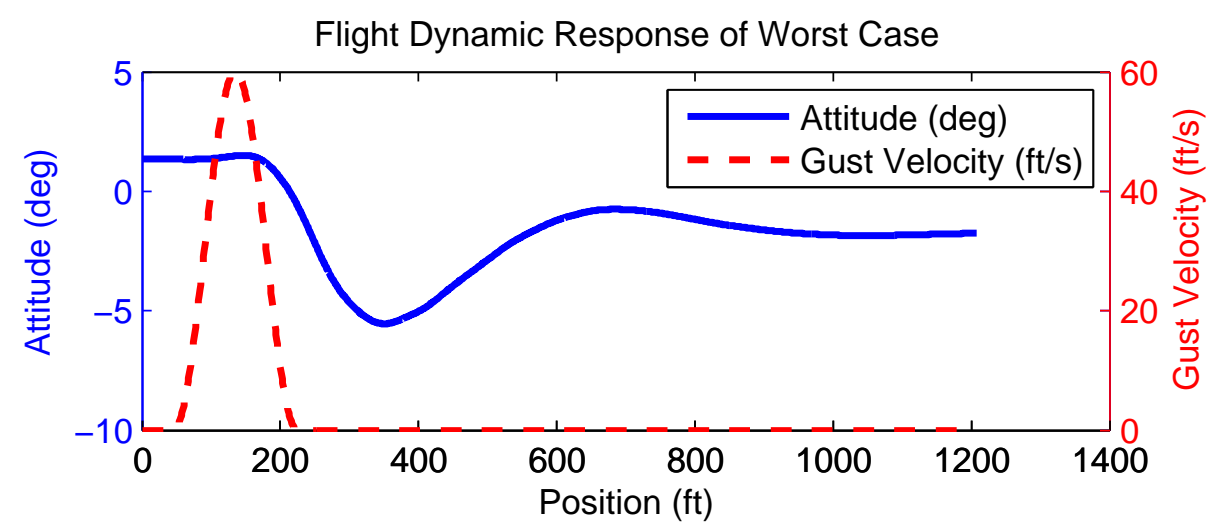

(b) Pitch response of the aircraft.

Flight Dynamic Response of Worst Case

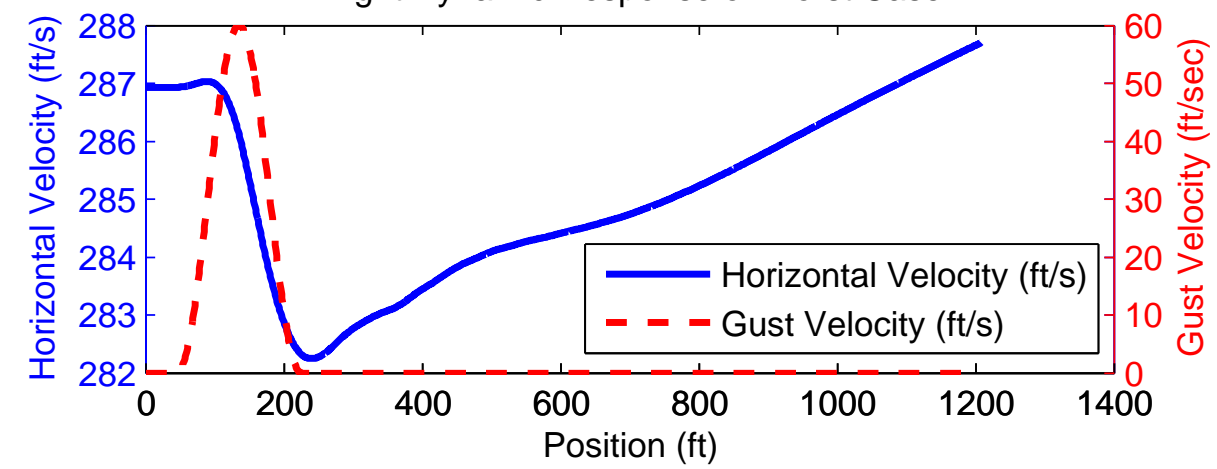

(c) Pure horizontal velocity of the aircraft.

Figure 4.8: Structural and flight dynamic response of the joined-wing aircraft. 
Flying Wing Parametric Response

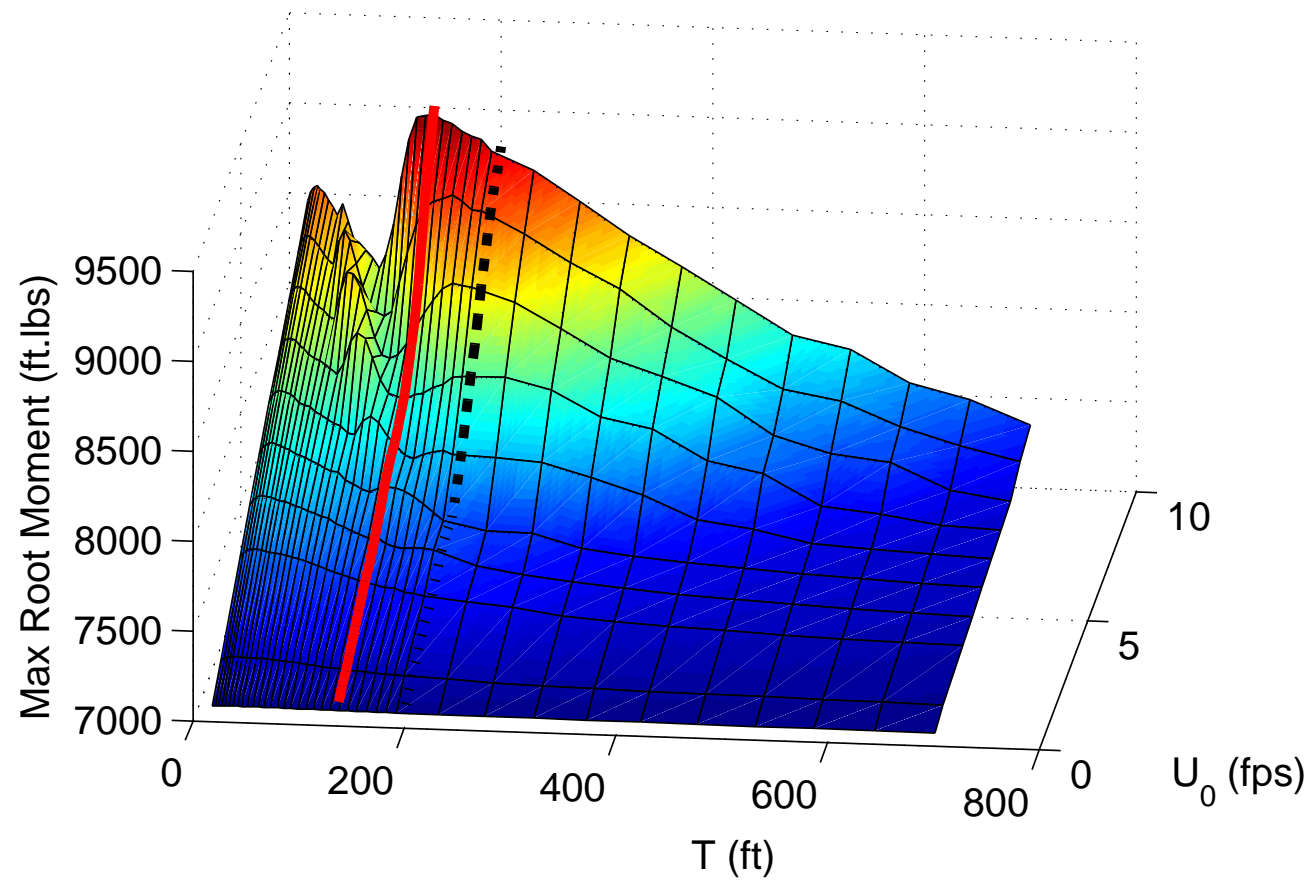

Figure 4.9: Parametric response of the flying wing model.

Flying Wing Response Comparison

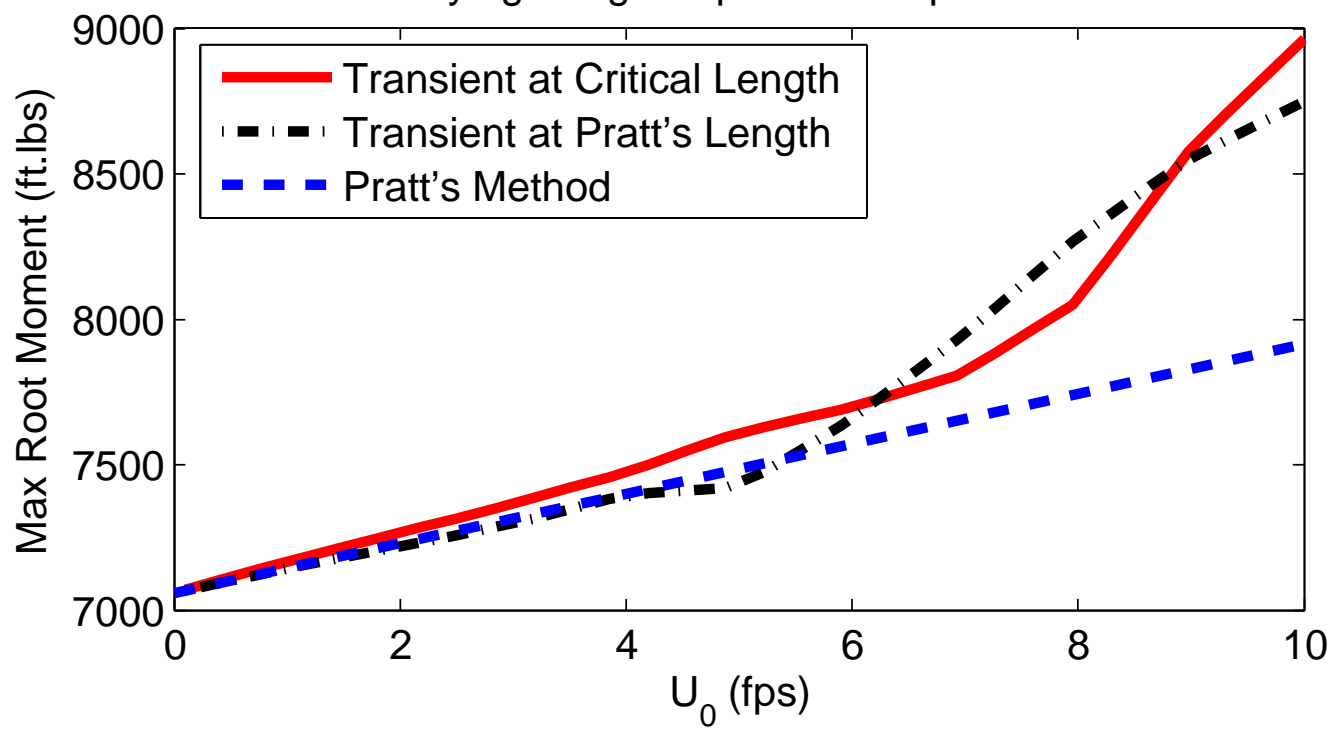

Figure 4.10: Response of the flying wing model at specific gust lengths. 


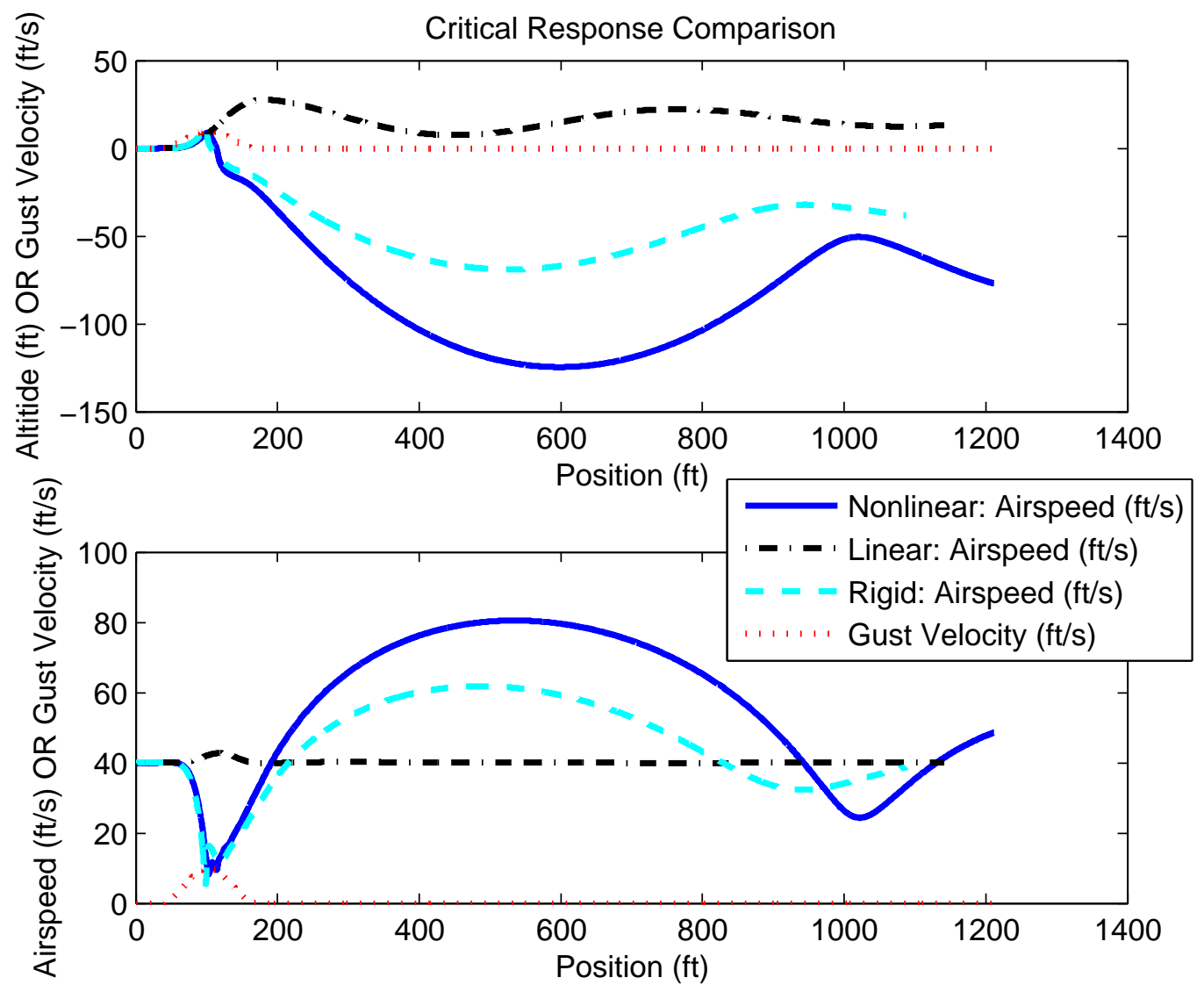

Figure 4.11: Response of the flying wing model at the critical gust length. Fully nonlinear, extrapolated linear, and rigid cases are presented. 


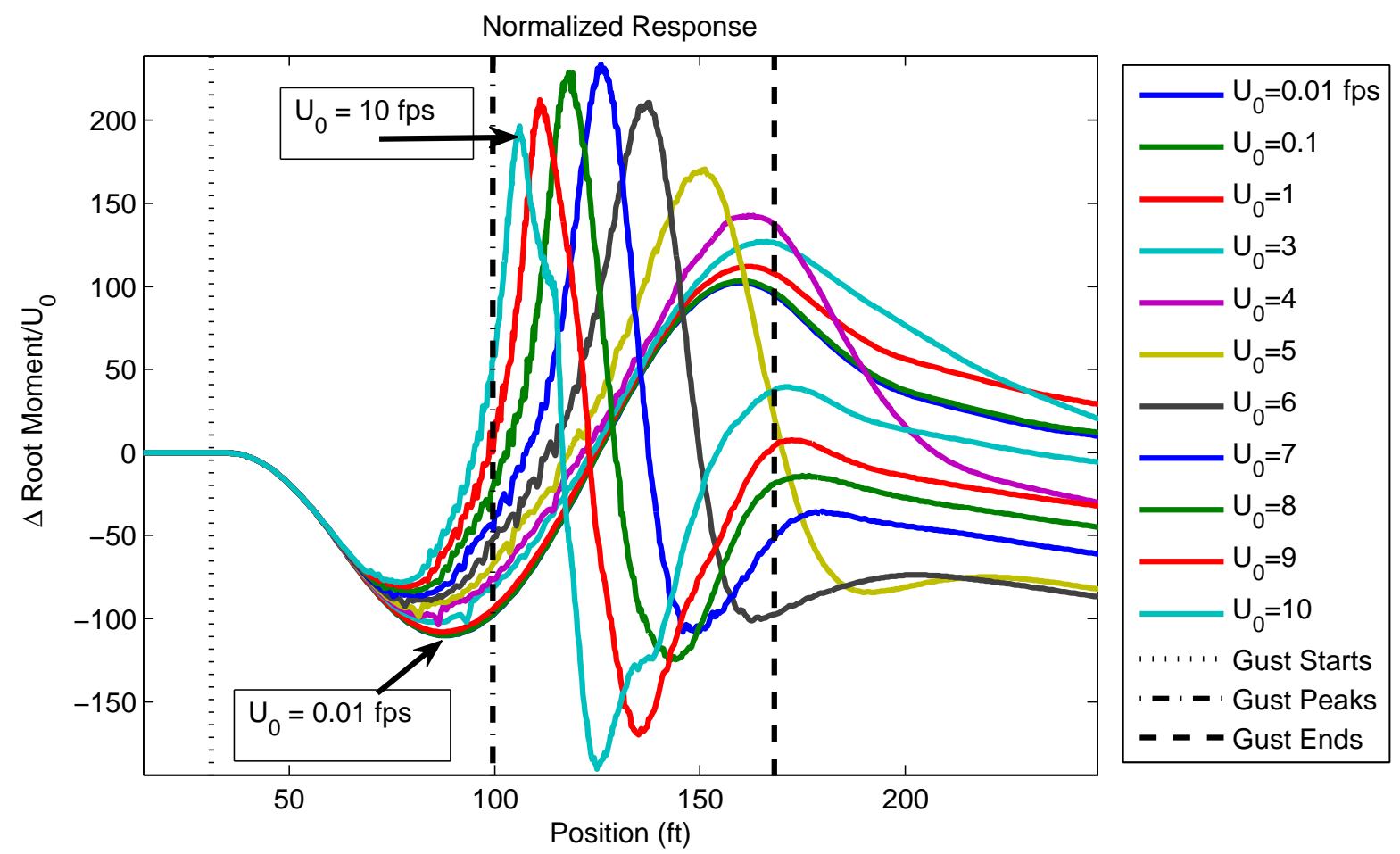

Figure 4.12: Normalized root bending moment response of the flying wing model at critical gust length.

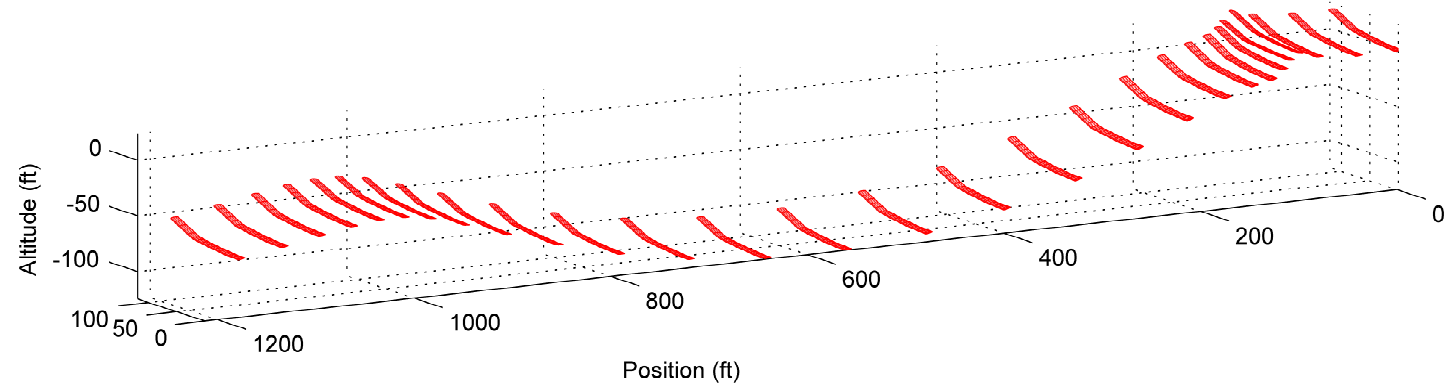

Figure 4.13: Aeroelastic and flight dynamic response of the flying wing model at critical gust length. Flight path of the elastic semispan is plotted every second. 


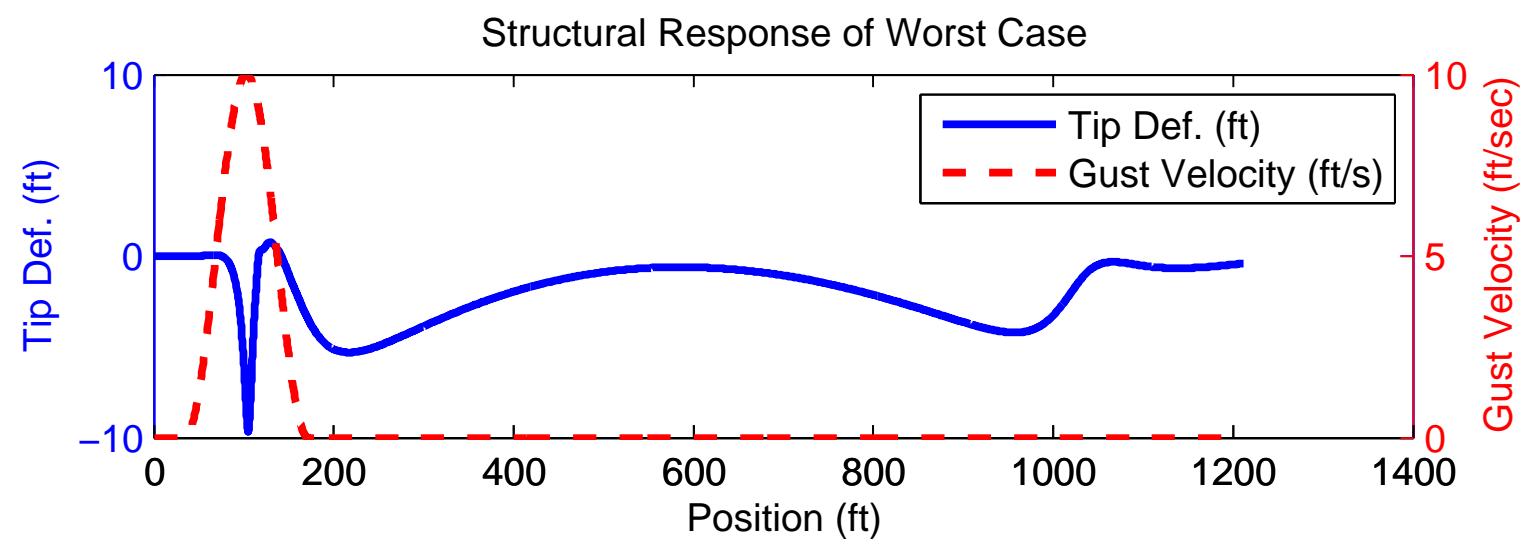

(a) Wing tip deflection in the body frame.

Flight Dynamic Response of Worst Case

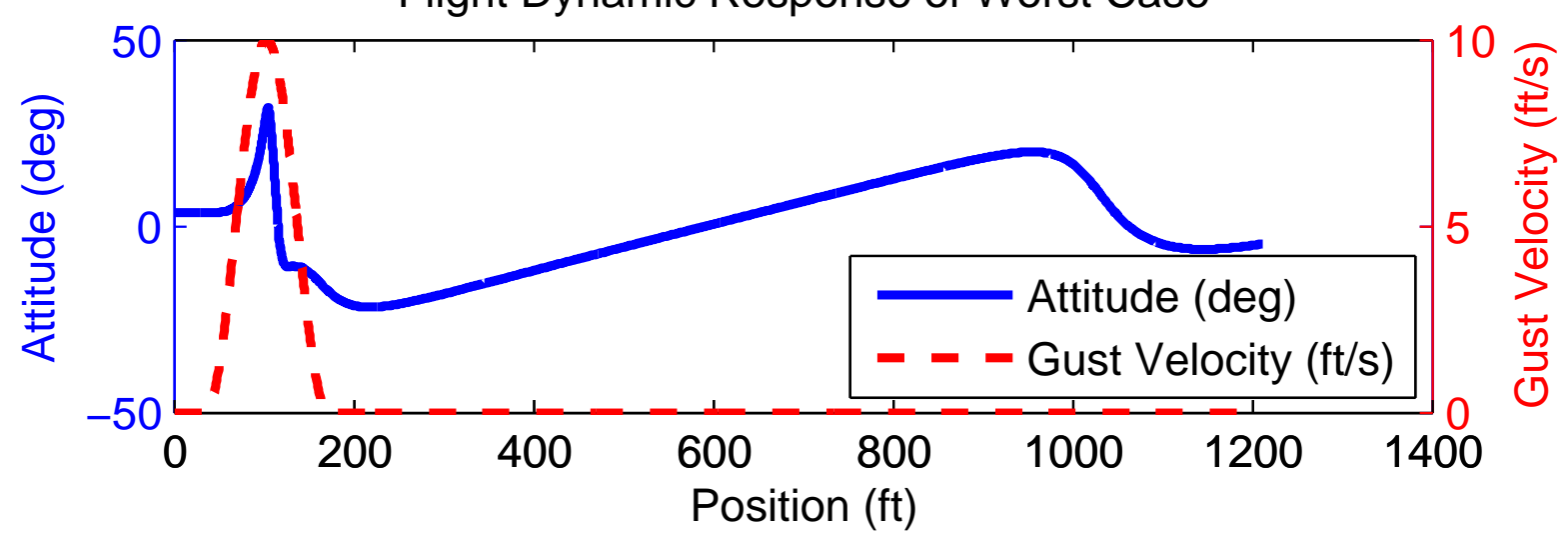

(b) Pitch response of the aircraft.

Flight Dynamic Response of Worst Case

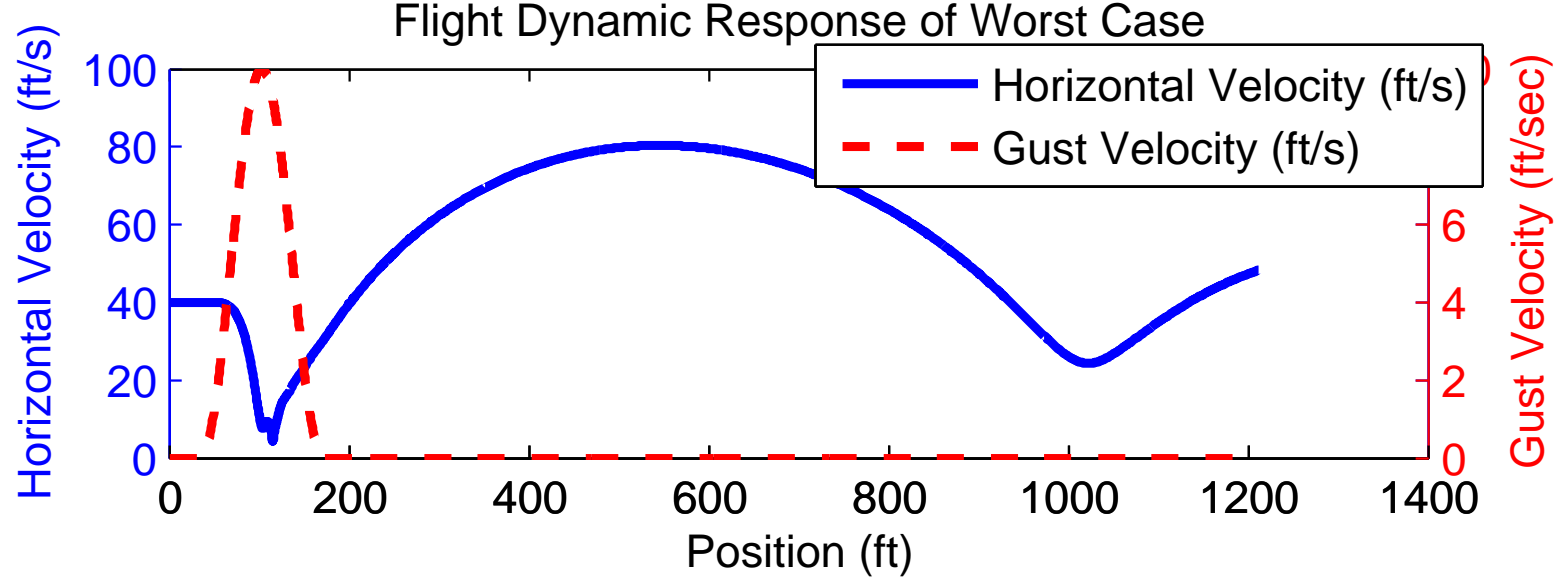

(c) Pure horizontal velocity of the aircraft.

Figure 4.14: Structural and flight dynamic response of the flying wing aircraft. 


\section{Chapter 5}

\section{Conclusions and Future Work}

\subsection{Conclusions}

Pratt's Method is a low cost means to determine gust loads on aircraft. The complete derivation of the method was reviewed and the assumptions were identified. Error in the curve fit equation encapsulating the solution of Pratt's flight dynamic EOM was quantified

directly. Results showed that the curve fit error is negligible for conventional aircraft, but on the order of $20 \%$ for flying wing HALE aircraft similar to Helios.

Interpretation of certain conventional parameters are not straightforward for unconventional configurations. The values for wing area and mean aerodynamic chord feed into the mass ratio and load factor calculations used in Pratt's Method. Using the conventional approach to calculating the wing area of the joined-wing configuration would leave out crucial primary lifting area from the body and aft wing. Use of all primary lifting surfaces is recommended for the wing area and mean aerodynamic chord calculations.

A state of the art nonlinear aeroelastic code has been modified to more accurately capture 
the transient gust response of HALE aircraft. The transient analysis was used as a baseline for the evaluation of application dependent errors in Pratt's Method. Application dependent errors were presented in the context of two HALE applications. It was found that Pratt's assumptions were reasonable for the SensorCraft-inspired joined-wing model, but poor for the Helios-inspired Patil/Hodges model. Design loads were compared from transient and quasistatic methods. Loads for the joined-wing model matched reasonably well, but agreement was unsatisfactory in the design loads for the flying wing model.

Based on these results, it is concluded that Pratt's Method is useful for preliminary design of the analyzed joined-wing model, but higher fidelity transient analysis is recommended for detailed design and certification loads. Use of quasi-static analysis is not recommended for aircraft similar to the Patil/Hodges flying wing model.

\subsection{Future Work}

Several avenues for the improvement of the analysis have been identified.

Only spanwise uniform gust inputs were considered for this study. The modification of the gust field input to a spatial function already allows gust variation in the spanwise (or vertical) direction. This existing capability should be exploited in future studies to account

for realistic spanwise nonuniform effects. Impact of nonuniform spanwise gust fields on the joined-wing model should be considered.

Trim control input was maintained throughout the transient gust encounters in the present work. In reality there would be modifications to the control input by the pilot or autopilot. Realistic modeling of control adjustments should be considered. Ideally, most HALE aircraft would have a control system designed to alleviate loads from turbulence. Transient gust 
analysis should be used to support the design of gust load alleviation (GLA) systems. Impact of GLA systems on HALE aircraft design should be investigated.

Large angles of attack in some of the transient cases presented would have led to stall. Modification of the aerodynamics to include stall modeling should be considered. Spanwise and viscous effects were also neglected. A completely redesigned aerodynamic model could be implemented to capture these effects. Compressibility effects could be added through correction methods, or through implementation of higher fidelity aerodynamics.

Although fully nonlinear, the structure is approximated using beam elements. Use of nonlinear plate elements would allow for representation of local effects on skins, spars, and ribs. A plate analysis would also facilitate study of low aspect ratio wings (relevant for MAVs).

Nonlinear analysis of continuous atmospheric turbulence (e.g., von Karman gust spectrum) should be considered and compared with results from nonlinear transient analysis. Best practices for implementing nonlinear transient or continuous gust analysis into optimization studies should be established. Sensitivity methods should be developed to support gradient based optimization. 


\section{Bibliography}

[1] T. Anderson, D.E. Culler, D. Patterson, et al. A case for networks of workstations: Now. IEEE Micro, 1995.

[2] M. Blair and R.A. Canfield. A joined-wing structural weight modeling study. In 43rd AIAA/ASME/ASCE/AHS/ASC Structures, Structural Dynamics, and Materials Conference 22-25 April 2002, Denver, Colorado, number 1337, 2002.

[3] M. Blair, R.A. Canfield, and R.W. Roberts. Joined-wing aeroelastic design with geometric nonlinearity. Journal of Aircraft, 42(4):832-848, 2005.

[4] M. Borri, G.L. Ghiringhelli, and T. Merlini. Linear analysis of naturally curved and twisted anisotropic beams. Composites Engineering, 2(5-7):433-456, 1992.

[5] C.E.S. Cesnik and E. L. Brown. Modeling of high aspect ratio active flexible wings for roll control. In 43rd AIAA/ASME/ASCE/AHS Structures, Structural Dynamics, and Materials Conferences, Denver, CO, number 1719, 2002.

[6] C.E.S. Cesnik and E.L. Brown. Active wing warping control of a joined-wing airplane configuration. Proceedings of the 44 th AIAA/ASME/ASCE/AHS Structures, Structural Dynamics, and Materials Conferences, Norfolk, Virgina, April 7-10, AIAA Paper No. 2003-1715, 2003. 
[7] C.E.S. Cesnik and W. Su. Nonlinear aeroelastic modeling and analysis of fully flexible aircraft. In 46 th $A I A A / A S M E / A S C E / A H S / A S C$ Structures, Structural Dynamics, and Materials Conference, number 2169, 2005.

[8] J. Crimaldi, R. Britt, and W. Rodden. Response of B-2 aircraft to nonuniform spanwise turbulence. Journal of Aircraft, 30(5):652-659, 1993.

[9] P. Donely. Summary of Information Relating to Gust Loads on Airplanes. NACA Report No. 997, 1949.

[10] M. Drela. Integrated simulation model for preliminary aerodynamic, structural, and control-law design of aircraft. In AIAA/ASME/ASCE/AHS/ASC Structures, Structural Dynamics, and Materials Conference and Exhibit, 40th, St. Louis, MO, Apr. 12-15, number 1394, 1999.

[11] L.J. Ehernberger. Low-altitude wind conditions on Helios flight days at Kauai, HI. In 12th Conference on Aviation Range and Aerospace Meteorology, 2006.

[12] D. Floreano, J.C. Zufferey, and M.V. Srinivasan. Flying insects and robots. SpringerVerlag New York Inc, 2009.

[13] J.R. Fuller. Evolution and future development of airplane gust loads design requirements. SAE International Paper No. 975577, 1997.

[14] J.W. Gallman and I.M. Kroo. Structural optimization for joined-wing synthesis. AIAA Journal of Aircraft, 33:1216-1223, 1996.

[15] J.W. Gallman, S.C. Smith, and I.M. Kroo. Optimization of joined-wing aircraft. Journal of Aaircraft, 30(6):897-905, 1993.

[16] M. Goland. Flutter of a uniform cantilever wing. Journal of Applied Mechanics, 12(4):197-208, 1945. 
[17] Northrop Grumman. Northrop grumman aerospace systems products \& capabilities page, August 2011.

[18] F.M. Hoblit. Gust Loads on Aircraft: Concepts and Applications. AIAA, 1988.

[19] D.H. Hodges. A Mixed Variational Formulation Based on Exact Intrinsic Equations for Dynamics of Moving Beams. International Journal of Solids and Structures, 26(11):1253-1273, 1990.

[20] D.H. Hodges. Geometrically Exact, Intrinsic Theory for Dynamics of Curved and Twisted Anisotropic Beams. AIAA Journal, 41(6):1131-1137, 2003.

[21] J.C. Hunsaker and E.. Wilson. Report on Behavior of Aeroplanes in Gusts. NACA Report No. 1, 1915.

[22] T.M. Kier. Comparison of unsteady aerodynamic modelling methodologies with respect to flight loads analysis. In 2005 AIAA Atmospheric Flight Mechanics Conference and Exhibit; San Francisco, CA, pages 1-14. American Institute of Aeronautics and Astronautics, 1801 Alexander Bell Drive, Suite 500, Reston, VA, 20191-4344, USA,, 2005.

[23] E. Livne. Aeroelasticity of joined-wing airplane configurations - past work and future challenges - a survey. In 42nd AIAA/ASME/ASCE/AHS/ASC Structures, Structural Dynamics, and Materials Conference, number 1370, 2001.

[24] M.H. Love, P.S. Zink, P.A. Wieselmann, and H. Youngren. Body freedom flutter of high aspect ratio flying wings. In 46 th $A I A A / A S M E / A S C E / A H S / A S C$ Structures, Structural Dynamics, and Materials Conference; Austin, TX; USA; 18-21 Apr. 2005. pp. 1-23. 2005, number 1947, 2005. 
[25] D.J. Lucia. The sensorcraft configurations: A non-linear aeroservoelastic challenge for aviation. In 46 th $A I A A / A S M E / A S C E / A H S / A S C$ Structures, Structural Dynamics, and Materials Conference, number 1943, 2005.

[26] R.D. Milne. Dynamics of the Deformable Aeroplane. HMSO, 1964.

[27] R.D. Milne. Some remarks on the dynamics of deformable bodies. AIAA Journal, 6:556-558, 1968.

[28] H.N. Murrow, K.G. Pratt, and J.C. Houbolt. NACA/NASA Research Related to Evolution of U. S. Gust Design Criteria. In AIAA, ASME, ASCE, AHS, and ASC, Structures, Structural Dynamics and Materials Conference, 30 th, Mobile, AL, Technical Papers. Part 4, number 1373, 1989.

[29] N. Nguyen. Integrated flight dynamic modeling of flexible aircraft with inertial forcepropulsion-aeroelastic coupling. In 46th AIAA Aerospace Sciences Meeting and Exhibit, Reno, Nevada, number 194, 2008.

[30] T.E. Noll, J.M. Brown, M.E. Perez-Davis, S.D. Ishmael, G.C. Tiffany, and M. Gaier. Investigation of the Helios Prototype Aircraft Mishap Volume I Mishap Report. NASA, 2004.

[31] M.J. Patil. Nonlinear gust response of highly flexible aircraft. In 48th AIAA/ASME/ASCE/AHS/ASC Structures, Structural Dynamics, and Materials Conference, number AIAA 2007-2103, 2007.

[32] M.J. Patil and D.H. Hodges. On the importance of aerodynamic and structural geometrical nonlinearities in aeroelastic behavior of high-aspect-ratio wings. Journal of Fluids and Structures, 19:905-915, 2004. 
[33] M.J. Patil and D.H. Hodges. Flight dynamics of highly flexible flying wings. Journal of Aircraft, 43(6), 2006.

[34] M.J. Patil, D.H. Hodges, and C.E.S. Cesnik. Nonlinear aeroelastic analysis of complete aircraft in subsonic flow. Journal of Aircraft, 37(5):753-760, 2000.

[35] M.J. Patil and D.J. Taylor. Gust response of highly flexible aircraft. In 47th AIAA/ASME/ASCE/AHS/ASC Structures, Structural Dynamics, and Materials Conference 14th AIAA/ASME/AHS Adaptive Structures Conference 7th, Newport, Rhode Island, May 1-4, 2006, number 1638, 2006.

[36] D.A. Peters and M.J. Johnson. Finite-state airloads for deformable airfoils on fixed and rotating wings. In Symposium on Aeroelasticity and Fluid/Structure Interaction, Proceedings of the Winter Annual Meeting. ASME, 1994.

[37] D.A. Peters, S. Karunamoorthy, and W.M. Cao. Finite state induced flow models; Part I: Two-dimensional thin airfoil. Journal of Aircraft, 32(2), 1995.

[38] K.G. Pratt and W.G. Walker. A revised gust-load formula and a reevaluation of v-g data taken on civil transport airplanes from 1933 to 1950. NACA Report No. 1206, 1954.

[39] C.C. Rasmussen, R.A. Canfield, and M. Blair. Joined-wing sensor-craft configuration design. Journal of aircraft, 43(5):1470-1478, 2006.

[40] CC Rasmussen, RA Canfield, and M. Blair. Optimization process for configuration of flexible joined-wing. Structural and Multidisciplinary Optimization, 37(3):265-277, 2009. 
[41] C. Reschke. Flight loads analysis with inertially coupled equations of motion. In Proceedings of the AIAA Guidance, Navigation, and Control Conference, number 6026, 2005.

[42] R.V. Rhode and E.E. Lundquist. Preliminary study of applied load factors in bumpy air. NACA Report No.374, 1931.

[43] A.P. Ricciardi, M.J. Patil, R.A. Canfield, and N. Lindsley. Utility of quasistatic gust loads certification methods for novel configurations. In 52nd AIAA/ASME/ASCE/AHS/ASC Structures, Structural Dynamics and Materials Conference, number AIAA 2011-2043, 2011.

[44] D.K. Schmidt and D.L. Raney. Modeling and simulation of flexible flight vehicles. Journal of Guidance, Control, and Dynamics, 24:539-546, 2001.

[45] C.M. Shearer and C.E.S. Cesnik. Nonlinear flight dynamics of very flexible aircraft. Journal of Aircraft, 44(5):1528-1545, 2007.

[46] W. Su and C.E.S. Cesnik. Dynamic response of highly flexible flying wings. AIAA Journal, 49(2):324-339, 2011.

[47] R.L. Swaim and D.G. Fullman. Prediction of elastic-airplane longitudinal dynamics from rigid-body aerodynamics. Journal of Aircraft, 14:868-873, 1977.

[48] R.L. Swaim and G H. Staab. Prediction of elastic-airplane lateral dynamics from rigidbody aerodynamics. Journal of Aircraft, 15:392-398, 1978.

[49] Z. Wang, P. Chen, D. Liu, D. Mook, and M. Patil. Time domain nonlinear aeroelastic analysis for HALE wings. In 4 7th AIAA/ASME/ASCE/AHS/ASC Structures, Structural Dynamics, and Materials Conference, number 1640, 2006. 
[50] M.R. Waszak and D.K. Schmidt. Flight dynamics of aeroelastic vehicles. Journal of Aircraft, 25:563-571, 1988.

[51] D.J. Willis, E.R. Israeli, P.O. Persson, M. Drela, J. Peraire, S.M. Swartz, and K.S. Breuer. A computational framework for fluid structure interaction in biologically inspired flapping flight. In 25th AIAA Applied Aerodynamics Conference, Miami, Florida, June 25-28, 200\%, number 3803, 2007.

[52] J. Wolkovitch. Joined wing aircraft, March 1976. US Patent 3,942,747.

[53] J. Wolkovitch. Joined wing aircraft, December 1982. US Patent 4,365,773.

[54] J. Wolkovitch. The joined wing: an overview. Journal of Aircraft, 23(3):161-178, 1986.

[55] W. Yu, D.H. Hodges, V. Volovoi, and C.E.S. Cesnik. On timoshenko-like modeling of initially curved and twisted composite beams. International Journal of Solids and Structures, 39(19):5101-5121, 2002. 